Florida International University FIU Digital Commons

$2-27-2009$

\title{
Attitudes towards the Marine Environment and Implications for Marine Resource Management in Seward, Alaska
}

Meredith Ann Marchioni

Florida International University

DOI: $10.25148 /$ etd.FI10022532

Follow this and additional works at: https://digitalcommons.fiu.edu/etd

\section{Recommended Citation}

Marchioni, Meredith Ann, "Attitudes towards the Marine Environment and Implications for Marine Resource Management in Seward, Alaska" (2009). FIU Electronic Theses and Dissertations. 192.

https://digitalcommons.fiu.edu/etd/192 


\section{FLORIDA INTERNATIONAL UNIVERSITY}

Miami, Florida

ATTITUDES TOWARDS THE MARINE ENVIRONMENT AND IMPLICATIONS FOR MARINE RESOURCE MANAGEMENT IN SEWARD, ALASKA

A dissertation submitted in partial fulfillment of the

requirements for the degree of DOCTOR OF PHILOSOPHY

in

COMPARATIVE SOCIOLOGY

by

Meredith Ann Marchioni

2009 


\section{To: Dean Kenneth Furton}

College of Arts and Sciences

This dissertation, written by Meredith Ann Marchioni, and entitled Attitudes towards the Marine Environment and Implications for Marine Resource Management in Seward, Alaska, having been approved in respect to style and intellectual content, is referred to you for judgment.

We have read this dissertation and recommend that it be approved.

Dennis Wiedman

Roderick Neumann

$\overline{\text { Juliet Erazo }}$

Liliana Goldin, Major Professor

Date of Defense: February 27, 2009

The dissertation of Meredith Ann Marchioni is approved.

Dean Kenneth Furton
College of Arts and Sciences

Florida International University, 2009 
(C) Copyright 2009 by Meredith Ann Marchioni

All rights reserved. 


\section{DEDICATION}

I dedicate this dissertation to my parents. Without all of their, patience, understanding, instruction and encouragement the completion of this work would not have been possible. 


\section{ACKNOWLEDGMENTS}

I wish to thank the members of my committee for their patience, instruction and encouragement. Dr. Juliet Erazo, Dr. Dennis Wiedman and Dr. Rod Neumann have offered their instruction and support along the way. I would particularly like to thank my major professor, Dr. Liliana Goldin for her time, her patience, her support and her knowledge. I would also like to sincerely thank her husband, Dr. James Jaccard. Without both Dr. Goldin and Dr. Jaccard's support and time this dissertation would not have been possible. Also, I would like to thank the people that encouraged me along the way Dr. Damien Thompson, Dr. Jose Castro, Ms. Eleanor Kip, Mr. and Mrs. John Farr, Mrs. Jane Kinkle, Ms. Kris Joppe-Mercure, Mr. Michael DiBari and Mrs. Lauren Thomas. And last, but not at all least, the people of Seward for allowing me into their lives and onboard their boats. 


\section{ABSTRACT OF THE DISSERTATION \\ ATTITUDES TOWARDS THE MARINE ENVIRONMENT AND IMPLICATIONS \\ FOR MARINE RESOURCE MANAGEMENT \\ IN SEWARD, ALASKA \\ by}

Meredith Ann Marchioni

Florida International University, 2009

Miami, Florida

Professor Liliana Goldin, Major Professor

This research, conducted in 2006-2008, examines the ways in which various groups involved with the marine resources of Seward, Alaska construct attitudes towards the environment. Participant observation and semi-structured interviews are used to assess how commercial halibut fishers, tour boat operators, local residents and government officials understand the marine environment based on their previous experiences. This study also explores how ideologies relate to the current practices of each group.

Two theories orient the analyses: The first, cultural modeling provided a theoretical and methodological framework for pursuing a more comprehensive analysis of resource management. The second, Theory of Reasoned Action (Ajzen and Fishbein 1980), guided the analysis of the ways in which each participant's ideology towards the marine environment relates to their practice. Aside from contributing to a better understanding of a coastal community’s ideologies and practices, this dissertation sought to better understand the role of ecological ideologies and behaviors in fisheries 
management. The research illustrates certain domains where ideologies and practices concerning Pacific halibut and the marine environment differ among commercial fishers, government, and management officials, tour boat operators and residents of Seward, AK. These differences offer insights into how future collaborative efforts between government officials, managers and local marine resource users might better incorporate local ideology into management, and provide ecological information to local marine resource users in culturally appropriate ways. 


\section{TABLE OF CONTENTS}

CHAPTER

PAGE

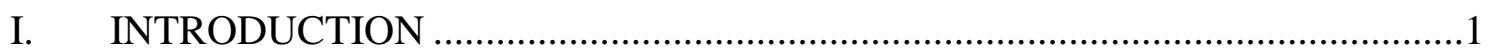

Commercial Halibut Fishers ........................................................................

Sport Fishing Tour Boat Operators..............................................................

Government and Management Officials......................................................

Seward Residents .................................................................................

Implications for Resource Management .............................................................

II. CHALLENGES TO THE PACIFIC HALIBUT FISHERIES IN SEWARD, ALASKA ENVIRONMENTAL IDEOLOGIES AND PRACTICE THEORY.......7

Management of the Halibut Fisheries .............................................................

Commercial Halibut Fishery's Management ................................................8

Management of Halibut Sport Fishery........................................................

A Brief History of Fisheries Anthropology .......................................................10

Local Ecological Knowledge...................................................................12

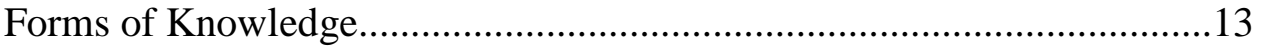

Species of Capital ..................................................................................17

Different Views Lead to Blame .............................................................18

Tourism and Fisheries ..........................................................................19

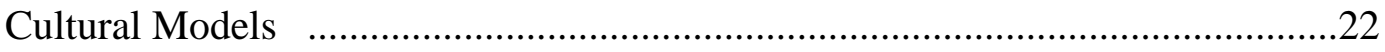

A Contribution to the Cultural Modeling Approach.............................................26

The Theory of Reasoned Action .......................................................................27

Using TRA in Environmental Studies .......................................................30

III. LIVING AND WORKING BY AN ALASKAN FJORD ......................................35

Research Area Description: Seward, AK and Resurrection Bay ..............................39

Methods

Participant Observation.........................................................................44

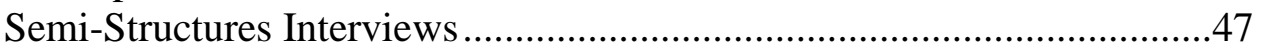

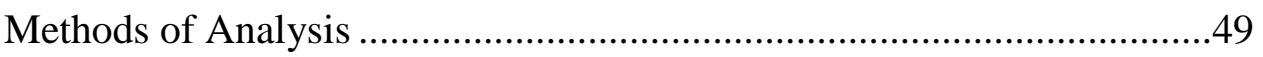

Descriptions of Resource Users ...........................................................................50

Sport Fishing Tour Boat Operators............................................................50

Wildlife Viewing Tour Boat Operators ………………………………....52

Commercial Halibut Fishers ......................................................................54

Government Officials and Managers .........................................................56

Alaska Department of Fish and Game...............................................56

International Pacific Halibut Commission (IPHC)..............................57

National Oceanic Atmospheric Administration (NOAA) ....................57

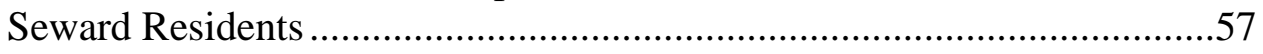




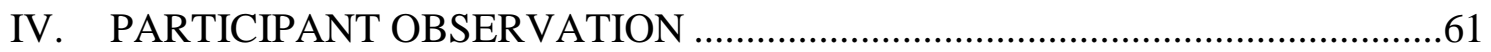

Practices Regarding the Marine a Environment as a Whole...................................61

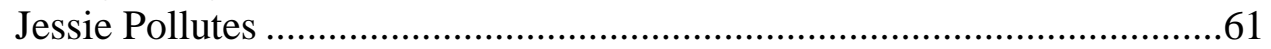

Practices Regarding Particular Species...............................................................64

Displays of Aggression towards the Dogfish..............................................66

Chip Shoots...........................................................................................

Captain J's Respect for the Halibut .............................................................73

Fish and Game Senior Scientist Favors Brown Bears .................................77

Sport Fishers, Weather and Environmental Responsibility .........................79

Conclusions: Behavior Justification ....................................................................83

V. EMIC PERSPECTIVES TOWARDS SEWARD, ALASKA'S MARINE

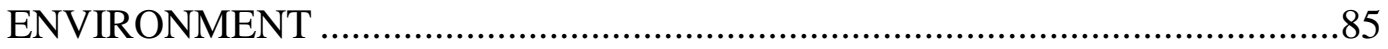

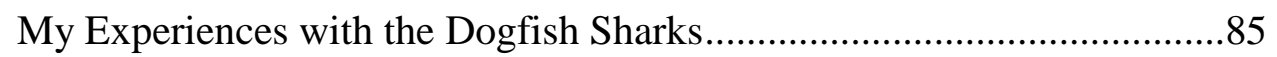

Valuation of the Marine Environment as a Whole .................................................88

Valuation of a Particular Species ........................................................................92

VI. ANALYSIS OF VALUATION RESULTS .....................................................106

What Influences Someone's Beliefs? ..........................................................108

Who holds the Power in Forums Concerning the Marine Environment? .............112

Who is blamed for Damage to the Marine Environment? ...................................116

Environmental Responsibility.......................................................................122

VII. RELATIONSHIPS BETWEEN IDEOLOGY AND PRACTICE AND

THEIR IMPLICATIONS FOR RESOURCE MANAGEMENT .........................123

Summary of Findings...................................................................................123

Sport Fishing Tour Boat Captains............................................................123

Commercial Fishers ……………………................................................124

Government of Management Officials ....................................................124

Residents of Seward Alaska for More than Five Years ............................125

Contributions................................................................................................126

Utility of the Theory of Reasoned Action................................................126

Different Ideas of what is “Good” for the Marine Environment ...............127

Different Forms of Knowledge..............................................................128

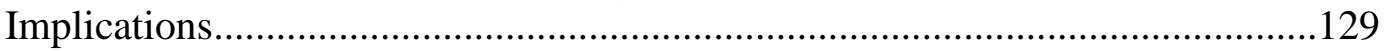

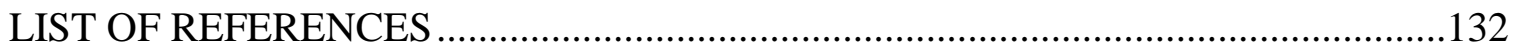

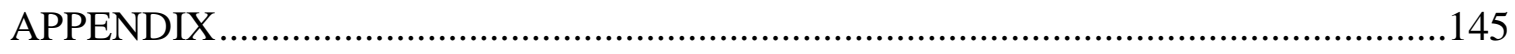

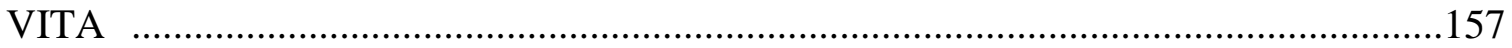




\section{LIST OF TABLES}

TABLE

PAGE

1. Valuation of the Marine Environment as a Whole .............................................89

2. Sport Fishing Tour Boat Captain’s Valuation of Species ....................................93

3. Commercial Fisher's Valuation of Species...................................................96

4. Government Officials and Manager’s Valuation of Species ..............................100

5. Seward Resident's (of Greater than 5 Years) Valuation of Species ....................104 


\section{LIST OF FIGURES}

FIGURE

PAGE

1. Why a Sport Fisher Kills a Dogfish............................................................. 70

2. Why a Commercial Fisher Shoots at a Sea Lion ...............................................72

3. Why a Sport Fishing Tour Boat Captain Shoots a Large Fish.............................76

4. Why a Government Official Suspends a Bear Hunter's License..........................79

5. Why a Sport Fisher Intends to Injure a Dogfish ............................................95

6. Why a Commercial Fisher Intends to Shoot at a Sea Lion .................................99

7. Why a Government Official Intends to Suspend a Bear Hunter's License ..........103 


\section{CHAPTER I}

\section{INTRODUCTION}

Day breaks to reveal the bustling town of Seward, Alaska. Cruise ships cart their anxious passengers into town early. Shops open their doors and tour boats start their engines in preparation for customers. Across town at the commercial fishing port, processing plants have been open for hours and prepare for the day shift to begin. Commercial dock slips are empty as the commercial fishing fleet has been at sea for days. Government offices in the center of town remain dark as employees will not come to work for hours.

This animated town is nestled between mountains and fjords within the Kenai Peninsula Borough of Alaska. It is a relatively large Alaskan town, stretching across 14.4 square miles of land and 7.1 square miles of water, with a population of approximately 3,016 people (2005 Census). A population density of 196 people per square mile makes it easy for people to separate themselves from the bustle of the tourists and other residents. The choice of many people to separate themselves and their families from the busy, coastal part of town is a hint towards the social and political dynamics of Seward. Seemingly organized and efficient, the town's layout reveals the deeper issues of discontent associated with conflict over the town's marine resources.

Within the past three decades, ecological, social, and economic changes have stressed the Southcentral Alaskan groundfish fishery and its participants. Collaboration between the Alaska Department of Fish and Game, the National Oceanic and 
Atmospheric Administration (NOAA) and the International Pacific Halibut Commission (IPHC) produced the current Individual Fishing Quotas (IFQ's), gear-restrictions and bag-limit fisheries management plans that regulate the commercial and sport fisheries today. These policies solved the basic problem of overcrowding because of open access along with the associated threats of continual gear and effort escalation. Despite this, the Pacific halibut fishery's landings have continued to decline since the plan's implementation in 1995 (Barlow and Bakke 2006). Like many other U.S. states, the investigation of the factors contributing to Southcentral Alaska's Pacific Halibut fishery decline is the responsibility of scientists and resource managers, not the people that utilize the marine resources on a daily basis. However, the Pacific Halibut marine resource users all feel that they can and should contribute to the effort to restore the fishery. With varied experiences and education, their solutions for harvest regulations and management protocols differ. Many of those who do not work directly for the government have contributions that come from their understanding of the fishery itself. The marine resource users differ in their individual ideologies and practices concerning the marine environment. They also differ in their concepts of what an appropriate halibut fishery management plan should entail.

The effort of social scientists to investigate and explore the ecological knowledge and beliefs of fishers and other marine resource users reveals a significant cultural division between the knowledge and values of those individuals who work with the marine environment directly and the knowledge and values derived from formal science in the Western world. The differentiation between environmental understandings is designated by social science through the terms "scientific" and "anecdotal" in reference 
to the knowledge of scientists and fishers, respectively (Blount 2002). The Western world uses empirical methodology and painstaking scientific research to produce definitive understandings of the biological, chemical and physical environment, though, in recent years, increasingly more attention is being paid to the knowledge and to an extent the values held by resource users such as fishers. Portraying their knowledge systems accurately requires the proper representation of culture (including traditions, practices, values and beliefs) and culturally specific bodies of knowledge, which according to Benjamin Blount (2002), may be the greatest challenge facing anthropologists today. Identifying representations of culture and bodies of knowledge among resource users is very important for resource management; a large part of this is determining existing ideologies and practices. This dissertation illustrates how the beliefs and values of the marine resource user groups studied in Seward, Alaska relate to their behaviors. The groups were formed with a careful awareness of the potential for bias in categorization. While differences are found amongst the groups, I am able to show important commonalities of knowledge, values and behaviors within each group. The following are brief descriptions of the people that were placed in each of the groups. I will elaborate ethnographic detail in Chapter Three.

Commercial Halibut Fishers: This group consists of captains and crew, who dock and sell their catch in Seward, and have worked onboard a commercial halibut long-lining vessel for at least one full season. At the time of the interview they were working fulltime onboard a commercial vessel. 
Sport Fishing Tour Boat Operators: Individuals interviewed were all residents of Seward and had all been captains for at least one previous season and at the time of the interview they were working full-time as captains.

Government and Management Officials: Government and management officials include current employees of the Alaska Department of Fish and Game (ADF\&G), the National Oceanic and Atmospheric Administration (NOAA) and the International Pacific Halibut Commission (IPHC). ADF\&G employees are all residents of Alaska, who are stationed out of Fairbanks, Anchorage or Juneau. The one NOAA employee and three IPHC members live outside of Alaska. All of them were involved in the management of Seward's halibut at the time of the interview.

Seward Residents: The individuals interviewed have all been year-round residents of Seward Alaska for five or more years. People that fell within the group "residents" of Seward, Alaska typically have jobs in city or state positions or are business owners/employees. None of the residents held positions that fell within the four groups of study. However, because of the small population of Seward many of them were relatives of people in these groups, or at the least associated with a person that fell within one of the groups. This was a comparison group used to show that individuals share the same attitudes towards the environment not because they live in Seward, but because of their different engagements with the marine environment. 


\section{Implications for Resource Management}

I develop a unique approach to show how marine resource users’ perceive and value their environment and how these perceptions and values relate to their marine activities. I use methods of data collection and analysis suggested by cultural modeling theorists, such as Ben Blount (2002) and Schelhas and Pfeffer (2008). I then employ Izek Ajzen and Martin Fishbein’s (1980) Theory of Reasoned Action (TRA) to explore the relationships between individual ideologies and actions. TRA is a theory of beliefs, attitudes, and behaviors developed in the field of social psychology. It is a general theory that can be applied to the analysis of a wide range of behaviors (Ajzen and Fishbein, 1980). I use it to analyze the ecological beliefs, values, knowledge and practices of individuals who utilize marine resources. I also explore how the results derived from the theory could enlighten resource managers of the reasons behind marine resource user's actions, potentially contributing information that would lead to a more holistic and inclusive approach to managing Seward's marine resources.

TRA acknowledges that there are many factors (class, positioning within society, prestige, gender and power differentials) that influence people's behavior. But Ajzen and Fishbein (1980) see those as more distal factors that impact behavior through their impact on beliefs, attitudes and norms. Since the purpose of this study was to look at behaviors, and the benefit of knowing the immediate reasoning behind why they occur, I focus on the final aspects of the process, namely the more immediate determinants of behavior (beliefs, attitudes and norms), not the distal variables. While I believe all of the distal variables to be important, this study focuses on the more immediate, cognitive-attitudinal 
variables. That is why my data reflects how I elicited them, with less emphasis on the complex context of each.

This study is described in several sections. First is a discussion of the individual behaviors within each of the groups, identifying practices regarding the marine environment as a whole and regarding particular species. Next, there is an analysis of the environmental beliefs, values and norms of the individuals within the groups of study. The Theory of Reasoned Action is used to enlighten the commonalities and differences amongst group ideologies and practices. Differences are shown to exist between the personal and normative beliefs of individuals of the various marine resource user groups, individuals born and raised in Alaska versus those born and raised elsewhere and individuals of different educational levels. Finally, there is a description of the relationships between each group's beliefs, values norms and practices, and the implications these relationships have for resource management. 


\section{CHAPTER II}

\section{CHALLENGES TO THE PACIFIC HALIBUT FISHERIES IN SEWARD ALASKA, ENVIRONMENTAL IDEOLOGIES AND PRACTICE THEORY}

\section{Management of the Halibut Fisheries}

Seward’s commercial halibut fishery has been managed under a treaty between Canada and the United States since 1923. The treaty was established by the International Pacific Halibut Commission (IPHC), which is responsible for the conservation of halibut worldwide. The IPHC conducts research and establishes catch regulations for each of the ten regulatory areas from Oregon to Alaska (Pautzke and Oliver 1997). The North Pacific Fisheries Management Council (NPFMC) is one of eight regional councils established by Congress in 1976 to oversee management of the nation’s fisheries. The council consists of eleven voting members, six from Alaska, three from Washington, one from Oregon and a federal representative, the Alaska Regional Director of NPFMC. Once the IPHC has set the allowable halibut catch for each area, it is up to the Council to portion the harvest between sport, commercial and subsistence users who fish U.S. waters. The Council can also set daily bag and possession limits for halibut. The Alaska Department of Fish and Game (ADF\&G) collects sport fishery data and provides it to the IPHC and the NPFMC to help them in making management and allocation decisions (Pautzke and Oliver 1997). 


\section{Commercial Halibut Fishery’s Management}

In 1995, the IPMFC, IPHC and NMFS implemented an Individual Fishing Quota (IFQ) program to manage the Alaska halibut fishery (Pautzke and Oliver 1997). The agencies who authored the program stated that the objectives of the program were put into effect not only to increase the length of the fishing season and promote economic efficiency and safety, but also to preserve the fishery’s traditional, “small-vessel character” and to create potentially better opportunities for Alaska’s native fishing communities (Pautzke and Oliver 1997).

Under the IFQ program, quota shares (user-privileges) are allocated to each fishery management area. Initial quota shares are then assigned to persons owning or leasing vessels that had made legal halibut landings during the three qualifying years. Initial assignment of quota shares per individual is based on the fisher's highest average, documented landings (a term used by fisheries biologists, referring to the amount of fish caught on vessels and "brought on land" during a period of time) during five out of the seven designated years. This average is then divided by the total landings in the management area to determine the percent quota share each person receives for that area (Pautzke and Oliver 1997).

Independent Fishing Quotas are designed to be a ratio between individual quota shares and the yearly total allowable catch (TAC) allocated to each IPHC management area. Each year, personal quota shares are converted to IFQ's (in pounds of halibut) by multiplying the individual's fraction of the total quota share pool for an area by the yearly TAC for that same area. A person's overharvest or underharvest of their IFQ from the preceding year (10\% maximum each) is also accounted for in an annual IFQ 
determination. Because the TAC and individual over/under harvest can vary each year, individual IFQ's also differ yearly (Pautzke and Oliver 1997). Compliance in the fishery is monitored and enforced by the National Marine Fisheries Services’ Alaska region Restricted Access Management (RAM) Division.

\section{Management of Halibut Sport Fishery}

The use of halibut sport fishing tour boats in Alaska has risen in popularity and the number of fish harvested per season has subsequently increased. The sport fishing industry is managed much differently than the commercial fishery industry. Sport fishing boat captains are given the option of filling out a survey where they can state their catch numbers, whereas commercial fishers are required to fill out a survey about catch numbers. Since not all boats participate in the survey, the industry's catch data are not accurate. There are minimal regulations placed on halibut harvested on sport boats, because they are perceived to have a limited impact on the fishery (ADF\&G). There is a two halibut bag limit (of any size) per day on each boat, and a boat can only make one trip for halibut per day (ADF\&G). Currently, the fishery is managed with Guideline Harvest Levels (GHL).

The GHL is a limit set on how many halibut can be caught in an area, but there is no immediate penalty given to the sport fishing industry for exceeding the GHL. When the sport fishing tour boats exceed their GHL, the next year's GHL is decreased and subsequently the commercial fisher's quota size is lowered. Because commercial fishers pay by the pound for their IFQ size, they lose money when sport fisher's catch over their limit. For the past decade, the sport fisheries have consistently exceeded the GHL and in 
increasingly significant numbers. Bumper stickers and posters are found on commercial fishing vessels which read "sport fishing is an organized crime." The lack of regard for limits by the sport fishery has caused friction between sport and commercial fishers and is currently a cause of stress for all individuals involved in the management of Seward's halibut.

\section{A Brief History of Fisheries Anthropology}

"Fisheries" or "maritime" anthropology arose as a distinguishable discipline in the 1960s and early 1970s through publications, faculty and student discussions, and academic meetings (McCay 2001:257). The International Congress of Anthropology and Ethnology of 1973 sponsored several important collections of anthropological research in fisheries (2001:257). These collections provoked more publications on the topic and eventually a discussion of whether a separate field of fisheries anthropology should exist. Through the 1980's, more specialized work concerning the anthropology of fisheries was published. Robert Paine soon created the Institute for Social and Economic Research at Memorial University, where several anthropologists from around the globe came to research questions concerning rural development, social structure and the culture of fisheries in Newfoundland (2001:257). In Newfoundland, Andersen and Stiles (1973) conducted the first research on how traditional fishing-related practices related to resource management. In the 1970s, Bonnie McCay (1978) studied the responses of islanders to depleted fish stocks and how they felt they contributed to such depletion (McCay 2001:257, Townsend 2000:16). This marked anthropology’s acknowledgement of marine resource depletion and the effects it has on fisheries. 
In the late 1980s and early 1990s, there was a crisis in the cod fisheries of both Canada and Norway. This resulted in further anthropological research of North Atlantic marine environmental issues (McCay 2001:256). Anthropologists and sociologists studied the causes and effects of the declining cod stocks. They collected data on fishers' ecological knowledge and examined how it was or was not utilized in science-based fish stock analysis (McCay 2001:256). Anthropologists also examined the rate of fisher participation in the management of the cod stocks. The Newfoundland cod fishery eventually collapsed in 1992, and Finlayson (1994) documented the "ideational and social bases for systematic errors and miscommunication within the scientific community” (McCay 2001:257). Finlayson and McCay (1998) further explored the fishery's collapse by exploring resistance to change in fisheries management institutions during the aftermath of ecological collapse (McCay 2001:257).

In the early 1990s, a network of Canadian and Scandinavian social scientists produced a book entitled "Community, State and Market in North Atlantic Fisheries" (Apostle et al. 1998). This book was influenced by the theories of both sociological work on science and anthropological work on fishers' ecological knowledge. The incorporation of anthropologists within this network of social scientists working towards fisheries management was important for the acknowledgement of fisheries anthropology as a discipline. From this point on, the anthropology of fisheries has progressed and become accepted in many academic, governmental and non-governmental forums. The data collected for this dissertation will contribute to both academic and government forums. 


\section{Local Ecological Knowledge}

Local ecological knowledge (LEK) has become a critical part of fisheries management and stems from the ethnographic work of fisheries anthropologists (Acheson 1981:291). Anthropologists have identified fishers as having the most comprehensive knowledge of their targeted resource. Fishers are on the water year after year, everyday throughout the season when their fish are present. They are aware of the life cycle, migration patterns, breeding cycles and food supplies of the fish they seek (Acheson 1981:291). Fishers are often well aware if there is a decline in fish stocks, a change in fish appearance (a potential result of pollutants) or if their food source has diminished. Yet, even though fishers often accurately record their observations, scientists are consistently the primary referents for policy makers and resource managers (Acheson 1981:291). While scientific data may be accurate in the short run, it is often the result of research conducted over relatively short periods of time that cannot be compared in length to the time spent on the water by fishers.

Fisheries anthropologists have brought the credibility and importance of fisher’s knowledge into the forum of public policy. Acheson (1988) discusses the apparent credibility of fisher knowledge and how fisheries anthropologists are continually trying to incorporate it into fisheries management (1988:97). The statements he collects from fishers concerning the factors influencing catch rates and lobster behavior in New England are considered valid by scientists (1988:97). Fisheries anthropologists, such as Acheson, continue to show the importance of LEK in the management of fish stocks around the world. While comprehensively documenting LEK of Seward fishers is not the goal of this dissertation, the ethnographic material I present illuminates how the 
education and daily experiences of different groups contribute to very different perceptions as to the roles of particular species in the ecosystem, and how particular species’ population numbers differ from the past. These perceptions contribute to individual beliefs about these species, which then influence behaviors, as will be further described below. Factors such as educational background, profession, and location, among others, do influence behaviors through the formation of diverse beliefs.

\section{Forms of Knowledge}

For the past two hundred years, Europeans and Euro-Americans have made nature literally "another world,” Euro-Americans endowed it with cultural and spiritual properties. According to William Cronon (1996:212-213) sculpting nature into country estates, celebrating it in pastoral poetry, manipulating it in the form of carefully landscaped gardens, literally “naturalized” its vast social and economic power. Jennifer Price (1996) says that Americans have traditionally invested in nature as "keystones of modern middle-class culture” (1996:188). Americans can purchase a pocket Waldens and John Muir field guide to enjoy nature as "wilderness - an untamed natural realm, a solitary refuge from the city, that's ideally as unpeopled as the landscape prints hanging in middle-class households" (Price 1996:189). Nature is also a place of "adventure” and personal successes. The middle-class portrays nature in their minds as being something they can enjoy in their leisure time (1996:189). In the nineteenth century appreciating nature by viewing it, painting it, or hiking through it helped factory owners and businessmen define themselves as rational and sensitive men, especially in comparison with rural and urban workers. Nature education in classrooms and summer camps has 
surely had many democratic and socially progressive uses. However, it has also been closely tied to efforts to model a hierarchical social order (Cronon 1996:212).

Cronon (1996) and Price (1996) explain why middle and upper class Americans and other Westerners hold "pristine” nature in such a high regard. In cases of resource management it is important to understand each group’s beliefs, attitudes, knowledge and values because they may differ from Westernized ideals. Scholars have described many forms of knowledge that inform people's beliefs and behaviors towards the environment. For example, Nadasdy (2003) describes wildlife biologists who frame debates over natural resources in the "Euro-North American languages” of biology and property relations, which put resource users at a disadvantage when dealing with government biologists and lawyers. Cronon describes urban environmentalists, who tend to see the world in terms of areas that are urbanized and areas that are untouched, pristine wilderness.

These theorists tend to divide their populations of study into those who are urban, formally educated and hold "Western environmentalist views" and those people who make their living from the land or the seas and hold a pragmatic perspective of the environment. The first group usually includes people who have grown up in urban environments and have only had brief and shallow encounters with nature. The second group tends to have grown up surrounded by the "natural” environment and have had many intimate experiences with it. The first often shows romanticized views of particular animals and plants while the second grouping has been manipulating plants and animals to suit their livelihood needs for centuries and feels there is no harm in this. The work of these scholars contributes significantly to issues of marine resources, in that they reveal 
the reasoning behind the beliefs of each social group’s actions regarding the marine environment.

Similar to Cronon (1996) and Nadasdy (2003), I found that people who were born and raised in Alaska have developed different views towards the marine environment than those who were born and raised in another state. Furthermore, in the town of Seward, people who are employed in certain professions and have different educational backgrounds embrace different perspectives of the marine environment.

Most of those individuals raised in a state other than Alaska, however, were exposed to Western environmentalists' views through popular media and university level education. They have adopted a value for "untouched" and "pristine” nature. Individuals raised in Seward were exposed to popular media; but they were raised with a more pragmatic view of the environment. For them, the environment is associated with their parents' livelihood. It is a force they deal with on a daily basis, from bears blocking their back doors, to winter freezes cracking their pipes, to glacial run-off flooding their yards. Nothing about nature is "pristine” or "untouched," rather it is a source of sustenance. Thus, Alaskan-raised individuals generally perceive and value nature differently from the people who are born and raised elsewhere.

Western environmentalist views are not exclusive to particular groups in Seward, but have influenced everyone in the town to some extent. To some, they inform a deep passion for protecting a particular species or the ecosystem as a whole. To others, they contribute to a "social norm" (subjective norm) of how species and ecosystems should be treated (regardless of one's personal feelings towards them). Indicative of the strength of this social norm (subjective norm) is the number of times during interviews in which my 
interviewee would begin with a platitude such as "biodiversity is important," or "all species are important to the proper functioning of the food chain,” but later in the interview reveal strong sentiments in favor of and/or against particular species.

Sport fishing tour boat operators who were born in Alaska tend to believe the environment is a plethora of resources to be utilized. However, due to the nature of their job, they tend to claim Western environmentalist views. They were raised with popular Western media, so they are aware that many of their customers from the lower forty-eight states want to see nature kept "pristine". It is different for commercial fishers, who have no need to cater to customer's beliefs of an untouched nature. It seems to be the case that many commercial fishers started fishing at a very young age of fourteen or fifteen and were not exposed to much of the popular media to which sport fishers have been exposed. Even if commercial fishers are aware of Western environmentalist perspectives, there is no need for them to display these perspectives as they have no clients to impose a subjective norm.

Wildlife viewing tour boat operators, government officials and managers were raised in states outside of Alaska. They were exposed to Western environmentalist views in both their primary and university education. Individuals in these groups have held professions that involve looking at the marine environment as something that is harvested, but their role is to protect and manage it from overharvest. Their values and beliefs follow Western environmentalist views; this includes an appreciation for ecosystem functioning and a value for specific species. 


\section{Species of Capital}

Value placement on individual species has been researched by theorists such as Nathan F. Sayre (2002) and Jennifer Price (1996). Sayre (2002:xxii) employs Pierre Bourdieu’s (1998) description of symbolic capital, which is "any property when it is perceived by social agents endowed with categories of perception which cause them to know it and to recognize it, to give it value” (1998:47). Sayre points out that symbolic value towards the environment is ultimately residing in the value that people ascribe to it, which is rooted in their experiences of it: In person, in books, in movies, etc. (2002:xxiii). Sayre’s example suggests that different "species of capital” are distinguished by the social forms and processes that mediate them (2002:xxiii). Symbolic capital encompasses any quality or attribute deemed valuable amongst a group of people, along with the social structures and practices that reproduce it as valuable (Sayre 2002:xxii). Some forms of symbolic capital are embodied in people and their actions (or in the case at hand, in certain animals); others are objectified in things or places. All are defined, consciously or unconsciously, relative to larger social fields, which are mediated in various ways and may intersect, overlap, contradict, or reinforce one another. Symbolic capital is socially constructed, but over time it is often taken for granted as natural. Reconstructing their historical origins is, for Bourdieu (1998), one of the central tasks of social science (2002:xxiii).

In Seward, much of the valuation of particular species follows the town's construction of symbolic capital placed on specific species. Pictures of puffins, orcas and sea lions are placed on scenic tour flyers and various gift shop items, making it easy for tourists and locals alike to associate great value with these species. However, fishers tend 
to despise many of these species. Due to the fact that they are so prevalent they are considered to interfere with their livelihood. Only people who were born outside of Alaska and hold professions that do not require them to be out on the water every day hold a positive value for certain species because of their popularized appreciation.

\section{Different Views Lead to Blame}

Issues of natural resource management are well known for their controversial allocation strategies. I believe in the case of Seward, this is primarily due to the wide difference in beliefs and values held by resource user groups and the lack of communication among groups. The fact that biases exist in government allocation strategies coupled with highly emotional opinions concerning who has rights to a resource makes for a politically and socially difficult environment. Arizpe, Paz and Velázquez (1998:59) hold the premise that individuals create new perceptions, such as those related to environmental change, by trying to fit them into previous frameworks that codify their relationships to their own and other social groups. In their study of predominantly corporate communities in rural Mexico, they found that social groups are continuously formed and reshaped while at the same time leaving a lasting impression in time. In other words, they believe that corporate affiliations will have a decisive influence on public policies and private strategies for sustainable development. The authors discuss the blame issued by all participants in their study of perceptions of deforestation in the Lacandon Rain Forest in Mexico. Since humans are all equally at risk from the irreversible changes altering the world's biogeochemical balance, and since reducing this risk means that every one of us will have to pay the cost, the first, very 
human, response is to look to others and to try to make them pay. Schematically, the North blames the South for overpopulation, and the South blames the North for overconsumption; governments blame ecologists for overreacting, and ecologists blame governments for not doing enough; the rich blame the poor for pollution, while the poor blame the rich for waste; urbanites blame rural people for overusing resources, rural people blame urbanities for destroying the environment (Arizpe, Paz and Velázquez 1998:60). Given the convenience to reciprocate assignments of blame, it is interesting to know what is believed and said by different groups in all case studies involving natural resource management.

As tends to be the case in any matter of natural resource allocation, Seward's ongoing management issues involve inconsistencies in blame placement. For the sake of management it is important to understand where issues of blame originate. This study does not focus on the placement of blame, but it does present some of the reasons why blame is placed. This is to illustrate a context in which to understand the current behaviors and attitudes towards the marine environment in Seward.

\section{Tourism and Fisheries}

Within recent years, the world has become more populated and natural resources have been significantly depleted. Anthropologists have shifted their theoretical take on the nature of culture to include such issues as the urban environment, the effects of immigration on cultural traditions, and the consequences of a sudden increase in affordable tourism. Fisheries anthropologists have also started to examine the effects of a growing population. They have concentrated on the economic, ecological and socio- 
cultural effects felt by fishing communities that have made recent shifts to tourism-based economies. One way that fishers around the world have managed to make a living has been to change from commercial to sport operations. When the resources in an area become so depleted that fuel costs exceed catch income, the idea of bringing tourists whale watching or sport fishing becomes appealing.

Carolyn Ellis (1986) talks of when tourists began coming to Crab Reef Island in the Chesapeake Bay (1986:174). The island's economy was based on commercial fishing until the early 1970s when many boat owners began to see the economic benefits of running sport fishing boats as opposed to fishing commercially (1986:174). Since then, the tourist industry has grown and more commercial fishers are switching to sport fishing. In places such as Seward, there are long time fishers who lack the social and economic skills to succeed in the sport fishing industry, have invested too much economically or emotionally in the commercial fishery, or do not want to give up their long-time livelihoods. With the continual addition of new sport fishing boats that share a portion of the Total Allowable Catch (TAC), many issues arise amongst the variety of individuals utilizing the resources.

The collection and application of LEK and ethnographic data are two of the more significant ways in which fisheries anthropology has spoken to environmental anthropology and US fisheries management. With crises occurring in fishing communities around the world, there is a need now, more than ever, for a sustainable model of fisheries management. Fisheries anthropologists are continually telling policy makers of the importance of incorporating fishers' ecological knowledge and opinions in discussions surrounding fisheries management. Commercial fishers are the ones most 
affected by policy decisions concerning regulation, so it is appropriate that they be allowed to contribute. Without their opinions, any initiative to conserve fish stocks will be less likely to succeed. Fishers' knowledge can be important to the management of fishing grounds, but fishers' cooperation is necessary to execute resource management regulations. Only when fishers are included in policy decisions, and educated in managerial ways, will they develop a respect for fisheries managers and scientists and follow regulations.

Relations between natural resource user groups can be complicated. Everyone wants a stake in natural resources, whether they have ancestors who have utilized them for centuries or they just appreciate them and wish to protect them. The management of marine resources tends to fall somewhere within the extremes of complete government control and complete fisher control (Jentoft and McCay 1995). Government-industry interaction can take many forms and the degree of fisher (or other marine resource user) involvement differs in all cases. In a study of the management strategies of several different countries, Jentoft and McCay (1995) found all the countries held some form of collaborative fisheries management systems. In all cases, there was some involvement by government, management agencies, fishers and other marine resource users in the design and implementation of management strategies. Also, Jentoft and McCay found that in all the countries they studied, scientific knowledge plays a significant role in fisheries management (1995). Fishers tend to be left confused by scientific jargon, and often times, even with marine resource user participation, there is a need for a deeper understanding of the beliefs, attitudes, knowledge and values of each of the management participants. 


\section{Cultural Models}

Anthropologists have recently used cultural modeling to illustrate and analyze ethnographic data of fishing communities. In the following section, I outline the theoretical framework of the cultural modeling approach. I then reference the work of fisheries anthropologists who have used the cultural modeling approach to show patterns in values, knowledge and beliefs, and the importance of including them in resource management strategies. I then explain how this study seeks to use the methods of the cultural modeling approach, but go beyond its theoretical framework to propose the use of a social psychological theory that complements existing cultural modeling frameworks.

Cultural models exist for different dimensions of social life and may either complement or contradict each other. Social carriers (conservation organizations, maritime organizations, churches, etc.) can also be used to represent one or more of these models. Cultural models incorporate both beliefs (how people view the world) and values (people’s views of what is moral) (Schelhas and Pfeffer 2008:17). Cultural models can be broken down into schemas, which are networks of strongly connected cognitive elements that are primarily built through human experience, and that provide an organized framework for objects and relations and thereby mediate many of the cognitive processes of individuals (Schelhas and Pfeffer 2008). When people have common and recurring experiences, they can come to share schemas.

An example of how cultural models have been used to illuminate behavior in fisheries is the work of Michael Paolisso and R. Shawn Maloney (2000) and colleagues. They have carried out extensive studies concerning the cultural models of different 
stakeholder groups in environmental conflicts around the Chesapeake Bay, including pollution, harmful algae, and fisheries declines (2000:33). The results indicate that different stakeholder groups hold different interpretations of what it means to be an environmentalist. They each have complex cultural models of nature that are closely tied to their group identity and livelihoods (2000:34). Farmers and fishers distrust science and feel that, because they are politically weak, environmentalists and politicians shift blame to them, rather than regulating other sources of non-point pollution (2000:36). Rural people sometimes frame these conflicts along rural-urban lines, seeing themselves as the real environmentalists opposing the "morally bankrupt, pollution-generating urban centers" that they feel are "the source of misguided environmental protection efforts" (2000:36).

Paolisso and Maloney's (2000) research demonstrates the importance of knowing the ideologies of all stakeholders involved in an environmental issue. Without knowing the beliefs, attitudes and values of these people, there could never be a complete understanding of why they feel and behave the way they do.

Another example of how the examination of ideologies reveals useful insights into attitudes towards specific animals or plants within the environment is the work of Niels Einarrson (1990:42). He used cultural models to study conflicts between environmentalists and Icelandic fishermen regarding seals. Icelandic fishermen have developed very negative feelings towards seals (1990:44). Einarrson believes that these feelings are a practical reaction of the fishers to the negative impact that the seals have on the fishery, as well as a symbolic reaction to the ways environmentalists have intruded upon their traditional seal hunts (1990:46). 
Commercial halibut fishers in Seward, I found, shoot at sea lions primarily because they interfere with their fishing practices. During interviews, commercial fishermen displayed anger towards marine resource managers and environmentalists for not allowing them to scare off sea lions by shooting at them. When out at sea, the fishers shoot at sea lions in privacy to protect their catch and equipment, but according to interview data, this also can serve as a release of anger held towards those that protect the seals.

In these case studies, differences emerge between the local people who make their living from natural resources and the outside environmentalists (managers and scientists who influence local people ideologically, politically and monetarily) who promote conservation with little consideration of local ideologies and practices (Paolisso and Maloney 2000; Einarrson 1990). Rural people find themselves with little power relative to Western environmentalist interests, and in some cases they can develop an active antienvironmentalism regime (Schelhas and Pfeffer 2008:24). As a result, environmental conflicts become intertwined with other social conflicts.

In a more recent study concerning environmental conservation of forests in Central America, John Schelhas and Max J. Pfeffer (2008) present their concepts for understanding environmental values. They see values as "artifacts grounded in social interaction," and are interested in how "various forms of social organization foster the systematic development of a logically interconnected set of values” (2008:15-16). Schelhas and Pfeffer acknowledge that individuals articulate certain values, and perform behaviors based on the priorities established with reference to these values, but they also see the bases of these values as being complex (2008:16). In their case study, it was 
found that organizations created these values, and then acted as social carriers that disperse the values across a "cultural landscape” (2008:16). These findings are different than those of Paolisso and Maloney (2000) and Einarrson (1990), who found that commercial fishers did not adopt environmentalists’ discourse, but rather rebelled against it. This difference highlights the need for a holistic approach to analyzing the actions and behavioral intentions of individuals. Holistic in that it looks at the discourse of people in all sectors who participate in resource use and management, as well as people's behaviors when managers are not present.

Paolisso and Maloney(2000), Einarrson (1990) and Schelhas and Pfeffer (2008) analyzed the content of individual transcripts in view of: individual environmental experiences and social locations of the respondents, national and international social and political discourse, material and structural relationships, and power dynamics within which local people live. The intent of this study was somewhat different. Specifically, the present study used an approach that complements cultural models by identifying core ways of conceptualizing and thinking about the proximal determinants of the behavior of individuals who affiliate with or identify with different groups who use marine resources. The focus is not so much on analyzing the broader national and international social and political discourse (and the power dynamics that surround this), but instead on elaborating relevant beliefs, knowledge, attitudes and values of those who use marine sources and how this varies as a function of group identification. The study used methods employed by anthropological researchers (i.e. semi-structured interviews, participant observation and the analysis of secondary sources) to determine the values, beliefs, knowledge and actions of individual marine resources users. 


\section{A Contribution to the Cultural Modeling Approach}

Recent research questions the degree to which people share cultural models when they live in communities made up of different interest groups and politically positioned individuals (Shore 1996; Schelhas and Pfeffer 2008). Strauss (2005) extends traditional cultural models and considers how they may differ by social subgroup. Cultural models can be expected to differ according to content and structure among social subgroups. Strauss and Quinn’s (1997) research also examined how similar schemas may have different levels of "motivating force” for individuals and thus different levels of influence on behavior. Motivating force depends both on factors “internal to the individual” (i.e. emotional saliency) and the context in which the individual acts (i.e. social discourses and institutions) (Strauss and Quinn 1997). Strauss and Quinn (1997) found that many cultural models give "lip-service” motivation, in which people have internalized a widely accepted or “dominant model," but without its leading to corresponding action (Schelhas and Pfeffer 2008).

Looking further into the idea of “dominant models”, Strauss (2005) conducted research on how people internalize public culture. She refers to "social discourses”, which she says are different from cultural models because they stand out amongst competing belief systems. Social discourses are developed by "ideologists" and distributed to the public, which absorbs at least fragments of the discourse (Strauss 2005:18). Environmental thinkers, educators, and activists construct and spread environmental social discourses (Strauss 2005). Strauss suggests that social discourses can be identified in people’s talk "by the presence of ideas, jargon, and phraseology typical of the discourse” (2005:19). 
Schelhas and Pfeffer (2008) say that these concepts (shared schemas, motivations, social discourses) help us to understand variations in environmental values, their operation, and their influence on behavior under different conditions. In the tradition of Strauss (1993; 2005), Schelhas and Pfeffer (2008) and Strauss and Quinn (1997), I look beyond the cultural modeling approach to find a way of empirically accounting for the "motivating factors” and "personal beliefs” behind individual's actions. There exists a well established model in social psychology, called the Theory of Reasoned Action, which lends itself well to such analyses. The cultural modeling approach can benefit by borrowing perspectives from the Theory of Reasoned Action.

\section{The Theory of Reasoned Action}

The work of Fishbein and Ajzen that came to be formulated as the Theory of Reasoned Action (TRA) first appeared over 30 years ago (Fishbein and Ajzen 1975). The TRA can be thought of as having two general conceptual components. The first component starts with a simple proposition, namely that people do what they intend to do, and they do not do what they do not intend to do. In other words, a person's behavior is determined largely by the person's intention to perform that behavior. Despite the strong relationship between intentions and behavior, the TRA explicitly recognizes that sometimes people do not do what they intend to do. The Theory describes a host of factors that interfere with the translation of intentions into behavior. For example, a person may intend to catch a large number of fish, but if s/he lacks the skills or resources to do so, then the intention will not match up to behavior. A central component of TRA is conducting a careful analysis of people's intentions to perform behaviors and whether 
these intentions translate into action. If they fail to translate into action, then the focus is on identifying factors that impede the translation of intentions into behavior (Ajzen \& Fishbein 1980).

The second component of the theory identifies factors that influence a person's intention or decision to perform a behavior. The focus of the theory is on two classes of explanatory, social-psychological variables. The first class of variables focuses on what individuals perceive as the advantages and disadvantages of performing a behavior, what Ajzen and Fishbein call behavioral beliefs. In general, if individuals see a behavior as leading to positive consequences and not leading to negative consequences, they will be more likely to intend to perform the behavior, everything else being equal. A key facet of applying the TRA is to carefully document different perceived advantages and disadvantages that people have about performing a behavior. A person's attitude toward performing the behavior (i.e., how favorable or unfavorable the person feels toward performing the behavior) is a psychological summary of the totality of a person's behavioral beliefs about performing the behavior.

The second class of explanatory variables is the normative pressures to perform the behavior. In place of one's own behavioral beliefs about the advantages and disadvantages of performing the behavior, the decision or intention to perform the behavior can be a function of how much a person thinks that important others will approve or disapprove of the person performing the behavior. These are called normative beliefs and recognize that our actions are sometimes not influenced by what we personally want to do but instead by what we think others want us to do. The overall felt normative pressure to engage in a behavior is called the subjective norm, and it is said to 
be a function of or a psychological summary of the totality of the normative pressures a person experiences to perform the behavior.

The TRA recognizes that there may be other factors that impact a decision to perform a behavior, such as a person's political orientation, social class, gender, and social networks. However, the influence of these more distal variables are thought to influence behavior through the more immediate proximal determinants of behavioral beliefs, normative beliefs, attitudes, subjective norms, and behavioral intentions. The TRA complements cultural models by providing a conceptual roadmap for analyzing the proximal determinants of behavior through these constructs.

Substantial empirical support exists for the predictive utility of the Theory of Reasoned Action (Randall and Rollins 2004, Fishbein and Manfredo 1992). I use this theory to explore the relationship between behaviors and ideologies and ultimately to propose its use in the management of marine resources. Each component of the TRA, attitudinal and normative, is given a weight reflecting its relative importance as a determinant of the intention under consideration (Ajzen and Fishbein 1980). To determine an individual's intentions in a situation where there is a conflict between attitude toward the behavior and subjective norm, Ajzen and Fishbein emphasize the importance of identifying the relative importance of the attitudinal and normative factors as determinants of intentions. Frequently, both factors are important determinants of the intention. However, in some cases, normative considerations will dominate the formation of intentions and in other cases, attitudinal considerations will dominate the formation of intentions (1980:22). It is possible to predict and gain some understanding of a person's intention by measuring his or her attitude toward performing the behavior, his or her 
subjective norm, and their relative weights (1980:22), as well as the behavioral and normative beliefs that underlie these attitudes and norms (1980:22).

\section{Using TRA in Environmental Studies}

TRA has been used extensively to study and explain a variety of behaviors related to the environment (Aipanjiguly et al. 2003). Bright et al. (1993) found that the TRA model explained attitude and behavior changes in their study of public perceptions of the U.S. National Park Service’s controlled burn policy. Pate et al. (1996) found that attitudes toward wolf reintroduction in Colorado were predictive of how an individual would vote on this issue, using the TRA. Young and Reichenbach (1987) reported that differences in behavioral beliefs and in the normative influence of social groups were observed between woodland owners who intended to harvest timber and those who did not. Other studies of the human dimensions of conservation have used the theory to examine outdoor recreation behavior (Young \& Kent 1985), differences in the attitudes of farmers and conservationists (Luzar and Diagne 1999; Carr \& Tait 1991; Heong and Escalada 1999), recycling and other waste disposal behaviors (Boldero 1995; Taylor and Todd 1997;

Cripe 1998; Park et al. 1998; Gamba 2000), attitudes toward wildlife viewing (Miller 1995), attitudes towards water conservation (Kantola et al. 1982; Seligman, Hall, and Finegan 1983; Trumbo and O’Keefe 2001), attitudes towards nuclear power (Showers and Shrigley 1995), energy conservation behavior (Stutzan and Green 1982) and value orientations and attitudes influencing hunting and fishing activities (Fulton et al. 1996; Rossi \& Armstrong 1999). Each of these studies looked at particularly important 
environmental behaviors and used TRA to examine the behavioral intentions and the reasons behind them.

Researchers, such as those described above, that have used the Theory of Reasoned Action as a framework find that it is useful to help explain and predict behaviors, and that it provides a useful guide for designing intervention strategies to replace, alter, or maintain behaviors (Ajzen \& Fishbein 1977; Sheppard et al. 1988). While intervention and behavioral change may be a goal for many social psychological applications of the TRA, the goal of anthropologists is different. I think that the application of TRA by anthropologists will provide a useful guide for informing management strategies that include the beliefs, attitudes, norms, intentions, and behaviors of marine resource users. The results of an anthropological study employing TRA would identify not only relevant target behaviors, but also can identify relevant beliefs and norms that are important to consider in designing effective management strategies.

TRA is particularly appealing for use within environmental anthropology because of the discipline's research methods. Participant observation is used by anthropologists to get closest to the emic (insider's) perspective of a culture. It is the best found way to observe the behaviors of a culture's members and get the closest sense of what occurs within a culture. Aipanjiguly, Jacobson and Flamm (2003) used TRA to explore the relationships between the beliefs, attitudes, norms, and behavioral intentions of boaters toward observing speed zones in manatee areas. They were unable to observe boaters directly disregarding speed zones but used TRA to examine the relationships among attitudes toward disregarding speed zones, subjective norms, and the intention to follow speed zones set in manatee areas. If perhaps they had used participant observation to 
complement their methodology, they may have obtained additional insights into the behaviors of the boatmen and the attitudinal bases of those behaviors. For instance, participant observation may have made clear that there were relevant subjective norms operating while the person was on the boat that were not apparent from the interview process. Thus making the application of TRA that much stronger, one might use participant observation methodologies.

Many researchers who have been able to study both attitudes and behaviors have found a significant, positive relationship between the two variables (Olson et al. 1984; White 1993; Aipanjiguly et al.2003). Zelezny’s (1999) meta-analysis of 18 studies related to pro-environmental behavior, found strong correlations between knowledge and behavior and concluded that the use of education could effectively change environmental behavior (Aipanjiguly et al. 2003). The results of many studies not only reflect the importance of identifying target audiences and target behaviors but also stress the usefulness of identifying target beliefs in the process of designing effective education strategies. The use of the results in educational strategies will be discussed in greater depth at this study's conclusion.

This study found many instances of similarities and contradictions between marine resource users' ideologies and behaviors. I use TRA to explain both the similarities and the contradictions between the two components. I think the application of this theory introduces an important theoretical piece for environmental anthropologists employing a cultural modeling approach. The link between a person's ideology and his or her behaviors is found through ethnographic methods such as interviews and participant observation, yet TRA explains the links between the behaviors observed and 
the ideologies expressed in an empirical fashion. This fashion can easily be expressed quantitatively for presentations to resource managers. Unlike Q-sorting, which I found to be a difficult method to employ and with variable results on an individual basis, yielding data that are not easily translated to resource managers, the TRA constructs can be summarized and communicated in a more meaningful fashion.

Moreover, what has sometimes been difficult to accomplish in anthropological studies of fisheries is participant observation of fishers while out on the boats. Therefore cultural models of fishing industries are often based upon methods such as interviews and focus groups. The cultural modeling approach used for management is not inclusive of the actual behaviors of individuals using the resource. As this study shows, the values and beliefs provided during interview sessions are not always sufficient for understanding behaviors when the presence or absence of the subjective norm is taken into account.

Resource managers should have an understanding of the direction and strength of resource user’s attitudes. Further, managers need to understand beliefs, both personal and normative, regarding management policy in a communication plan in order to account for behaviors. An understanding of the relative importance of attitudes, behavioral beliefs and normative influences is important because it may help to explain why regulations are successful or unsuccessful. Developing messages that specifically target the attitudes and underlying beliefs of the resource users will assist resource managers in maintaining resource sustainability. This study applies the Theory of Reasoned Action as a framework to examine marine resource user attitudes and norms with respect to the marine environment and specifically to address the following questions: How do marine resource users' value the marine environment? What are the 
beliefs and attitudes underlying marine resource user's behavioral intentions? What are the norms relevant to marine resource user's intentions? What implications does this study set forth for resource managers? 


\section{CHAPTER III}

\section{LIVING AND WORKING BY AN ALASKAN FJORD}

A walk down to the harbor any day of the week from May $15^{\text {th }}$ to September $15^{\text {th }}$ between the hours of 6 and 8 pm will provide anyone with quite a show. These are the times when all of the sport fishers arrive in the harbor after a long day of fishing. During this time all of the day's catches are brought up to the docks for hanging, pictures, filleting and shipping. Each deckhand hangs their catch for all the tourists to see in the hopes that they will book with their company the next day. This is also the time for vanity and achievement, as this is when the fish are cleaned and hung and the customers can take pictures beside, on top of, kissing, hugging and posing next to their fish. These pictures will be kept for posterity, particularly the ones that include a three hundred pound halibut. Everyone booking a sport fishing boat has the high hopes of landing a “hog”. A halibut over the weight of one hundred pounds (relatively speaking) is considered a hog, anything between fifty and a hundred is a turkey and halibut under fifty pounds are mere chickens. No self respecting halibut fisher wants to take home a picture of himself or herself next to two chickens. However, if it is a tourist's first time fishing, they are often excited by the prospect of having reeled an Alaskan halibut up from two hundred and thirty feet of water no matter the size. Doing the math, if there are one hundred and fifty boats in the harbor and on average each boat holds ten people, and each person can keep two halibut per day, the amount of halibut being harvested in Seward per day during the allotted months for fishing is three thousand. Over the course of four months that becomes 360,000 halibut a season. The average weight of a halibut 
kept a season is about thirty eight pounds, which makes for approximately 13,680,000 pounds of halibut harvested by sport fishers in Seward, Alaska alone each season. This is not including Seward's commercial fishing fleet or the people that fish for recreation on private boats, nor is it including the amount of fish harvested by commercial fishers or sport fishers in the many other towns bordering the Kenai Fjords National Park.

How does the day pan out for a sport fishing boat crew? The morning starts at five am when most captains roll out of bed and start their coffee makers. A Heavy coat is thrown on and coffee is poured into a large mug and brought to a Ford F350 or a Chevy Durango where the coffee is never actually placed in a cup holder, but held and drank the entire way to work. Sometimes deckhands are passed riding their bikes or walking and occasionally picked up by the captain, particularly if they are going to be late. Parking at the harbor is allocated to the sport fishing tour boat companies. By nine am the parking lot looks like a used pick-up truck dealership. After parking the captains go to grab another cup of coffee from the young, attractive girls working at one of the two coffee shops. The captains then stand outside the coffee shops talking about their incompetent deckhands, unreliable engines, pestering wives, overly expensive mechanics, fish stock depletion or their winter activities.

While this banter is exchanged by the captains, the deckhands are scurrying to get everything prepared by the time the customers and more importantly the captain arrive at the boat. First, the deckhands start the engine to warm it up, and then they make sure the boat is in perfect shape which means the windows and deck are spotless. Next they run up to "Captain Jacks" (the local bait store) where they get the day's case of bait, they bring the twenty five pound case of frozen herring (small and oily fish) down to the boat 
and immediately drench the box with salt water to thaw the fish out. Next they run up to the Fish House (a store by the harbor that has everything and anything people may need for fishing) and buy several energy drinks and some energy bars to accompany the sandwich they will grab from the bakery or sandwich shop after. One last stop by the company office to get another large coffee on the way to the boat along with a list of the names that will be on the boat that day. The deckhand heads down to the boat and gets the licensing paperwork ready for customers. All of the customer's sport fishing license information must be recorded in the daily log for the Alaska Department of Fish and Game (ADF\&G). The deckhand's hope is to have all of this completed by the time the customers arrive at 6:45 am, or at the very least ready by the time the captain arrives at 6:55 am.

As the customers arrive tickets are collected and licensing information is written in the ADF\&G logbook. If a glitch occurs (someone's license is expired, the wrong name is on the license, etc.) the deckhand will need to call or radio up to the office for confirmation. Once the captain arrives he gives the safety speech and it is time to get things underway. The deckhand runs to undo the bow and stern lines (the two ropes holding the boat against the dock) and make sure the boat clears its slip as it pulls out (this involves pushing the boat from the dock and jumping aboard at the last minute). The captain then takes his or her cup of coffee in hand and begins the two to three hour journey out to the "good" (productive) halibut fishing grounds.

The deckhand starts to make his or her rounds on the boat, first securing all buoys, bumpers and lines around the boat (using the proper knots to tie all ropes to the rails). He or she will spend time talking to all the customers, getting acquainted and 
learning names for the purposes of better tips. Finally, the deckhand will check in with the captain concerning the day's plan (where they will be fishing, how many and what type fish they are aiming for, etc.). Soon the deckhand will get time for an hour's long nap; if the captain is nice.

A half an hour before reaching the halibut grounds the deckhand will be awoken by the captain and will proceed to put his or her rain gear on. The deckhand goes out on the back deck and begins to prepare the bait, poles and all the gear. This is started early so that no time is lost and the customers can begin fishing immediately upon anchoring.

Once the captain finds the designated fishing "hole", he or she will yell out to the deckhand who will drop the anchor exactly according to the GPS mark the captain is viewing on his or her screen. Once the anchor hits bottom a buoy is put on a metal ring that is secured loosely to the anchor lead (rope that attaches the anchor chain to the boat). The deckhand then runs to the stern of the boat and beckons all of the sleepy customers out of the cabin. He or she instructs them on the safest way to fish with a three pound lead weight in 230 feet of water. They are concerned for the customer's safety as well as their own, as most deckhands have been knocked out by flying weights once or twice. The rest of the day remains consistent, "fish on", "fish up", "do you want to keep it?”, “are you sure?”, “no, I cannot hold your wife's pole so she can come over and look at your fish" and other such sayings. Fish are gaffed by the deckhand and brought onboard, wacked repeatedly with a tin or wooden baseball bat, marked with a knife (different shapes are carved into the fish so they know whose it is), bled and tossed into the fish hold (large well in the center of the boat) until they are filleted by the deckhand during the long ride into port. If the catch is significantly large in either quantity and/or 
quality, the fish are not filleted until the boat reaches the dock and the fish are hung for pictures. This does not make for a good ending to the day, as the crew will not be finished with hanging the fish for pictures, filleting the fish and cleaning the boat thoroughly until well after $9 \mathrm{pm}$. The crew will then go home and it all begins again the following morning.

\section{Research Area Description:}

\section{Seward, AK and Resurrection Bay}

Above is a detailed ethnographic description of a sport fishing boat operator's daily routine any day between May and September. The description is based on participant observation I conducted during those months of 2007. In the proceeding paragraphs I describe the community of Seward Alaska, the surrounding Resurrection Bay and the local fishing and tourism industries. I also discuss the methodology I employed to obtain cultural information from Seward's community members and a description of some informants from each group of study.

In this study I compare attitudes towards the environment among commercial fishers, sport fishing tour boat operators, local residents of Seward (people living in Seward year round for over five years) and government and management officials (employees of Alaska Department of Fish and Game, National Oceanic and Atmospheric Administration and the International Pacific Halibut Commission). Individuals from each of these groupings interact in some way on a daily basis with the marine environment. This interaction could range from experiencing a view of Resurrection Bay from an office window to working on a boat in Resurrection Bay for periods of a week at 
a time. I assume, based on the cultural modeling studies of Benjamin Blount (2002) presented in the previous chapter, that these loosely based groups share a general perspective on the environment based on their engagement with the sea and marine resources.

Seward, Alaska borders Resurrection Bay which is a part of the Kenai Fjords National Park (KFNP). Because of its close proximity to the bountiful KFNP, Seward is the seventh most lucrative fisheries port in the United States (Cook and Norris 1998: 25). Cod, salmon and halibut are the species primarily targeted in KFNP and are the species processed by the plants in Seward. Pacific Halibut is processed in the largest numbers by Seward's plants (Cook and Norris 1998: 25).

Pacific Halibut was first harvested in 1888 off the Washington coast. During the first decade of the 1900's, a heightened demand for halibut caused the Pacific halibut fleet to move northward in search of new fishing grounds. A chart issued in 1905 of the North Pacific fishing banks noted that the principal halibut banks were in Alaskan waters (Cook and Norris 1998: 25). Around 1911, commercial halibut harvesting was occurring in the Gulf of Alaska. Over the next several years, halibut harvesting in the Gulf of Alaska continued, probably in small but increasing amounts (Cook and Norris 1998: 26). In fall of 1916, the San Juan Fishing and Packing Company agreed to buy halibut from independent fishers. By March 1917, even before the plant had been built, the industry boat caught 176,000 pounds of halibut within 50 miles of Seward's coast. The San Juan's cold storage facility was completed during the summer of 1917. Seward soon became a very important halibut port. However, the annual number of halibut processed in Seward during this period remained relatively small. 
With the closure of other processing plants, good publicity and a growing fleet size, the San Juan plant soon increased its amount of halibut. In 1923, the San Juan plant announced that it was shipping between 1.5 million and 1.75 million pounds of frozen halibut per annum; a year later, the plant received some 2.5 million pounds of halibut (Cook and Norris 1998: 38). Their volume of halibut remained high for the next several years. In 1927 the plant again received 2.5 million pounds. Then a dramatic change in numbers came, the number of fish caught in waters outside of Seward dropped from 3.3 million in 1929 to 2.1 million in 1931 (Cook and Norris 1998: 32). As a result of further decline in stocks, the San Juan plant closed in 1931.

Although Seward, during the 1930s and 1940s, did not play a significant role in halibut processing, the waters south of Seward witnessed a boom in halibut harvesting. The harvest area rebounded from 2.1 million in 1931 to 3.7 million in 1933. The halibut industry, as it was foreseen in 1920, did not crash, but rather remained productive for years (Cook and Norris 1998: 36). During the 1950s and 1960s, halibut fishing in Statistical Area 25 continued at a high, stable level.

In 1958, the Seattle-based Halibut Producers Co-operative opened in Seward and for the next five years processed a modest volume of halibut (Cook and Norris 1998: 38). The volume increased significantly to more than four million pounds of halibut, which was the largest annual volume for a Seward plant. Ever since then, Seward Fisheries has been a major West Coast halibut processor. It has processed more than two million pounds of halibut in every year except one, and in both 1972 and 1973 it was the top halibut plant on the West Coast. 
In the 1920s a new industry was introduced to Seward, tourism. And in 1926, motor boat rides to Fox Island and around Kenai Fjords National Park were advertised (Cook and Norris 1998: 40). Soon bear hunts were organized, and boats took hunters nearby to hunt in isolated areas. It was not until 1962 that the first boat ran a sport fishing trip in the fjord for halibut. The first men to run sport fishing trips out of Seward were retired commercial fishermen whose families were tired of them being away at sea for long periods of time. Soon, younger men entered the business seeking a small fortune and the opportunity to fish for a living. Today, sport fishers in Seward are a range of ages, genders and backgrounds and as of now anyone with the proper tonnage on their captain’s license can get licensed to start a sport fishing boat.

Seward today is not only a buzzing tourist attraction during the summer months, but also a busy commercial fishing port. These two very different worlds both rely heavily on the continued existence of marine natural resources, most importantly the halibut. Much of Seward's tourism is based on its heavy flow of sport fishers and those looking to discover the grand beauty of Kenai Fjord National Park. The following section presents the methodology used to conduct this research.

\section{Methods}

This research was conducted over a six month period in 2007, from May to October. For the purposes of studying the ideologies and practices of marine resource users in Seward, the population was broken down into the four groups previously discussed (commercial halibut fishers, sport fishing tour boat operators, Seward residents for five or more years, and government officials and managers). These groups emerged 
through my pre-dissertation research in the town and were then verified for each individual through the interviews. It became clear during my research that occupation was the most important indicator of behavioral beliefs and behaviors towards particular species within Seward's population. People’s occupations summarized many distal factors that contribute to their attitudes towards the environment (i.e. their place of birth, their level of education, class, etc.). Important ideological and behavioral differences were found among the groups, as well as important commonalities were found within the groups.

Engaging individuals about their ideologies (values, beliefs and knowledge) is proven most promising through intimate interaction and proper rapport between researcher and participant (Ajzen and Fishbein 1980). According to Emerson (1983), fieldwork involves intimate participation in a community, observation of modes of behavior and the organization of social life. My principal methods in this study included participant observation, semi-structured interviews and analysis of secondary sources such as newspapers and Alaska Fish and Game publications.

The original proposal for this study also included the use of Q-sorting as a method in obtaining valuation from marine resource users. I later used the Q-sort method for work on a project with marine resource users in England and found the method to be extremely time consuming for both the researcher and the participant, to the point where the method could negatively impact the participant-researcher rapport. I also found that while the method can be used effectively in creating a "local discourse" that reflects the direct values of the sample population; it only does this effectively if the researcher is addressing a specific topic. For instance, Q-sorting was employed by a colleague in 
Scotland to determine whether the people of a small community wanted a wind farm placed in their town. The initial discourse worked in Scotland as all of the statements were surrounding the phenomenon of the wind farm. However, when I used the Q-sort method to assess people's valuation of biodiversity in a community in England (a much broader, more complicated issue) the discourse was not representative of the population. Therefore, when I began the Q-sort process with sample participants, many of them could not relate to particular statements. I found many commonalities between the community I worked with in England and that of Seward, as well as commonalities in the types of questions I was asking, and therefore decided against using the Q-sort method for my research in Seward.

\section{Participant Observation}

Participant observation was only conducted with sport fishing boat captains and commercial halibut long-lining captains. The nature of my research led me to use a convenience sample in which to conduct participant observation. Seward has a sport fishing captain population of just over a hundred individuals. In attempting to keep the sample representative of the population, I used stratified sampling. The four groups were stratified based on whether the captain had worked for someone else or owned their own business (one or more sport fishing boats) and if he or she had been an active captain for more or less than five years. The initial four participants were then selected to represent each stratified group and composed of one captain who had worked more than five years and one who had worked less than five years, and two captains who owned their own business, one who had been a captain for more than five years and one who had been a 
captain for less than five years. Because my sample was based upon ease of access and propinquity, not all captains that originally agreed to participate were selected (I did interview them later to contribute to the sample) and not all captains agreed to take me out with them at first. Each of the original four participants was a designated member of one of the strata. Once the initial participants were found, the rest were acquired through snowball sampling based on each of the primary participants.

The same method was used to break down the population of commercial halibut long line vessels that dock in Seward, and whose crews are residents of Seward. I again stratified the initial population into groups according to the years they had worked and if they owned or only captained their boats. From these stratified groupings I identified one representative who was willing to let me work and observe on their vessel. I then used snowball sampling from these four initial participants.

After the participants were found, I began my rounds as a "relief” deckhand for many of the sport fishing boats and commercial halibut long-lining vessels. I chose to accept a "relief" position so I could observe the largest sample of captains and crew. A “relief” deckhand is an individual that works a rotating schedule, giving each of the permanent deckhands' days off. Each sport fishing boat's permanent deckhand needs one day off a week, and on that one day the relief deckhand works with the captain.

Similarly, I spent weeks at a time relieving deckhands on commercial halibut boats and conducting participant observation. Commercial halibut crew members make most of their money during the summer months and do not want days off, so often times I helped out on the boats beside the regular deckhands. Participating in daily activities on 
all the boats gave me the opportunity to establish a great rapport with crew members, making them comfortable in my presence and visibly more inclined to perform naturally. I also attended town council meetings where I had hoped that marine resource management issues would be discussed. While I had originally foreseen these meetings to be an important piece in gaining information about how the community viewed and valued their marine resources, I was proven wrong. As I mention in the previous section on the history of resource management of the Pacific Halibut, this is by no means a state, let alone locally, regulated resource. While Alaska Fish and Game officials do contribute data to policy making institutions, and ultimately the International Pacific Halibut Commission, they are only in the towns where they collect the data a select amount of days during the year. So the town council meetings I attended only in one occurrence produced information concerning local's perspectives of marine resources in regards to whether or not snagging (throwing a line out with a hook to snag hatchery raised salmon anywhere on their body) should be allowed from the public beaches. However, the regulation was not proposed for ethical reasons, but rather for the purposes of keeping the beach free of filleted salmon carcasses. While this could contribute to the fact that community members value a clean beach, I felt that the interview data provided more accurate depictions of locals' beliefs.

In addition, town council meetings during the summer months are not often attended by commercial fishers (who are out on the water), sport fishers (who are exhausted at the end of the day) or, as I described above, marine resource management officials. They are often attended by business owners discussing hours of operation or parking restrictions, locals discussing four wheeler access roads, school teachers trying to 
get grant money used for different activities and materials, etc. Meetings involving any

of the marine-resource users groups are primarily held in the off-season (NovemberApril).

\section{Semi-Structured Interviews}

Government officials and managers were the smallest of the groups; there are only a select few fisheries biologists within the department of Fish and Game that deal with Seward's Pacific halibut and I interviewed the three main ones and four that are not directly related but are familiar with certain aspects of the fishery. Of the IPHC, I interviewed four individuals who are on the Commission and were once commercial halibut fishers. I also interviewed one individual who works for the National Oceanic Administration and addressed concerns from the area. This made for a total of twelve interviews with people in the government officials and managers category, all of which were done over the phone as none of them live in Seward.

Informants that fell within the category of residents, were individuals who had lived in Seward for greater than five years, were somewhat knowledgeable about the marine environment (they had experienced it in some way) and were willing to be interviewed (Rubin and Rubin 1995:66). I initially approached people working in local shops, frequenting coffee shops and working at the local aquarium, churches and library. And from there I used snowball sampling to discover my other resident informants. Informal semi-structured interviews were also conducted with all sport fishing and commercial boat captains with whom I conducted participant observation. I also interviewed and observed three wildlife viewing tour boat operators based on an 
availability sample. Because of the small population of wildlife viewing tour boat captains, I only include them in the study because their attitudes are so different from those of the sport fishing captains and they offer an interesting comparison.

My approach in conducting semi-structured interviews involved open-ended questions to offer a forum for people to discuss their feelings in full about a particular topic "providing an overall sense of the meaning of a concept" (Rubin and Rubin 1995:72). A question such as, "how do you feel when you are out on the water” would be used as a prompt for initial responses to the topic of marine environment valuation. Depending on the response, I would sometimes use a probe to get deeper feelings. If a response involved fish jumping, I may probe with a “why?” or “can you recall a specific experience that has led you to feel this way”. I would continue in this manner throughout the interview, saying very little and using intentionally unbiased wording. This was in keeping with Earl Babbie (2002) who defines bias as referring to any property of questions that encourages respondents to answer in a particular way (2002:246). Interviews would last as long as the participant let them. I would never initiate an ending to an interview, as I feel it is important to get as much free spoken information from individuals as possible. In addition, the longer an interview lasted, the better rapport I gained with the participant.

The cultural modeling approach suggests that the context in which a discourse takes place influences its content. It is important to address the specific context in which the narratives are generated. Leach and Fairchild (2003) discuss how, as a result of unequal power relationships, rural inhabitants interacting with outsiders may talk about the environment differently than they do in everyday discourse, for example by adopting 
outsider terms or saying what they think outsiders want to hear (2003:25). However, Claudia Strauss and Naomi Quinn (1997), in discussing the way that discourses are constructed between researchers and interviewees, find that, while what people say cannot always be taken at face value, what people choose to say or leave unsaid in the interview process is itself very revealing (1997: 241). I found it important to follow the methods of these researchers and lead people beyond simple responses, probing deeper and engaging in lengthy interviews that bring individuals well beyond their initial reactions. I developed a unique rapport with each individual during the course of interviews and in particular during the course of participant observation. This rapport brought out beliefs that often differed and were better explained than the initial, simple responses. Also, being out on the boats, I often found that interview data and initial responses were much different than behaviors and statements made when out on the water.

\section{Methods of Analysis}

Schelhas and Pfeffer say that environmental schemas and models can be identified through discourse analysis of transcripts of individual interviews, and variations in them can be reviewed with qualitative analysis (2008:17). While I was not looking for information to form schemas, I was looking for the same types of information representing people's attitudes, values and beliefs. I coded for commonalities and differences between individuals’ interview transcriptions and field notes from my participant observation. I also coded for behavioral beliefs, values and attitudes as well 
as perceived normative beliefs. I then analyzed the results from the coding (beliefs, values, attitudes, behaviors) using the Theory of Reasoned Action.

\section{Descriptions of Resource Users}

Over a six month period I conducted interviews in Seward, Alaska with roughly fifteen individuals from each of the four groups of study for a total of over sixty interviews. The interviews lasted anywhere from one to six hours and some people were interviewed on more than one occasion. Participant observation was also used and allowed me to establish a good rapport with my interviewees by interacting with them and observing their behaviors on a daily basis. The combination of in-depth, open ended interview questions and participant observation made for a very personal ethnographic description of each individual. To protect the identities of the individuals involved, I am careful not to disclose any personal information that would lead to their identification and I use pseudonyms in all cases. In this section, I describe a few informants from each social group, including brief personal histories, education level achieved, if they were born and raised in Alaska and their current involvement with Seward's marine environment. These descriptions are provider to give the reader brief examples of the backgrounds of individuals from each marine resource user group.

\section{Sport Fishing Tour Boat Operators}

Seward is a hub for many cruise ship companies, it is easily accessible by car, bus or train from Anchorage, and it is the site of one of Alaska's largest maritime training centers. The institute trains many deckhands for their captain's license and the tour boats 
provide them with sea time (hours on the water) necessary for the completion of their license. Many of the tourists that come to Seward are strictly interested in the marine wildlife, either for viewing or for fishing. Fifteen sport fishing tour boat operators were interviewed.

Captain Cat is over the age of forty five and holds a high school diploma. Her father used to take her two older brothers fishing when they were younger, but he told Cat she could not fish because she was a girl. Cat grew up in another Alaskan town and when she turned eighteen she left home and became a mechanic, another profession her father discouraged women from pursuing. After ten years as a mechanic she took a position as a deckhand on a sport fishing boat in Seward. Three years later she had acquired enough hours to obtain her captain's license and went on to work for a family owned sport fishing company in Seward where she is considered an excellent captain. When asked what she does during the winter months she replies, "part-time bartender and part-time bum”.

Cat's previous experiences with the federal government, have led her to be very careful about obeying government regulations. She curses and gets angry when an unwanted fish comes onboard that is protected by federal law, but she is very careful not to harm them for fear of penalty. This contradiction between attitude (anger) and behavior (displays of compassion) is apparent in most cases of sport fishing tour boat captains and their reluctance to obey government regulations.

$\mathrm{C}$ is a sport fishing boat captain; he is in his late fifties and started one of the first sport fishing companies in the area. He was born and raised in a mid Western state where he attended one year of undergraduate coursework in biology. During his year of school 
he met a professor that needed interns up in Alaska to do photo identification of brown bears for a university funded study. After spending a summer in Alaska he decided he did not want to go back to school. He did work on the pipeline, deckhanded on a commercial crabbing boat, dredged off a large tug boat and worked off a boat cleaning up after the Exxon Valdez spill; throughout the course of this boat work he acquired his captain’s license. In 1991 he bought his first two boats and started a sport fishing business.

C was often questioned by customers about why he continues to run sport fishing trips during the summer months when he could easily retire. C responds the same every time, “It’s simple, I love seeing people’s smiles when I make their dreams come true. And I love being on the ocean and fishing each day of course.” This love for being on the water and for fishing is not uncommon amongst both the sport fishing tour boat operators as well as the commercial fishermen.

$\mathrm{J}$ was raised in the sport fishing industry in Alaska; he started working for his father when he was seven as a "fish beater". He would ride along on the boats and when the fish were brought on board he would beat them with a tin bat. He graduated to deckhand at the age of fourteen, soon graduated high school and then acquired his captain's license at the age of eighteen. He is now in his early twenties and plans on taking over his father's sport fishing business when he is ready to retire.

\section{Wildlife Viewing Tour Boat Operators}

As previously mentioned I interviewed and observed wildlife viewing tour boat operators because they were distinct in their beliefs and behaviors. However, because of 
their small population and resulting sample size of three they do not form a separate group within the study; the individuals are brought in merely for comparison. The wildlife viewing excursions are primarily run by one of two large companies; both are owned by various Alaskan Native organizations and provide a flat rate or salary to their employees. This is opposed to sport fishing tour boat companies which are often owned by middle class men who own anywhere from one to five boats and while they pay their employees a flat hourly rate, the employees often double this rate in tips.

In addition to the income distinction, there is a notable distinction of environmental interests between the sport fishing and the wildlife viewing tour boat captains. Wildlife tour boat operators support Western environmentalist views and hold negative opinions towards commercial and often times sport fishers. Sport fishing operators hold a passion for fishing and while they claim environmental responsibility, their values and actions differ from those of marine resource managers, wildlife viewing tour boat captains (this discrepancy will be discussed in later chapters) and commercial fishers in most respects.

One thirty-two year old male, Captain Jo, has spent the past eight summers working for the largest, Native Alaskan owned wildlife viewing tour boat company in Seward. He is in his mid thirties, holds a bachelor's degree and was born and raised in another state. He started coming up to Alaska in his mid twenties to work as a guide for various eco-tourism based companies. Jo works winters as an environmental instructor in the southern states and loves his seasonal lifestyle. He shares his knowledge with passengers and is known for consistently navigating his tours towards whale spottings. 
Jo's views, along with those of many wildlife viewing tour boat operators, run parallel to his behaviors, he sticks to what he terms an "environmentalist" attitude.

Another wildlife viewing tour boat operator, Captain M, is a retired park ranger for the local national park, and now runs boats for one of the smaller tour companies. He is over fifty years old and holds a bachelors degree. He still runs boats because he enjoys being out on the water every day and he never plans on leaving. Similar to Captain Jo, Captain M identifies himself as an "environmentalist”, and his behaviors and beliefs reflect this mentality.

Many differences were found between captains of wildlife viewing vessels and captains of sport fishing vessels. Thirteen of the fifteen sport fishing captains hold a high school diploma from the state of Alaska and were born and raised in Alaska, while all three wildlife viewing captains hold a college degree from a state other than Alaska. Wildlife viewing tour boat operators hold Western environmentalist beliefs. Sport fishing tour boat operators speak according to Western environmentalist attitudes, but their actions are not consistent with those expressed attitudes. They seem to be used as “lip-service” for clients and the general public (Strauss 1993;Schelhas and Pfeffer 2008). This issue of adopting socially desired discourse appeared in many contexts of this study. Fishers often pay lip-service to groups holding Western environmentalists beliefs.

\section{Commercial Halibut Fishers}

All commercial halibut fishers I interviewed held very similar attitudes towards other resource user groups, the people that create regulations and the marine environment. Each of them held negative feelings towards sport fishers, 
environmentalists and resource managers. They all held strong, positive feelings towards the marine environment.

Chip is a deckhand for a commercial long-lining vessel. He is originally from another state, a high school graduate and he fondly remembers growing up fly fishing in rivers with his friends. His first summer in Alaska was spent deckhanding on a sport fishing boat, after that first summer he got a commercial job and has deckhanded on the same boat for the last four years.

Captain Greg was initially very reluctant to talk to me because he assumed I was a scientist working for the government. When he found that I was an anthropologist doing research for a university he became much more open. He was born and raised in another coastal town of Alaska, where he started deckhanding on commercial halibut boats as a teenager. He graduated high school, and continued to work as a deckhand, and then as a captain for several boat owners until he bought his own boat when he was about thirty five; he is now forty seven. He spends the majority of the summer away from home, bringing most of his catches into Seward or another port far from his home town.

Captain Ron has been a commercial halibut fisherman for over thirty years. He is sixty years old and was born and raised in Seward. He holds a high school diploma, and many of his friends who graduated with him also became commercial fishers. He says that while fishing was one of the few options in Alaska when he was younger, he always knew he wanted to be a fisherman.

Seward's commercial halibut fishers hold strong opinions, but do not easily lend them to outside ears. Nine of the fifteen commercial fishers interviewed have their high school diploma or GED. With the exception of two, all commercial fishers were born 
and raised in the state of Alaska. Their behaviors are consistent with their attitudes; more so than those of any other resource user group.

\section{Government Officials and Managers}

Four of the fifteen government officials and managers interviewed were born and raised in Alaska, and three of them were retired commercial fishers working for the IPHC. The IPHC members were the only ones not to hold a degree past high school and they were also the ones to hold views that conflicted with Western environmentalism.

\section{State Government Employees}

I found that state government jobs tended to appeal to a particular individual who was driven to Alaska by an intense desire to live and work there. These individuals hold a love and respect for the Alaskan environment that I believe they developed because they came to the state later in life.

Bill is responsible for the program that estimates harvest statistics for the sport fishing industry of Seward and other towns on the Kenai Peninsula. He supervises a monitoring program that provides estimates of recreational catch and catch composition for any management agency that needs it. Bill holds a Master's Degree in science and is over the age of forty. Bill was born in a Midwestern state and moved to Alaska to work for the department of Fish and Game in the early 1980's. He has performed various roles within the agency since then, including dealing with Seward's halibut sport fishery over the last fifteen years. For Bill, moving to Alaska was a life style choice; he moved up 
there out of a love for the outdoors and marine life. He has lived in Alaska now for over twenty five years and does not plan on leaving anytime soon

All of the Alaska Department of Fish and Game (ADF\&G) employees had had moved to the State after the age of twenty one, often in search of an area with "greater wildlife.” Also, all ADF\&G employees hold a biology degree of some sort, but with no added education in the biology of the particular species they managed, nor in issues of fisheries management. Furthermore, fisheries biologists had reached or obtained their current job through a lower rung fisheries technician position.

\section{International Pacific Halibut Commission (IPHC)}

Jake is a member of the IPHC, he has been for three years. He holds a high school diploma from a Northwestern State, where he also commercial fished for halibut for thirty five years. He feels very strongly about the management of Pacific Halibut, which is why he chose to be involved with the IPHC.

\section{National Oceanic and Atmospheric Administration (NOAA)}

Conner has been employed by NOAA for eighteen years and he is responsible for the federal involvement in the halibut industry. He was born in a Northeastern state and he obtained his bachelors and masters degrees from a different state. He plays a small role in overseeing many fisheries issues. His residence is based out of a state in the northeast and he has travel to Alaska twice in his life. 


\section{Seward Residents}

The residents of Seward are unique because as individuals they each hold very different attitudes and this is not the case for the other groups. The residents did tend to hold the beliefs and values of the groups with whom they were closest associated, further reinforcing the fact that those groups tend to hold similar beliefs and values.

Sheila is an accountant for one of Seward's fish processing plants. She is originally from a southern state, is in her mid forties and holds a bachelor's degree. She originally came to Seward after college to work the "slime line" in the processing plant and when she came back the following summer she decided to establish residency. She stayed in Seward because “it is beautiful, it's small, it's charming, and it's weird.” The "slime line” is what they call the conveyor belt surrounded by young people (often students) that gut and gill all of the fish as they go past. Canneries typically provide housing for slime line employees, the shifts are typically eleven hours and seven days a week. While many employees cannot handle the work, they are all bound by a contract that says if they leave early they will not receive their summer bonus which is typically fifteen percent of their total pay. After two summers on the slime line Sheila moved up the processing plant's hierarchy until she was hired as a principal accountant. She also enjoys Seward because she likes to bike, hike and ski, and Seward is conducive for all of these activities.

Nathalie is in her early thirties, was born in Wisconsin and holds a bachelors degree. She says that she grew up always appreciating the natural environment and knew from a young age that she wanted to pursue a career relating to it. Nathalie originally 
moved to Seward to pursue a research internship at the local aquarium. She soon decided to stay primarily because of the "landscape" and took a full-time job with the aquarium.

Susan is a wildlife biologist for a state regulating organization that deals with forestry resources. She was born in another state, where she obtained a bachelor's degree. Growing up, Susan always loved animals and for a while she wanted to be a veterinarian, but was not involved in outdoor activities. When she started working for the forest service in a Midwestern state, she became exposed to the natural environment. She originally came to Alaska to visit a friend that lived in Seward. She decided to stay and get a job working as a wildlife biologist because "the wildlife was amazing and the mountains were beautiful”.

Sara is the director of public relations at the largest and oldest scenic tour company based out of Seward. She was born on the West coast and has lived in Seward year-round for nine years. Before coming to Alaska she had lived in many states and had completed coursework for a graduate degree. Sara stayed because she found herself in a comfort zone socially that she had not experienced since grade school. She says that being in academia; she was so poorly socialized that getting away from it made her realize how lonely she felt. In Alaska she found peers her age that had similar backgrounds and common interests, and appreciated the environment around them.

Sara and the other residents described above each display very distinct opinions concerning the marine resources around Seward. At first glance, it appeared that their beliefs were consistent with the beliefs of the resources users that they most closely associated. But it became apparent that while they may be influenced by the ideas of their friends and family, this is only one cultural model of which they are exposed. As 
Blount (2002) discusses in a review of the cultural modeling process, there are several cultural models a person engages when looking at the world. The individuals within the group of residents are not members of the other marine resource groups and while some of their opinions may be similar, many of them are different. What is key in keeping this as a comparison group is that only one of the individuals in the group of residents held values, beliefs and behaviors that consistently reflected those of another group. And none of them held schemas that were similar to each other within the group, thereby supporting that aspects of locality and town culture were not defining the views of the local residents.

I have presented a setting of the local community, the methods I used in conducting my research and a brief background of a few participants in each group of study. In the next chapters I discuss the data on behavior collected via participant observation. 


\section{CHAPTER IV}

\section{PARTICIPANT OBSERVATION BEHAVIORS OF MARINE RESOURCE USERS}

\section{Practices regarding the Marine Environment as a Whole}

\section{Jessie Pollutes}

While conducting participant observation with the commercial fishers, I found myself working on Ron's commercial halibut boat one week with another deckhand, Jessie. We were taking our slow trip back into port after a long four days on the water. Four days is not a long time for a commercial fisher to be out on the water, but the time seemed longer as it took us a while to find a good fishing spot. The weather was forecasted to turn bad in the next 48 hours so Ron made the decision to head in. As we were going in Jessie and I were cleaning the boat; I was primarily doing the outside and Jessie was working on the inside. Cleaning the outside of a boat is much easier for me, as each Captain is different in their organization and can be very particular. The outside is the same for me always; the key for every captain is that the deck is spotless. Jessie threw a huge garbage bag of hydraulic soaked marine towels, plastic and paper food containers and empty cleaning supply bottles out on the deck. I turned and continued to scrub the deck with simple green and water. Next I heard a small splash in the water and as I looked the way of the noise I saw the large white garbage bag sealed and filled to the top with trash floating behind the boat. I immediately looked at Jessie who was facing the other direction on his way back into the cabin. I finished cleaning the back deck and went inside the cabin, and calmly sat at the "booth". The Cabin is designed with a small 
door that enters into a very small room with a diner style booth on the right that seats four comfortably and a diesel stove on the immediate left with a steering console farther towards the front on the left. Directly under the bow of the boat were four steps leading down to two very small bunks.

I sat at the booth and looked over to Ron who was chewing on a toothpick; looking straight ahead with one hand on the steering wheel. Ron, wouldn't it be simpler to just throw the garbage over as it is created rather than bother keeping garbage bags aboard? He looked at me expressionless. "Well, Jessie just collected all the garbage and then threw the bag overboard, is that typical? I am just asking." "Jessie get your ass in here", he yelled. "Boy what is wrong with? You don't just throw shit overboard". Jessie responded quickly and with an irritated tone. "It seems the only ones who have a problem with it are the people that aren't from Alaska. We were just fine doin' it until all the damn cruise ships and tourist and shit started commin' up here and dumpin'. Then you blame us for throwing little shit overboard that we have been doing for years. We didn't see problems before you guys came up from the lower forty-eight and caused the problems." Jessie ranted for a while. "Jessie, this is your home though, do you really think that contributing to the problem is the best thing to do?" I asked. "It wasn't a problem till you guys made it one," he responded again. I stopped talking and looked out the cabin window at the small white dot floating behind the boat in the vast blue ocean.

After that incident it seemed that Jessie threw everything over board instead of placing it in the trash can, until Ron screamed at him to stop. The example above is provided to address how some people's behavioral beliefs, and subsequent behaviors, revealed a lack of knowledge, and not a lack of respect for the environment. Jessie 
justified his actions in relation to those of other marine resource user groups. He claims that because he was born and raised in Alaska this is his water and his land. Therefore he can treat it as he sees fit and no damage is caused from his pollution. Furthermore, he feels justified in his actions because boats of larger size (cruise boats and barges) pollute on such a grandiose scale that there is no way his actions could be felt by the environment in comparison. His behavior seems to be in spite of people from outside the state that have imposed Western environmental ideals on his community. This is similar to the case of Niels Einarrson's (1990:42) work with Icelandic fishermen, where he found them to be acting out against environmentalists and managers by illegally killing seals.

Throughout the course of fieldwork I observed ten of the fifteen commercial fishers throw something overboard. The items ranged from garbage bags full of garbage to empty bottles of liquid dish detergent to half eaten sandwiches. I observed twelve of the fourteen sport fishers throw something overboard (that was not initially from the ocean), whether it be a used piece of paper towel or an energy drink. Of those that threw items overboard, only five commercial fishers and seven sport fishing tour boat operators threw something that was not quickly biodegradable and was obviously harmful to the marine environment (i.e. bottles, cans, plastic containers). I never witnessed a wildlife viewing tour boat operator throw anything overboard; in fact they were careful to turn around and collect items that customers would often drop.

None of the interviewees of any group want to see the marine environment around Seward treated poorly. Aesthetically, they want it to remain unchanged. Their behaviors reflect these feelings; no one I worked with, even Jessie, behaved in ways they believed would harm the environment. Certain individuals may shoot at sea lions, fish for baby 
halibut in the breeding grounds and throw their garbage overboard, but they also believe that these behaviors do not impact the environment in enough of a way that they would see or feel a difference. This distinction is important and will be discussed in Chapter VII in relation to the importance communication and instruction amongst all groups.

\section{Practices regarding a Particular Species}

Wildlife viewing tour boat operators take customers out for a couple of hours and show them sites within Resurrection Bay. The sites are all well publicized, regularly visited and where there is an abundance of marine wildlife (e.g., sea lions, puffins, etc.). A wildlife viewing tour boat captain's day could be considered relatively easy.

Sport fishing boat captains differ from wildlife viewing tour boat operators because there are several places they can take their customers within a day's voyage. If a wildlife viewing boat does not encounter any rare wildlife (i.e. orcas), they will still see common wildlife (i.e. puffins and sea lions) as well as glaciers and mountains. The captain of a sport fishing boat that does not find any fish for his customers to catch cannot offer anything in its place. Sport fishing captains have to go beyond the protection of the Bay in order to reach the good fishing spots. They need to keep a very close check on the weather. Sport fishing captains take into account the tides, fish migration, visibility, the winds, warmth of the water, time of day, feeding behaviors of all species, the location of fishing holes, what their clients want to catch, etc. All of these factors make for a much different and more difficult day for sport fishing captains than for wildlife viewing captains. 
Captains and crew are constantly on the move on sport fishing boats, their duties involve prepping the boat in the morning, cutting up the bait, keeping customers happy and safe, navigating the boat, selecting the fishing spots, baiting hooks upon order, gaffing all fish that are brought to the surface, untangling lines, filleting fish, hanging fish for pictures, and thoroughly cleaning the boat at the end of the day. All of these duties make for a very intense environment for most captains and crew of sport fishing tour boats. They are constantly on display for their clients and must act in accordance with what the clients want to see. Sport fishing boat captains hold pragmatic views towards the marine environment as they were born and raised in Alaska and grew up working in the marine environment. They were however exposed to Western environmentalist views through popular media and the clients they began catering to at a young age. Sport fishing boat captains' behavioral beliefs are overshadowed by their subjective norms while out on the water, because they must perform in accordance with their clients' beliefs. This tends to make captains and crew very hostile and sarcastic when dealing with anyone who is not a paying customer.

Subjective norms have an impact on the behaviors of all people in this study. However, I found that the presence of subjective norms on a daily basis adds to a unique behavioral tendency for sport fishing boat captains. Sport fishing captains tend to present two sides of self during each work day. One side is that which is shown to the customer, a conservative, yet intense and often sarcastic side. The other side is shown to the crew, the unforgiving and often demeaning side. The first side develops because the customers impose a subjective norm on the sport fishing boat captains. This subjective norm coerces the captains to use care when handling all marine wildlife, to abide by laws and 
regulations and to take care of all clients' needs. The second side, however, develops from the traditional hierarchical process of becoming a captain and the difficulties one encounters as a deckhand, which lead to a display of condescending behavior when only the crew is present. However, as is the case in many professions, this cycle depends also on the demeanor of each person's previous supervisors, experiences and current supervisors.

Resulting from these two distinct presentations of self are behaviors according to each extreme. Aggressive behaviors are shown to people who are not paying customers and friendlier behaviors are shown to people who are paying customers. For example, they may treat dogfish with the utmost care when clients are present and maul them when clients are not present.

\section{Displays of Aggression towards the Dogfish}

It was the "crew trip" for the large family owned, sport fishing company that I spent a great deal of time working for and so I was invited to come along. The crews of each of the company's five boats had the day off and were at the boat early to take off. Nine crew members were onboard including me; there were about 10 cases of beer, bags from the local deli and a couple gallons of water. It was 7 am and Matty (a deckhand) was already on his second Alaskan brewed beer. Everyone had a coffee in their hand as well, including myself. As we left the harbor we all felt uncomfortable as every person aboard was a crew member and each of us jumped to grab the lines, the buoys, push us off the deck etc. Soon I just gave up and let the guys fight for the work (it was our day off after all); I went up to the helm to sit with Carl who was the first driver in rotation. Soon 
enough I realized there was no need for me to be awake this early in the morning as we had no customers aboard. I made my way down to the birth and hopped on one of the incredibly uncomfortable wooden bunks and passed out. "Fish On”, I heard a scream from above that woke me up. I jumped up and put my boots on and ran out to the deck. The guys were sitting in lawn chairs on the deck, beer in one hand, rod in the other. The scream had come from Cat, who was currently running around the anchor line at the front of the boat following her line as a giant king salmon took it around the boat. The idea is not to pull on the rod when you have a salmon on the end, and to let them wear themselves out as they circle the boat, because if you pull you will most likely pull out the hook. Cat was running around the boat like a mad woman screaming for a gaff. All the guys were lying in their lawn chairs watching and laughing. I grabbed a gaff quickly from the top of the boat and ran after her. Eventually the fish got tired enough that I could throw a hook in him and bring him onboard. Cat started punching the fish in the back of the head as it went crazy on the deck. Eventually, after a few good left hooks the fish did its "death shake" (a last quiver as its nervous system gives out) and stopped its flopping. "You asses" she screamed out, "five fucking deckhands onboard and the only one I got to help was the one I woke up!!” The guys were in hysterics at the whole scene. "It's our day off, besides you girls did a great job by yourselves” yelled Matty still laughing.

Hours of fishing went by, switching spots, trying each captain's "secret spot". Eventually the inevitable happened and we wound up in a school of dogfish feeding in a fishing hole of small halibut. "Fucking dogfish!" T yelled as he reeled in a halibut that looked like Swiss cheese and had two dogfish sharks hanging by their teeth. Tony pulled 
the whole mess onboard; one half eaten halibut, one five pound lead weight and two unhooked, angry dogfish sharks. The two sharks went sliding across the deck and everyone started laughing, I hopped up on the fish box to avoid a hole in my boots. The sharks flopped around violently, chomping their jaws at the air. T stomped hard on one of them, pulled out his pocket knife and began slashing and stabbing its tough skin with the sharp knife. The dogfish was going crazy and blood was squirting everywhere. The knife penetrated the strong denticles that make up the shark's skin as T continued to stab away. He had a cigarette hanging out of his mouth as he switched to the other shark and back and forth he went, eventually snapping them both in half and sending the limp fish several yards out into the ocean. "I hate those fucking things, I wish I could kill them all”, said $T$ as he finished his cigarette, lit another and walked back to his pole. The guys were all laughing hysterically. On any other day when there were tourists aboard, $T$ would have treated this fish with respect, but because no one on the boat that day would report him to Fish and Game he could behave according to his behavioral beliefs.

T's actions in the instance described above reflect his behavioral belief that dogfish sharks have been ill-managed to the point where they are now in an overabundance. T's behavioral belief dominated the behavioral intention as there was no one present to make salient the normative belief of disapproval of killing the dogfish shark because they are federally protected. His intention was to kill the dogfish shark out of frustration for both the creature and frustration with the regulations protecting them and his behavior reflected this intention. Had this not been the day of the crew trip, $\mathrm{T}$ would not have behaved the way he did, and he would have carefully placed the dogfish back in the ocean. 
Figure 1 depicts these dynamics graphically using an influence diagram. Solid boxes represent variables and arrows represent presumed causal effects, with the variable from which the arrow emanates representing the presumed "cause" and the variable to which the arrow points representing the presumed "effect." The diagram is read from left to right. The far left boxes represent the major behavioral beliefs that were judged to be relevant and the sources of normative pressures to behave one way or another. The behavioral beliefs produce either positive or negative attitudes (i.e., overall feelings of favorableness or unfavorableness) towards performing the behavior. The normative beliefs produce a generalized perception that important others (for example, one's clients) either approve or disapprove of the person performing the behavior (what the TRA refers to as a subjective norm). The attitudes and subjective norms combine to determine a person's decision or intention to perform the behavior. The dashed boxed in the middle of the diagram summarizes conclusions about the relative importance of attitudes and subjective norms in influencing intentions (recall that for some individuals and behaviors, attitudes are more important than subjective norms, while for other individuals and groups, subjective norms are more important than attitudes). Finally, a person's intention or decision to perform a behavior influences whether that individual actually performs the behavior. I will use influence diagrams throughout this chapter to summarize graphically the results of my fieldwork. 
Figure 1: Why a Sport Fisher Kills a Dogfish.

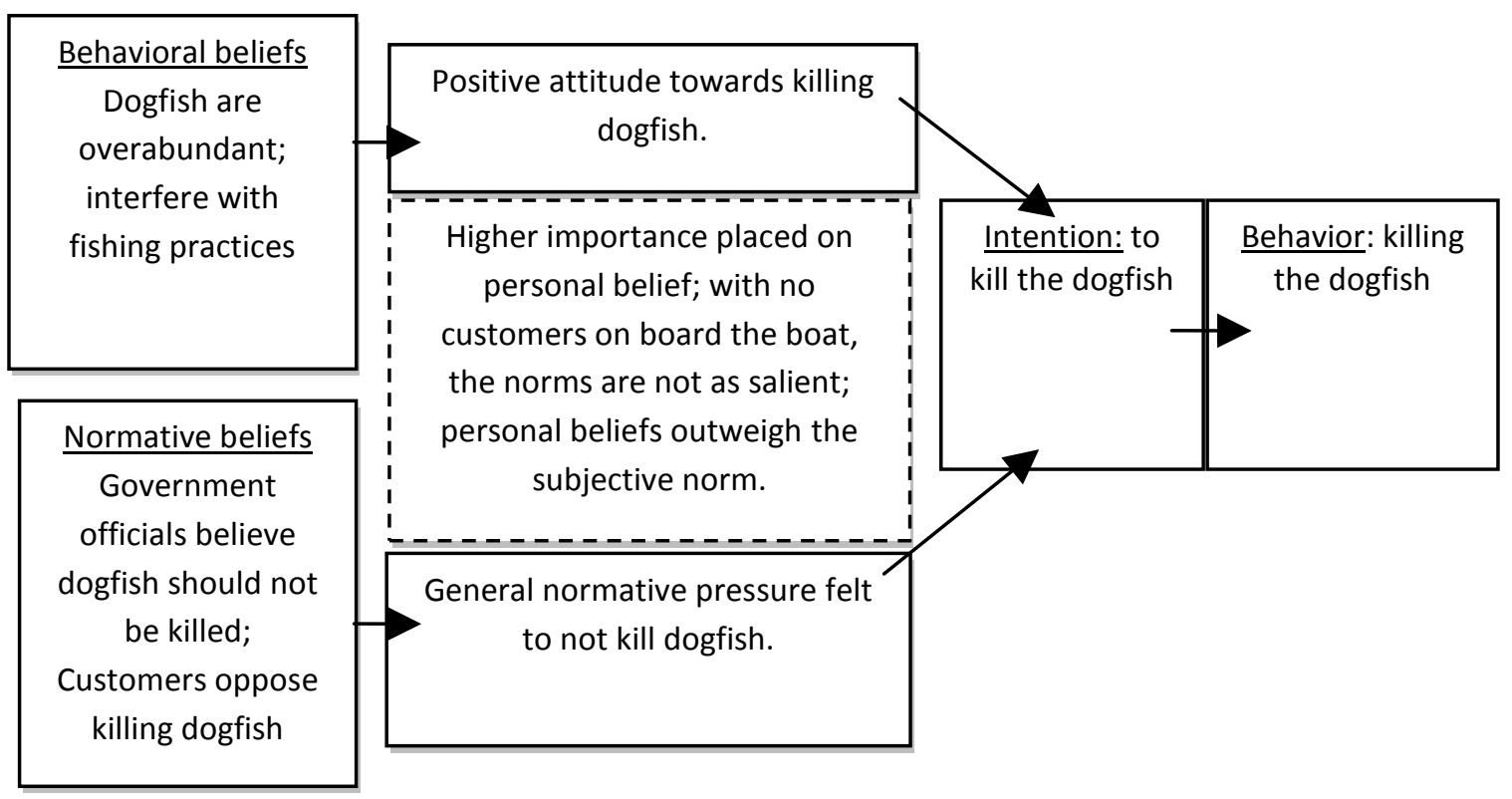

\section{Chip Shoots}

We had been out on Ron's boat for only two days and the morale of the crew was good but not great as we had experienced some engine troubles our first day. The engine, which was new as of this year, was giving the captain serious problems. We spent about 8 hours the day prior handing wrenches of various sizes, screw drivers, hammers, towels, pliers, wire cutters, every tool on the boat, down to the captain as he kneeled uncomfortably in the tiny space between the twin diesel engines cursing like only I have heard fishing boat captains to curse. This went on for roughly six hours, until the problem was fixed. The problem had been caused by an oil leak from the right engine. The oil tank for this engine was located on the right side of the right engine, which meant crawling behind the engine and to the right side which was maybe a foot from the wall of the hull. Oil changes were often designated to be my job on boats because of my size. 
However, finding and fixing a leak in an engine was a much more difficult task. I crawled behind the engine twisting my legs awkwardly around diesel and hydraulic lines. Several hours were spent flushing the engine again and again until I located the leak and fixed it. Needless to say our morale was decent but definitely not as fresh as we should have been arriving at our first fishing grounds.

The other boats had been in the area for varying amounts of time, a luxury afforded by the Individual Fishing Quotas and no opening time limitations. We had just set down our lines and it was time to wait. The captain got on the radio and began explaining the situation of the engine with all the fishers in the area. Not hesitating to brag about the "little lady" he had on board this week to save him from knee and back pain. Everyone got a kick out of hearing about me, as many of them had already had me on their boat at one point. Roughly a half hour into the set, I heard Chip yell something I couldn't make out. He ran in the cabin and grabbed a rifle from behind one of the booth's cushions. [This boat's cabin is designed with a booth that seats about two people comfortably and has a TV/DVD player above it, and the steering console and counter for the propane stove are on the right side. There are four steep steps to walk down into the “captain's quarters” where there are four comfortably sized bunk beds.] After grabbing the rifle Chip almost tripped on the lip of the cabin door he ran out of the cabin so fast. He ran up the ten steep, small steps to the top deck, which is about one third the size of the main deck, and is surrounded by a metal railing at hip height. Chip aimed at what I immediately saw to be a large sea lion jumping and playing around the long-line. He shot once and missed the animal by about ten feet. The sea lion immediately dove, most likely to grab another bite of a meal he was already working on. Chip remained in a 
ready to shoot position and adjusted his stance. The sea lion popped its head up again and looked around, but this time it was well out the range of Chip's gun, though he fired anyway just as the sea lion went down for a final dive.

Shooting at the sea lion from a distance is not an action intended to kill; rather it is an attempt to condition the animal to stay away from long-lines. The justifications for the actions are that the catch is rightfully the fishers and the sea lion will not be killed, just taught a lesson. The act of shooting within a certain radius of a sea lion is however illegal, and had Fish and Game or Coastguard officials been present the captain would have received a citation, if not been put under arrest. The other commercial fishers who were present at the time share the same cultural model; sea lions are a nuisance and need to be conditioned to stay away from the long-lines. Without a subjective norm present to oppose the behavior, there is no reason for the fishers not to scare away the sea lion.

Figure 2: Why a Commercial Fisher Shoots at a Sea Lion

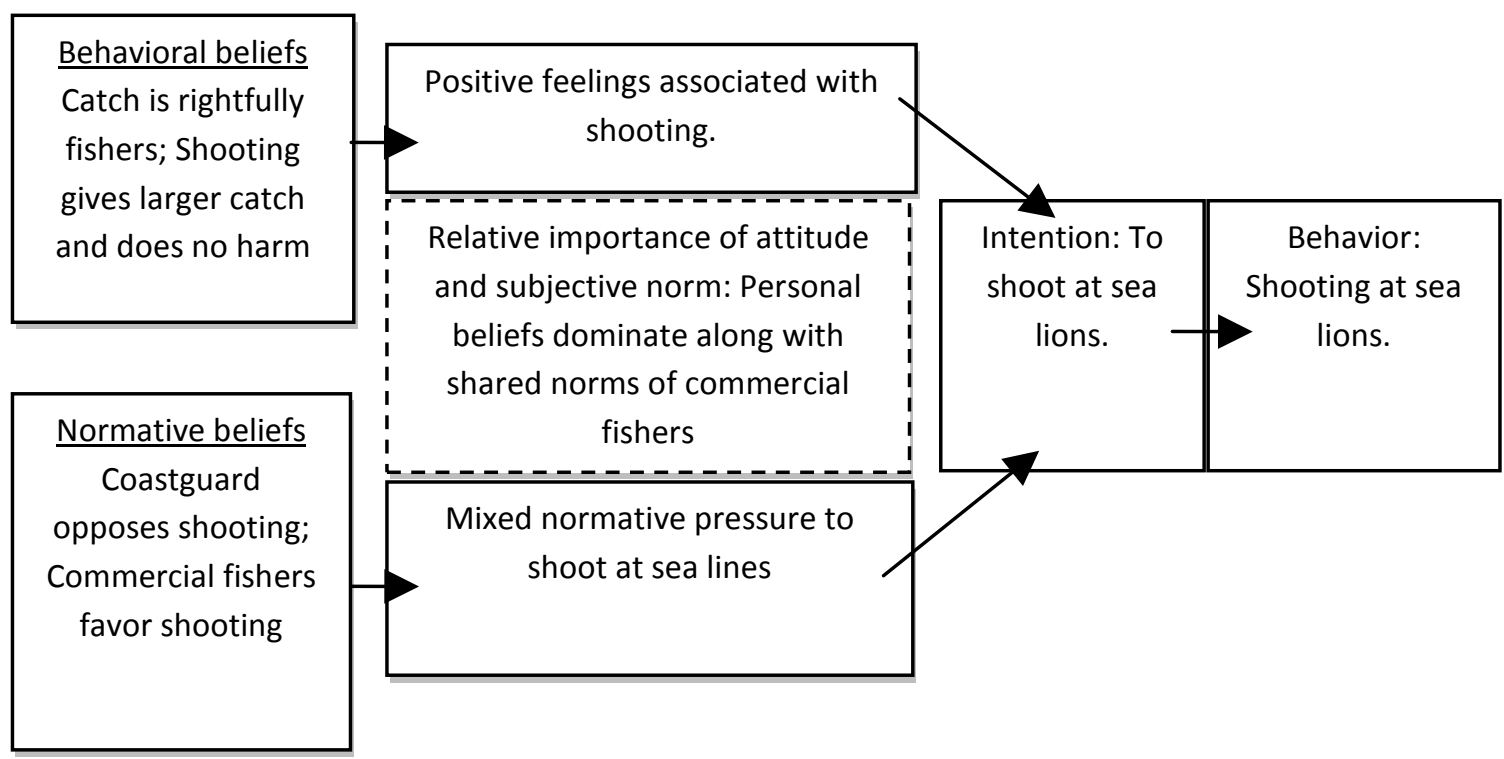




\section{Captain J's Respect for the Halibut}

“Fish on!!!!” was yelled from the stern of the boat as I was busy releasing around my fiftieth dogfish for the day. I sighed, thinking of how long this day was going to get if I had to keep sending back dogfish. I made my way to the back of the fifty foot sport fishing boat and started thinking as I saw the end of the man's rod who had yelled "fish on". It was one of four things. One, he had hooked a rock on the bottom and was trying to "pull the plug". Two, he was pulling up a giant Lynn cod with its huge mouth agape which was creating a large amount of weight to be pulled up because of the many pounds of water hitting the surface area of its mouth. Three, he had a large salmon shark. Or, four, he had a huge halibut. I got to him and took the rod carefully from his hands. "I got a hog!!" he yelled excitedly. "Hold on, let me see”, I said. I held the rod and lifted and took a few cranks down, I lifted again and took a few more cranks down. The ability to lift and crank down and make headway on the line took out the option of “pulling the plug”. As I continued to gain some headway and had very little movement I knew it was not a salmon shark as it would have taken a great deal of line, if not snapped the line by now. I thought about our depth, the fishing hole we were at and the weight I felt on the pole. I soon ruled out a Lynn cod, as they tended to hang out on the slopes of large underwater formations, most likely not on the top of a 240 foot rock formation, and definitely not creating that much weight on the line. "You got a hog buddy!!" I said laughing excitedly as I handed the man back his fishing pole. "Keep pulling up and reeling down, I am going to get you a belt”. I ran and got a fishing belt. This is a wide and thick plastic circle that does not complete, but rather has an open back and can be widened to fit around someone's waist. Once it is circled around the person's waist, it 
snaps back to its circular shape, adjusting to most average sized wastes. The front of the belt has an open circle device that acts as a rest for the fishing rod. There is a metal bar that secures the end of the fishing rod as well so it does not slip out of the circle. I got down low and placed the belt around the man's waist while he continued to hold the rod (not one of the more appealing parts of my job, though the women often found having me onboard very comfortable partly for that reason).

After many sexual innuendoes from the rest of the clients I had the two people closest to him reel up their lines so when the fish surfaced it didn't swim and tangle in their lines. The gentleman was sweating profusely and breathing hard. "Keep it coming, it's almost here," I said encouragingly. Truth be told, he was probably only about halfway up. I ran and got a harpoon ready and Captain J ran inside to grab a rifle. I had witnessed very few fishers use rifles; typically it was in circumstances where the fish was either coming aboard a very small boat where the customers would be in danger if it flopped around on the deck, or the clients were veteran hunters and fishers and loved to see the action, so the captain would present a good show. As the fish rose and showed its size I was shocked, the fish turned out to be 390 pounds, and it had a seriously large amount of surface area. I felt an initial sense of guilt as I held the harpoon steady; I did not want to kill this incredible fish that had lived in the ocean for so many more years than I had been alive. "Now, Meredith," I heard J yell behind me. I used all my force and threw the harpoon right through the fish's stomach. The fish took off with the harpoon arrow straight through him and a buoy line attached to the arrow. He took a lot of line from the guy's rod and went out about 100 feet then tried to go down and took the buoy with him. Within about ten seconds the buoy popped back up and started moving 
back and forth viciously. The man reeled and reeled and eventually the fish slowed down and he was able to get it back beside the boat. J did not hesitate, "Back-up" he yelled menacingly to all the clients. I held my ears and he shot the fish right above the eyes. The fish was dead and soon stopped moving. I jumped on the swim deck in back of the boat and stuck a knife through its gills, then sat there with it bleeding out in the water rather than on the deck I would later have to clean. I was very sad looking at it, but soon got over it as I knew I was just supposed to observe and participate in the process. I gaffed the fish in its belly near the harpoon and John grabbed the harpoon buoy and rope and on the count of three we pulled the fish onto the deck with two loud grunts. I reached under the huge fish and grabbed hold of the spear from the harpoon and pulled it out. I undid the buoy and pulled the rope attached to the spear straight through the fish. Next I took out the hook and weight and pushed the fish with all my force into the fish hold. The fish was so large I could not see any of the fish that had been caught and were now under it. The man that caught the fish sent me pictures later documenting the whole event.

What I came to realize through the interview process is that the sport fishing boat captains (and often the sport fishing customers) hold respect for the large halibut. It is the kind of respect that is displayed through the triumph of guiding a customer to a successful catch and displaying a large fish. The old fish is respected as a worthy opponent for a fisher, not necessarily as an ancient creature that should remain in the ocean. However, many sport fishing boat captains do not like to shoot a fish, even if they may recognize that they probably have to in order to land it in the boat. They like the fish to put up a fight, and for the fisher to win that fight fairly. If they have to shoot the fish to prevent its escape, they are not showing respect for the opponent. Many captains will 
shoot at the fish anyway, however, because they do not want to anger the customer by losing the fish. The Western environmentalist perspective is held by the same clients who are content with killing big fish because they paid money to go fishing. This respect represents an interesting element in the sport fishing boat captain's normative beliefs, because they have to find a balance between their clients' beliefs and desires.

In discussing peasant and bourgeois attitudes towards nature, Frykman and Löfgren say that it is the alienation from the natural world that was a prerequisite for the bourgeois sentimental attachment to it (1987:83). When captains are on the water every day, utilizing marine resources for their livelihoods, they become much less alienated from the natural world than those who do not utilize the resources. Sport fishing captains and commercial fishers hold a pragmatic attitude towards the environment; the ocean is abundant with resources that should be harvested. Their beliefs are different from Western environmentalist beliefs that pristine nature exists and should be left untouched. This dichotomy positions the Western environmentalist beliefs as the fishers' normative beliefs. 


\section{Figure 3: Why a Sport Fisher Shoots a Large Fish}

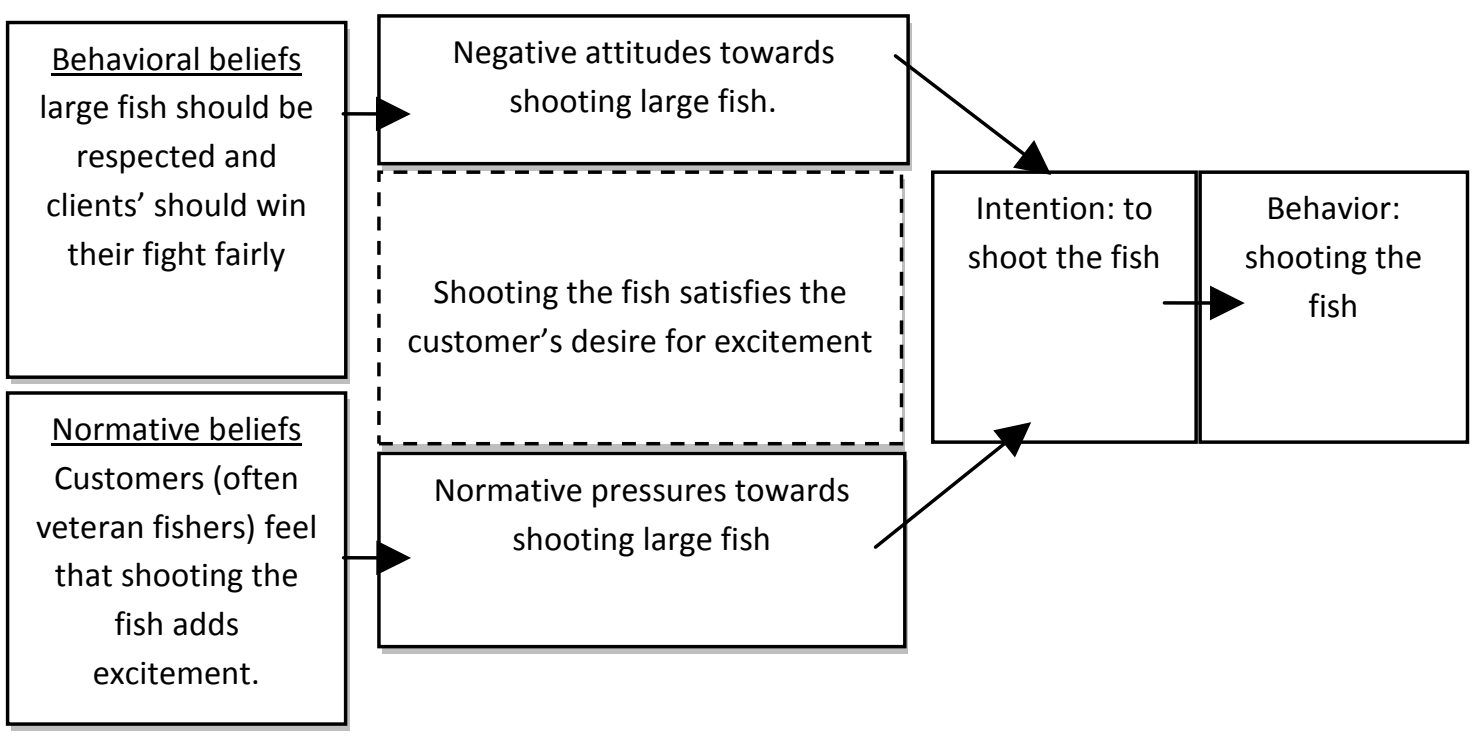

\section{Fish and Game Senior Scientist Favors Brown Bears}

[(note: the following ethnographic entry was written prior to my employment as a deckhand on Captain Ron's boat]

“Oh you have no idea Meredith” said the Fish and Game Senior Scientist after I asked him about Captain Ron. I had met Ron a few days earlier at the pub I was bartending at purposely to meet fishers and speak with them. "Captain Ron is a piece of work, I tell you, that man will shoot a beautiful old brown (bear) just for the trophy." The scientist was obviously getting heated at the thought of this man. I proceeded with caution in my inquiry. "But hunting large, old brown bears is his profession and he is licensed for it, is he not?" I asked. "Well, yes, he is a licensed guide, but we are working on that," the scientist said. "Working on it? You mean you are trying to get him unlicensed, or you are trying to do away with bear hunting all together.” I asked. "Both, 
ideally," he exclaimed. "Currently, we are just waiting for him [Ron] to screw up so we can take his hunting license away."

The senior scientist went on during the next year to succeed in temporarily suspending Ron's license on a small paperwork technicality (a misprint in the name of his co-guide). The small misprint required that Ron pay a fine over 40,000 USD and refund his clients money for the year.

The senior scientist is what Ron calls a "greenie", a term often referring to people who moved to his small town from somewhere else (generally another state in the U.S.) and hold Western environmentalist views. This scientist fits with Ron’s greenie theory; he moved to Alaska for the Fish and Wildlife job fifteen years ago from another U.S. state, is college educated and is often closing the fisheries for the slightest difference between predicted and actual harvest (numbers explained how many fish were expected by a given point in the season and those actually counted to be present at that point). The senior scientist, on several occasions, during my employment with Fish and Game was quick to admit his hatred for Ron, primarily because Ron is an excellent hunter and hunts for mature bear. Ron does not hunt for what he calls "teddy bears” or females; he only goes for the older males that put up the best challenge. Ron is native Tlingit that has hunted bear since childhood and makes a living out of sport hunting during the spring and fall and commercial fishing for halibut during the summer. The senior scientist feels Ron is a bad guy, more so then the other commercial fishers, because his guiding industry targets the coveted brown bear.

The scientist is fairly neutral with most commercial fishers, not lenient, but neutral in terms of everyone getting the same treatment. Two fishers, however, receive 
much harsher treatment, one is Ron and the other is another part time hunter. This scientist loves brown bears as he often talked to me about during my employment. His job involves the management of natural resources, as well as the management of the people who base their living on those resources. He favors a particular resource over others as well as over people, and this bias shows in his job.

Figure 4: Why a Government Official Suspends a Bear Hunter's License

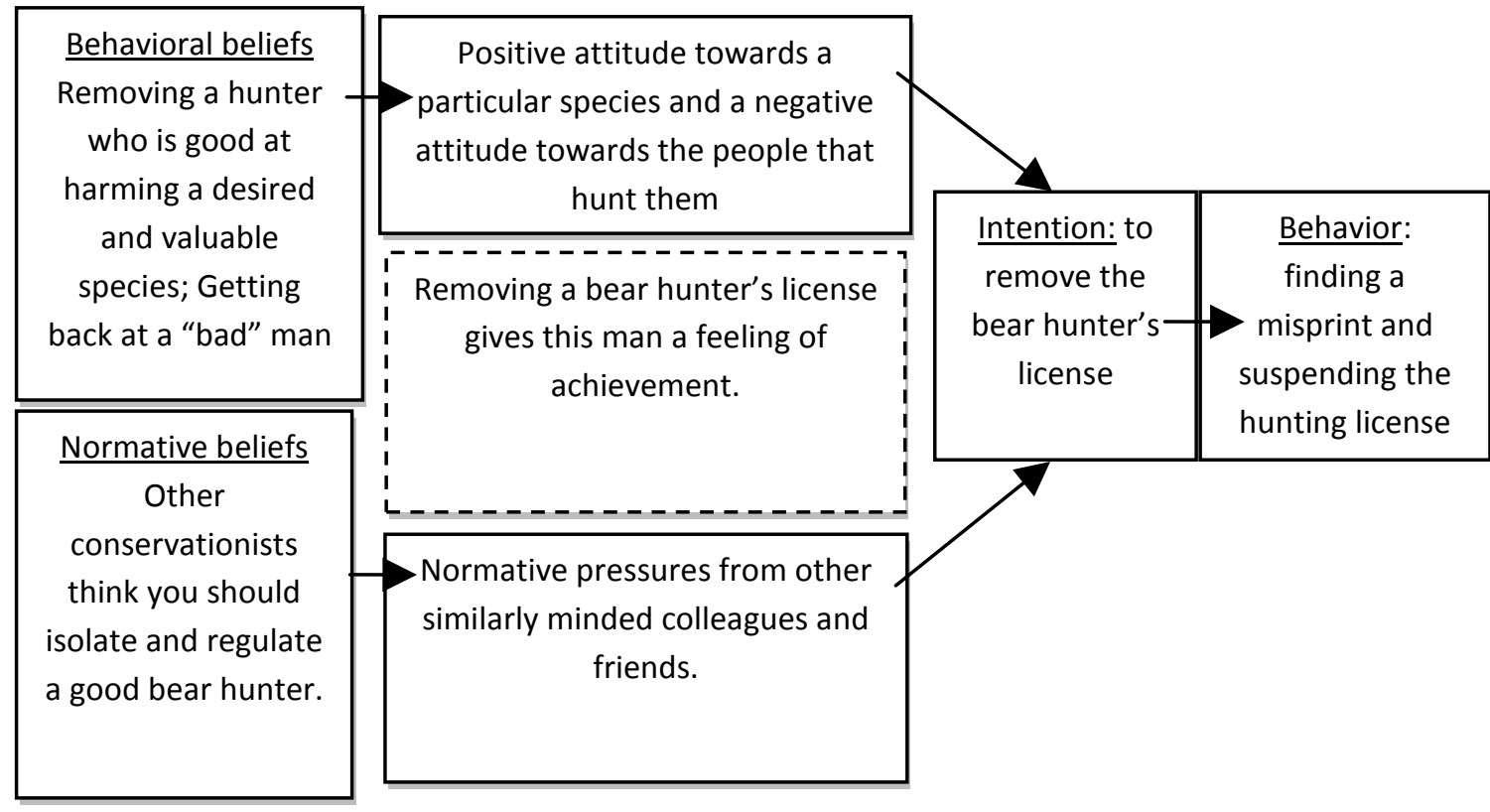

\section{Sport Fishers, Weather and Environmental Responsibility}

My time in Seward was spent on the water an average of five or six days a week. This average was dependant on the weather, specifically the wind. Most boats, commercial, sport or private, will go out in any temperature or precipitation during the open fishing season on halibut from May to September, they will not however go out if the wind is blowing from the South or the West over twenty five miles per hour. As the winds increase several fishing factors are affected negatively; halibut cannot see the bait 
and are therefore less likely to be caught, high winds bring high seas which are not only dangerous to be out on a boat in, but on sport fishing boats they have a high potential of making customers sick, and high winds bring harsh currents which will carry customer's lines far from the boat and often times create many tangled lines. (When lines tangle you have to cut them, and losing gear means losing money).

To provide the reader with an example of how strong winds can negatively impact a day of fishing I include below a journal entry of my own experience deckhanding on a sport fishing boat one day when the winds were bad.

I arrived at the charter company's office at 530 am as usual, expecting to be allowed back to bed after listening to the National Oceanic and Atmospheric Association's weather prediction for Prince William Sound and Resurrection Bay. The winds were expected to gust up to $45 \mathrm{mph}$. It was unheard of to go out in winds this strong, but the owner of the company Carl said that he would send out the fifty foot delta and the boat would be able to get out the opening of the bay, as the winds were only 20 mph at the time. And once they got out there the people could put down, get their two halibut and come in before the winds really picked up. Also, with the wind gusting from the south, they would be working with the boat on the ride back in early afternoon. Since he was sending only one boat out, he put another deckhand on the boat with me.

Carl was right, we had no issue clearing the bay. There had been days when I came out with my captain to "take a look" past the bay's opening into the Pacific Ocean and the waves broke over the deck of the boat and it was time to turn back. This day we got past easy and got out to our fishing grounds (a chicken hole albeit). The plan amongst me, the other deckhand and the captain was to get the customers their chickens 
and get them home. This was often the plan in four circumstances; either the weather looked like it would turn bad, the customers were out of shape (crew would be reeling in all their fish), annoying or didn't know the concept of a chicken, the captain was sick, tired or had a date he wanted to get back in for, or finally I (the deckhand) had managed to break her finger pulling in the anchor by hand so for a couple days her captain went easy on her and didn't move spots too often (less anchor pulling). Today, it was due to increasingly bad weather. When we reached our fishing hole the other deckhand and I immediately had the customers let their hooks down. Within the course of ten minutes every single person on the boat was yelling "fish on". Myself and the other deckhand exchanged glances of "oh no" and ran to the stern of the boat. The current was so strong that it had carried all sixteen lines directly under the boat and out the back, and therefore entangling all sixteen lines. Everyone thought the tugging they felt on the end of their pole was a fish, when in fact it was them catching each other. We both yelled first "stop reeling" and then "move to the back of the boat while reeling slowly". I leaned over the bow of the boat and pulled all sixteen lines (mind you each with a three pound led weight, bait and at least 150 feet of line hanging off each of them) up and into the boat. The other deckhand began to pulling the line behind me and he went hands over hands bringing the lines in until we had all of the hooks and weights on the deck of the boat. Some lines were able to be untangled, but the majority had to be cut (captains hate this as they often have to supply gear for the boat). The other deckhand got started on redoing lines and leaders. I went to the captain's quarters and found a bucket of five pound lead weights. I then carried the 'heavy bucket up out to the deck as I was thrashed around the boat. The weather was getting worse. 
I proceeded to take one line and put a five pound weight on the end and let it out to the 230 foot depth. I immediately knew this was not enough weight as when I knew the weight should be bouncing on the bottom, it kept taking line. Soon I could see the line going out towards the stern of the boat. When fishing for halibut you want your line to go straight down to the ocean floor where it will bounce and then you can reel up a couple inches. You want to catch the halibut which are lying on the floor of the ocean. If the line goes out in any direction chances are it is not going to hit the bottom and hang somewhere far above where the halibut would smell or see it. Seeing the line go way out behind the boat was not a good thing and I knew I needed more weight. I reeled the weight back up the surface, using the momentum of the boat's swing to help me reel it in. I attached a three pound weight on with the five pound weight hoping to see positive results. This time I did, with eight pounds on the end the weight managed to hit the bottom, though when pulled off the bottom it still got pulled a bit by the current which even if it is a couple feet will make it very difficult to have sixteen passengers all drop down their lines without some tangling. I immediately picked out six customers which I then dispersed around the boat and put eight pounds of weight on the ends of their lines. We had lost two customers now to sea sickness at the stern, so there were only 14 that needed to catch fish. The customers were told to let down in the stern first and consecutively towards the bow of the boat as the lines were all trailing out behind the stern. As the temperature dropped, the rain picked up and the wind increased we rushed to get the customers their two halibut in the box. By $12 \mathrm{pm}$ we had each of the customers keeping two halibut and we were ready to get out of there and hoped to make it in. The other deckhand and I got started filleting as the boat tossed and turned its way back 
across the rough seas. Our knives were flying as we were filleting as fast but as carefully as we could, eventually the captain sent a customer back to tell us to stop filleting as it was way too rough for us to keep going.

The above description demonstrates two important things; one is the importance of weather in the commercial, sport and private fishing industries and the other is the ability to bypass one's behavioral beliefs and values in circumstances where large sums of money are involved. During their interviews, and when asked casually, the captain of the vessel and the owner of the company say they respect the resource and refuse to fish over the breeding grounds near the inside of the bay. Yet, they demonstrate that they would rather collect the customer's money and have them fish in the breeding grounds in bad weather than give the customers their money back and not go fishing because they feel strongly about not fishing the breeding grounds close to the bay.

\section{Conclusions: Behavior Justification}

Above are examples of behaviors that could be deemed as destructive to the marine environment, though the people performing them say they value and respect the marine environment. This contradiction arises because the people do not believe their behaviors are destructive, or they can justify them as not being destructive. Furthermore, the examples show how often fishers' normative beliefs contradict their behavioral beliefs. For example, the normative belief of the government officials and scientists is that dogfish sharks should be protected. The sport fishers believe they are not hurting the environment by killing the dogfish because they see no need for them in the ecosystem. Furthermore, they see the act of killing dogfish as beneficial to the halibut population and 
therefore better for the marine ecosystem because they place a high value on the halibut. The Fish and Game Scientists believe they are doing a good thing by suspending the license of a bear hunter, yet they have no problem with sport fishers. As this shows bias which is not allowed in a government position, to the public and all people outside the agency this action is disguised as a solution for a legitimate concern. The value a Fish and Game employee places on a species is directly related to how much a hunter or fisher of this species has to suffer for their actions.

The next chapter looks at how the ideologies of individuals in each of the marine resource user groups vary and what the variation tells us about the weight of their personal and normative beliefs. I will then examine how these ideologies and behaviors could make important contributions to marine resource management and environmental education. 


\section{CHAPTER V}

\section{EMIC PERSPECTIVES TOWARDS SEWARD, ALASKA'S MARINE ENVIRONMENT}

\section{My Experiences with the Dogfish Sharks}

It was late in the day and the captain was anxious about getting her customers their two halibut and getting in. I was exhausted from pulling the anchor in three times already, because we kept fishing areas that were lacking in halibut. We finally decided to go to a chicken hole at about four in the afternoon. I already knew the danger in doing this from previous experience. Fishing in chicken holes late in the afternoon is dangerous because sharks tend to feed in lower temperatures, and at four in the afternoon they are beginning to feed on the baby halibut. I dropped anchor and ran back to get everyone baited up. The ten customers let down, and as was my fear within five minutes every person on the boat had yelled "fish on" and began reeling in their lines. My captain sighed, gave me a look of frustration and lit up a cigarette. I didn't grab a gaff, I just went to the person who had yelled "fish on" first and sat on the railing next to him waiting for the fish to appear. He made a comment of how I should be careful or I would fall overboard, to which I let out a slight laugh, turned around and put my arms toward the water in a diving position, lifting my legs straight above the railing. With no hands on the railing and only balancing with my hips I grabbed his weight and line as the first dogfish broke the water's surface and flipped myself back inside the railing of the boat. The man looked at me perplexed and let out a little laugh. "I've been working on boats for a while.... and I have yet to fall overboard," I said. I found it to be a very 
common reaction for men to warn me, or tell me that I should or shouldn't do something on the boat. As opposed to women, who tended to either show some form of excitement or sign of being impressed, or they would ask "have you ever fallen overboard"?

Releasing a spiny dogfish shark from a rod and reel is not an easy task. First, you direct the customer to hold the pole and "let out some slack" so you can work on removing the hook from the fish and "step back" as the fish has "poisonous spines." Next, you must secure the lead weight to the deck of the boat in some way, with your foot, your knee, whatever is available. Then you must secure the fish. The fish's spines are not poisonous, they are however covered in marine bacteria which are very dangerous to marine, and even more so to terrestrial creatures. Securing the fish safely requires one hand placed open just above the dorsal fin. The shark's skin is made of little teeth (or denticles), so in grabbing them you often get "shark burn", which is the equivalent of rubbing your hands on harsh sandpaper. Next, you need to try and get the large halibut hook out of the shark. With most fish this means pushing down on the hook, twirling it clockwise and pulling it out, relatively easy with enough practice. The dogfish however swallows the bait whole and so the hook winds up in its stomach, or intestines. This requires a lot more finesse to remove, as the stomach is beyond multiple rows of teeth. Pliers sometimes help, but in the process part of the digestive system is often removed. Sharks are resilient creatures and can heal rather quickly, so this is not necessarily a life threatening injury. Once the hook is removed the fish must be held far away from the body as there are spines on both the front and back dorsal fins and when the fish is moving it is easy to get hit with a spine. Then the fish is tossed overboard and you move on to what is often another dogfish (they travel in schools) on someone else's line. 
Today, I had ten dogfish breaking the water's surface at once. I did not re-bait people's hooks right away as I knew we would be moving again with this many sharks on lines. I went through the customers one by one, trying not to spend more than four minutes on each person's line. On the sixth or seventh shark, I was holding the dogfish with one hand and positioning myself to place the pliers down the dogfish's esophagus with my other hand. A customer thought he would help and went to put his hand on the tail. I immediately went straight for his hand to block it from the spine. Then I felt it, the back dorsal fin spine. I thought initially that I had somehow managed to slip and put the knife on my belt straight threw my own hand. This was not possible, yet it was the only way I could describe the sensation at the moment. I looked down and there was a small break in the skin just above where my thumb met the back of my hand. I flipped my hand over again and again, expecting to see some sort of sharp metal object going through from one side to the other, but there was nothing but the small tear. The fish squirming in my other hand finally distracted me from my search and I realized I had hit a spine. I immediately cut the line with the hook still in the dogfish (again, these fish are very resilient) and threw it over board with a great deal of force.

One thing I found working on charter boats is the lack of proper medical supplies; captains don't want to spend the money to constantly fill first aid kits. I ran around the boat looking for something I already knew we didn't have, alcohol. The first aid kit was a plethora of band aids, ace bandages and Neosporin. No alcohol swabs, aspirin or EpiPens (epinephrine injections) were left in the kit. My thought process led me to the cleaning materials where I knew we had an unlimited supply of bleach. I proceeded to run out on the back deck, kneel down and pour bleach in the wound. I used 
my fingernail to open the wound more and more and continually pour bleach in it. At this point I was grunting loudly in pain as I started to feel a tingling sensation all over my body and a weakness come over me. I lay down on the deck, still pouring the bleach over my hand. The customers all stood in their spots by the railings holding their rods over the sides just staring at me. The captain had gone and grabbed four Advil from her bag and my water bottle and gave it to me; she already knew what had happened from experience. It took about twenty minutes for the bleach and Advil to kick in and I was able to stand up. Still feeling incredibly weak I made my way to the next customer and as I pulled the shark over the railing I said very angrily, "everybody needs to stay away from the damn shark while I am removing the hook, ok?”

On this day I realized two things. First, was the real reason why sport fishing boat crews hate dogfish sharks. Second, was the reason why sport fishing boat crews can be very mean and often condescending to the point of rudeness towards customers when dealing with issues of their own safety.

In this chapter I examine the beliefs which lead people to act in different ways. I place their beliefs within the context of their greater social history. Only the distal factors which have had the greatest impact on the current beliefs of study are examined.

\section{Valuation of the Marine Environment as a Whole}

All of the groups of study hold unique likes and dislikes for particular marine species, thereby differentiating themselves from the other groups. However, I did find the groups to be quite similar in their strong appreciation for the marine environment as a whole. It is not surprising that people who choose to live and work so close to the marine 
environment hold strong values towards it. The following questions were asked in an attempt to gauge how an individual values his or her marine environment and what experiences may have lead to these values. 1. Why did you choose to live in Seward, Alaska? 2. How would you be affected personally if there was an oil spill in Kenai Fjord's National Park? 3. How would you describe the marine environment near Seward? People from all the groups described the coastal scene as "brilliant," "beautiful,” "gorgeous,” “incredible,” and “amazing.” When asked about the effects of an oil spill, they all agreed the effects would be "catastrophic" to the environment. They would be "heartbroken” and "devastated”. Some representative examples follow:

\section{Table 1: Valuation of the Marine Environment as a Whole}

\section{Commercial Fishers}

\section{Questions}

\section{Responses}

Why did you choose to live in Seward, "I grew up here. I have fished in the AK? summers and hunted during the winter months. Why would I leave?”

-64 year old male

How would you be affected personally by an oil spill?

"The first oil spill [Valdez] was terrible; one right out here in the Bay would just be devastating to see.”

- 57 year old male

What do you like the most about the "[pauses] Well....the scenery, being out on marine environment? a clear day and being able to see every white mountain peak and the clear blue water while you are waiting for the day's catch"

-49 year old male 


\section{Sport Fishing Tour Boat Operators}

Questions

Why did you choose to live in Seward, AK?

How would you be affected personally by an oil spill?

What do you like the most about the marine environment?

\section{Responses}

"I came to Seward for the sport fishing. I loved sport fishing in Florida and always wanted to move to Alaska and start a business, so I did.”

-49 year old male

"The oil spill helped me a great deal economically. It gave me a good paying job for a very long period of time. I got my captain's license because of the hours I spent on the water during the clean-up."

-52 year old male

"I love spending everyday out on the water fishing. I love my job. The ocean is always where I want to be by.”

-43 year old male

\section{Government Officials and Managers}

Questions

Why did you choose to live in Seward, AK?

How would you be affected personally by an oil spill?

What do you like the most about the marine environment?

\section{Responses}

"I came up to Alaska when I was 25, and knew immediately that I was not going to be leaving. The scenery was unbelievable.”

-58 year old male

"I was, and still am, involved in the cleanup after Valdez. It would be awful to see that kind of devastation in Resurrection Bay, with all the wildlife in the area."

-55 year old male “.... (pauses, looking at the ceiling) I just love the ocean. I didn't grow up near one but now I couldn't imagine life without one and all the creatures and splendid scenery." -47 year old male

\section{Seward Residents ( $>5$ years)}

\section{Questions}

\section{Responses}

Why did you choose to live in Seward, AK?
"I came up from the midwest after college with a friend that had spent previous summers in Seward. I took a job as a barista, met a man and stayed that winter. Before I knew it I was a resident of Alaska and have been ever since." -34 year old female 
How would you be affected personally by an oil spill?
"Well, personally it would really break my heart to see the effects on wildlife or even marine life, because there is a lot of interconnection there. It would really hurt to see the horrible effects on everything. Personally, as far as my business goes, because I have $a \mathrm{~b}$ and $\mathrm{b}$ and a stained glass business, because things would not be visually pretty, it would be upsetting to people. It would really affect a lot of industry; people come specifically to town they want to see wildlife. They go out on the Kenai Fjord's Tours, they go to exit glacier, they go to the sea life center. I think it would have a huge affect on tours.”

-39 year old female
"The total and dramatic scenery, with the

What do you like the most about the marine environment? huge jagged mountains, and the glaciers and the water."

-46 year old female

It was found that the visual aesthetics are of great importance to people that live and work around the marine environment (Table 1). It is not surprising that for people in Alaska, whether they were born and raised there or not, the scene of grand mountains and water is appreciated. They are all exposed to media messages that present images of Alaska as examples of wilderness.

In her analysis of the Nature Company, Price (1996) talks of a CD entitled “Glacier Bay, Alaska” which shows Alaska as a superlative for natural beauty and unbounded wilderness. The call of the humpback whale promotes human piece of mind, and the arctic landscape and its animals become shadowy realities, subordinate to those meanings (1996:191). Malls, media, advertising campaigns, even today's education systems, bring people all over the United States and other Western nations to associate Alaska with natural beauty and wilderness. It is therefore not hard to see why all the 
participants interviewed agree that they feel fortunate to live in Seward and value the aesthetics of the Alaskan landscape as a whole in very similar ways

\section{Valuation of a Particular Species}

Commonalities in personal valuation were found amongst the individuals interviewed in each group. For the sport fishing boat captains there was often a strong sense of hatred for the spiny dogfish sharks. These negative feelings towards the dogfish were not found amongst the wildlife viewing tour boat captains. Each sport fishing boat captain interviewed portrayed a negative attitude towards the dogfish when they went out on the boats as well as during the interviews. However, over half of the interviewees also claimed an appreciation for all species in the marine environment. When asked about the contradiction, a common response was to stress that there is no commercial industry that utilizes the dogfish shark, so they have less worth than other marine species. Another response was that the dogfish are important in moderation, but an excess in the fishing grounds is unacceptable. The contradiction of expressing an appreciation for biodiversity, but also a strong negative or positive valuation for a particular species was found amongst sport fishing boat captains as well as wildlife viewing tour boat operators, government officials and managers. Managers, government officials and wildlife viewing tour boat operators differed in that they tended to accompany their valuation of all species with a personal valuation of a very specific species.

The following section presents each social group's most commonly valued species, whether it is one marine species or all marine species. The diagrams following will illustrate how a social group’s beliefs translate into their behaviors. 


\section{Table 2: Sport Fishing Tour Boat Operator's Valuation of Species}

Marine Species

All Species
Lynn Cod
Porpoise
Orca
Shark
Puffin

All Species

Lynn Cod

Porpoise

Orca

Puffin

\section{Responses}

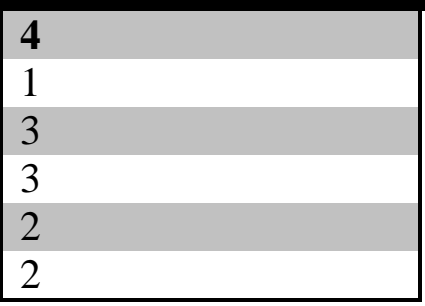

Table 2 illustrates each sport fishing tour boat operator's response to the following question: which, if any, species do you value the most personally? Seven of the fifteen tour boat operators said they value all of the species in the marine environment equally. During five of the interviews the respondents used the term "biodiversity”, four used the term "ecosystem" and six used the term "food chain" to describe the importance of all species.

One twenty-three year old sport fishing captain said that he valued the porpoise over any other species. He said, "a bad day of fishing can be made better by porpoise playing in the waves at the bow of the boat on the way back to port." When asked at the end of the interview how he valued the halibut he said that they are important for his business, so he values them economically and would be sad to see them continue to diminish in numbers. When asked to define the term biodiversity, he said "it's everything, isn't it? Like everything around us”. The company he works for caters to an array of tourists, from cruise ship passengers to local Alaskans. This particular captain was once fined for killing a dogfish during a trip because the customers filed a complaint 
with Fish and Game about his actions. He is the first to tell people that he treats dogfish with great care because he does not want another fine. During my participant observation on his boat I found that his Alaskan clients often times encouraged that he kill the dogfish because they saw and understood the nuisance, but the captain never wanted to risk the fine.

Two sport fishing boat captains said they valued sharks (excluding dogfish sharks) over any other species. Both individuals lead the highest numbers of salmon shark fishing charters out of Seward. This led to approximately six trips a season, out of roughly two-hundred and twenty halibut trips. When asked why they favor sharks over other marine species, the responses were the same; they are intrigued by the creatures and love the thrill of fishing for them. The value is a deep, personal appreciation and curiosity for sharks. Also, both of these men are over the age of twenty five and have a curiosity for sharks which developed around the age of twelve. They claim a great appreciation for sharks which is the reason they recently decreased their number of shark fishing trips.

Significant only to the sport fishing tour boat operator group, is the inclusion of the Lynn Cod in the species most personally valued. The one sport fishing boat captain that places the highest value on the Lynn Cod says it is his favorite to fish for and to eat. He values it the most because it has felt the greatest impact from fishing of any species in the area and has made a relatively good come back. The Lynn Cod is currently the closest managed species with the strictest regulations of any fish in Resurrection Bay or Prince William Sound (ADF\&G 2006:2). This is significant because it shows feelings of respect for a species that has overcome the pressures of fishing. 
The following diagram (Figure 5) illustrates the most common behavioral and normative beliefs specific to sport fishing tour boat operators.

Figure 5: Why a Sport Fishing Tour Boat Captain Intends to Injure a Dogfish

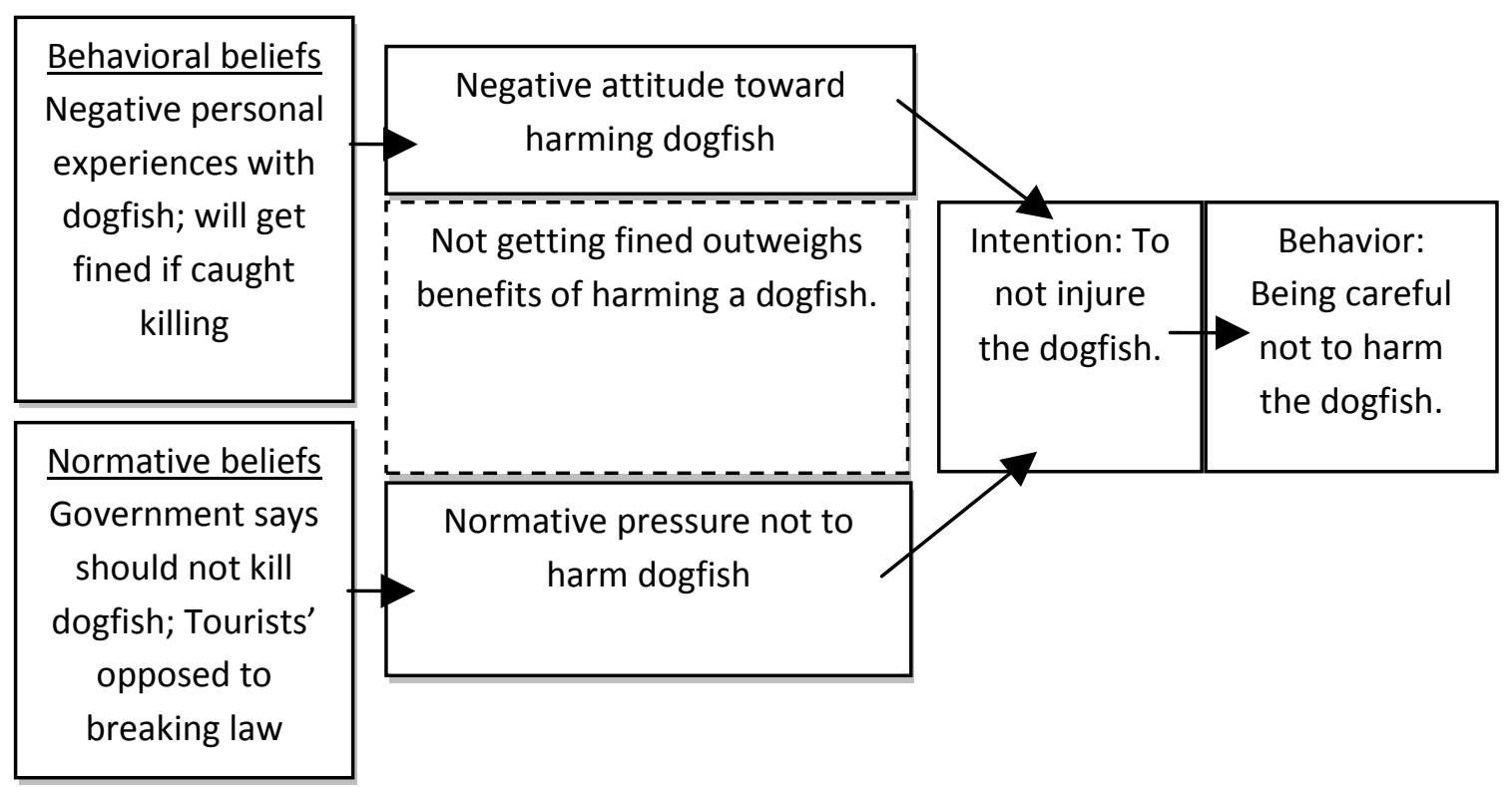

Behavioral Beliefs: A hatred for dogfish sharks from personal experience.

Normative Beliefs: The belief that tourists may report them to state officials if they injure the dogfish intentionally. 


\section{Table 3: Commercial Fishers Valuation of Species}

Marine Species

All Species

Halibut

Porpoise

\section{Responses}

4

10

1

Commercial fisher's responded very differently than the other groups to the question of which species they value the most (Table 3). Ten of the fifteen commercial fishers interviewed said they valued the halibut over any other species. One fisherman who has fished the waters around Seward for over thirty-five years said the following.

Oh I value the halibut by far the most, not just because I obviously need it to make my living, but because when I get a good catch [of halibut] it reminds me of when I was younger and we would get good catches consistently out here. Any time I am out fishing and we find a new hole of hogs [many large halibut] or just get the timing right, I remember why I am out here....the thrill, I can’t really explain it. It's the gamble of trying for a good catch, and without the halibut I would not get that chance.

Many of the other commercial fishermen were in agreement; they have sentimental value for both the halibut and the positive feelings associated with a good catch.

One commercial fisherman often works with a crew of only two deckhands and they are quite younger than he, so in the interview he expressed feelings of loneliness when out at sea. After being on the water for a number of days and he is tired and weather beaten; when the porpoise show up they will always change his feelings for the 
better: “They are like my dogs of the sea, they may not always be obedient, but they are certainly playful and up lifting.” The other four commercial fishermen expressed a deep understanding and value for all the species of the marine environment. These individuals tended to either have a greater education or a wider world experience than some of the others and the one that did not had a better comprehension of the biological concept of biodiversity and the interactions that occur within an ecosystem.

Many of the commercial fishermen defined biodiversity relatively close to the dictionary definition (according to the Merriam-Webster’s dictionary : biological diversity in an environment as indicated by numbers of different species of plants and animals), but when asked if the existence of the dogfish is important for the survival of other species in the marine environment, the common answer was: “no, I don't think if they were gone they would have an impact on the rest of the ocean or other species.” This valuation of species as individuals and not in respect to the whole reveals itself in the way commercial fishers behave when dealing with species they perceive to be a nuisance. The following is a section from my ethnographic field journal.

We had been out on the water for three days and were not doing very well with our catch. They were calling for a big storm on the radio with winds blowing $50 \mathrm{mph}$. We needed to get a decent catch and head in so we were fishing an area close to the coast which is known for its exceptional turkey holes (a step up from the youngest of halibut). Because of the weather there were approximately a dozen other commercial boats around us waiting on their long lines, hoping to make a catch before the wind picked up. We had been waiting about twenty minutes on our set when I heard a gunshot 
in the distance. There was a lot of yelling and then another captain got on the radio yelling about the damn sea lions. There were two large bulls (mature male sea lions) throwing a huge chunk of halibut meat between them. Another gun shot from a captain several hundred feet to the west. The bulls dove and Jesse (the deckhand on the boat I was working on at the time) ran in the birth (boat storage) and came up with a rifle and some bullets. Gun shots were heard from most of the boats in the area over the next hour or so, including our own. Eventually someone either nicked one of the bulls or they just got their fill and tired of the game and left the area. There were words exchanged over the radio about the "stupid sea lions", "fucking nuisances" and who in the fleet had the worst aim.

The preceding account demonstrates both a lack of value for certain species and a lack of a subjective norm from any non-fishers while out on the water. The only subjective norm on the water is to fit in with the rest of the commercial fishers and shoot at sea lions. Otherwise, the subjective norms brought about by government regulators and the public do not seem to be present while the commercial fishers are out on the water, therefore behaving according to their behavioral beliefs.

All of the commercial fishers I interviewed grew up in the commercial fishing industry and shared many similar experiences with the marine environment. They all mentioned that at one time or another they might have considered a land based job, but could never imagine not fishing. Many of them grew up in the business; their fathers or uncles were commercial fishers and passed their knowledge on to the next generation. For many of them it was a family assumption that they would take over the boats and the 
Individual Transfer Quota’s (pounds of fish they can catch per year, bought through brokers and the state government) when they got old enough. Two individuals had grown up in other small towns in Alaska where they saw the water every day and when they turned fourteen or fifteen years of age they got jobs deckhanding and went on to buy their own boat and eventually their own Independent Transfer Quote's.

All of the commercial fishers agreed that they never wanted to be anywhere but out on the water fishing. Most all past experiences on the water were not only enjoyable but exciting. And the times that fishing was economically or mentally challenging were easily overshadowed by the times that fishing was great. Positive past experiences led to the strong values placed on the fish that brought these feelings the most, the halibut. In select cases, it was a different creature that brought such good feelings, such as the example given above of the dolphin.

\section{Figure 6: Why a Commercial Fisher Intends to Shoot at a Sea Lion}

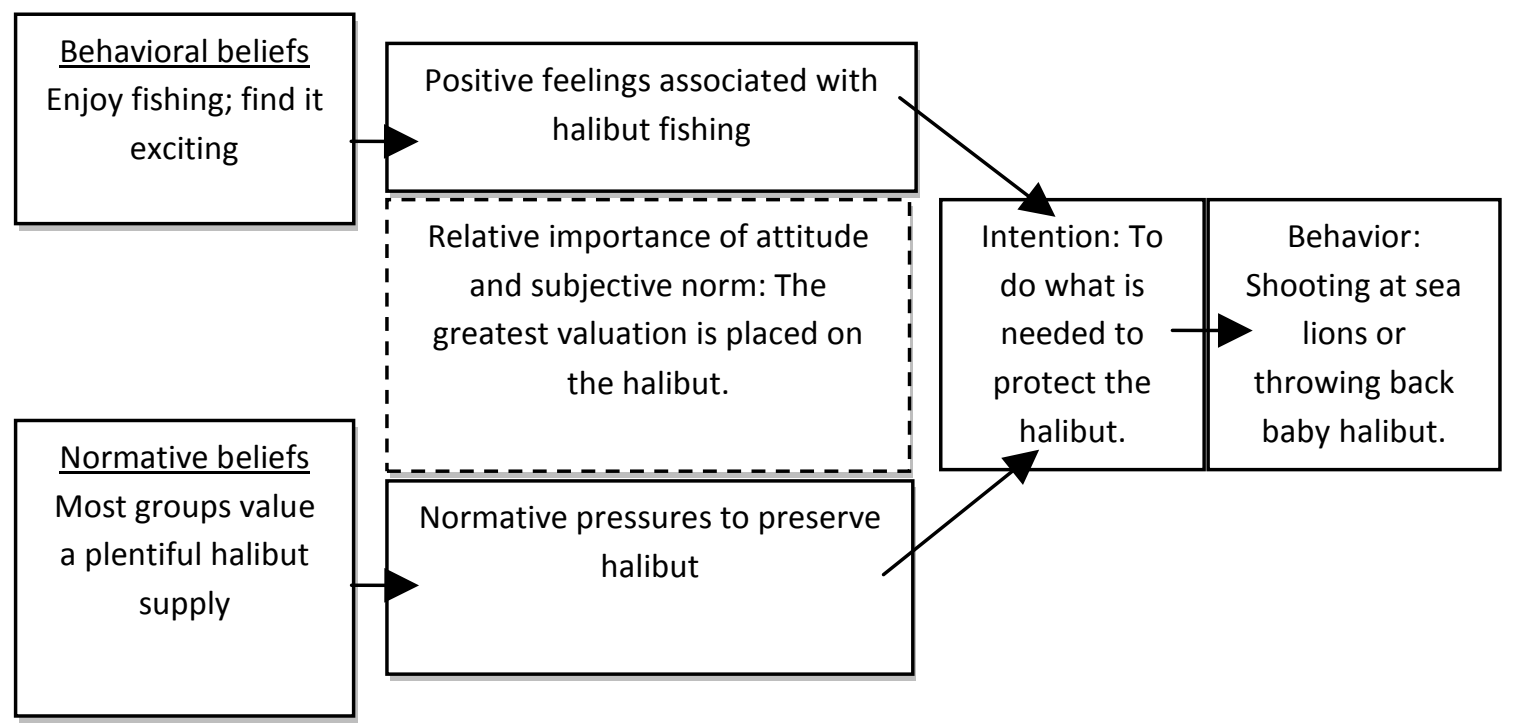


Behavioral Beliefs: Based on previous experiences the commercial fishers have developed a respect for halibut and dolphins and a lack of respect for sea lions, sharks, puffins and seals (Figure 6). Their experiences pulling puffins and sharks off long lines or pulling in an empty long line because a sea lion or seal took their catch have led them to associate negative feelings with these creatures. They also see the ocean functioning (providing sufficient fish) everyday no matter which creatures are being depleted or increasing in numbers. They see no reason to believe the ocean will be impacted by one creature going extinct.

Normative Beliefs: They do not need to perform for others on a daily basis as a part of their work. They are alone out on the water, aside from other commercial fishing boats, and therefore they only feel motivation to act as other commercial fishers, thus following their behavioral beliefs.

\section{Table 4: Government Officials and Managers Valuation of Species}

\section{Marine Species}

All Species

Shark

Puffins

\section{Responses}

$\mid$\begin{tabular}{l|}
10 \\
1 \\
1
\end{tabular}

Government officials and managers tended to place an initial value on all species in the marine environment. Their use of terms such as "biodiversity" and "ecosystem" led me to believe they may be speaking according to Western environmentalist paradigms. Probing deeper or allowing for long silences I found the interviewees did 
hold an affinity for particular species, and it was often linked to a previous indirect or direct experience with the species. The following is part of an interview with an ADF\&G employee that shows how after a long interrupted silence he began to reveal an "interest" for a particular animal after talking about the importance of biodiversity.

Um (hesitates) I don't tend to think of individual species as having more value or less value than other species. I would place value on maintaining diversity, although, now that may seem like a contradiction, because I was talking about the utility of halibut as a food species. But I would never want to see a population of any species [go extinct], even a heavily utilized food species. I would never want to see one of those populations get to the point where it has been driven out of the food chain so far that it is replaced by something else and then the balance is messed up...you know? I would like to continue to see a diversity of species, I hate to lose species, [and] I hate to see dramatic shifts in compositions that are not due to natural cause[s]. For example, I feel that a lot of the depression of shellfish stocks and forage fishes is probably due in large part to natural causes, natural changes in the environment. I think those things are cyclical, I think they will come back, and I am not as concerned about those as I am if over fishing would happen. But I don't typically think about individual species [as having more or less value]. There are some - I don't put a higher value on them - but I do find them very interesting, and those are sharks. I just think they are interesting, but I wouldn't necessarily place a higher value on them.

He goes on to explain that he has been "interested" in sharks ever since a family member got him a book on sharks when he was a child. I believe his initial value on biodiversity and his later "interest" in a particular species stems from an environmental science education in a state other than Alaska. Western environmentalism says that maintaining 
biodiversity is important for ecosystem functioning and sustainability. However, enticing the masses to protect biodiversity environmental organizations often concentrate on specific species [species of capital] that are "interesting." During interviews, all government officials and managers identified themselves as environmentalists and claimed that they followed the principles of Western environmentalism.

In a discussion of environmentalists involvement in Oregon's campaigns for ancient forests, James D. Proctor (1996) suggests that "what is critically lacking in the Pacific Northwest is moral leadership on contested matters of human relations with nature” (296). Proctor says that even if people get tired of shouting over ancient forests, they are sure to find something else to fight over. I find this to be true in Alaska when dealing with issues of marine resource management. People in positions of power in natural resource management often hold Western environmentalist perspectives. This leads to a lack of consideration for human involvement when making decisions about natural resources. Fisher's livelihoods, families and opinions are not always taken into account in management decisions. Proctor adds that the "fundamental task for environmentalists, then, is not just to save nature” (1996:296). Environmentalists need to find and promote answers to the moral questions that loom large in contemporary debates over nature.

The following diagram (Figure 7) illustrates an ADF\&G employee's behavioral beliefs interfering with the fair treatment of a resource user. The employee holds a strong value for brown bears and his behavioral belief is that the brown bear should be protected. 


\section{Figure 7: Why a Government Official Intends to Suspend a Bear Hunter's License}

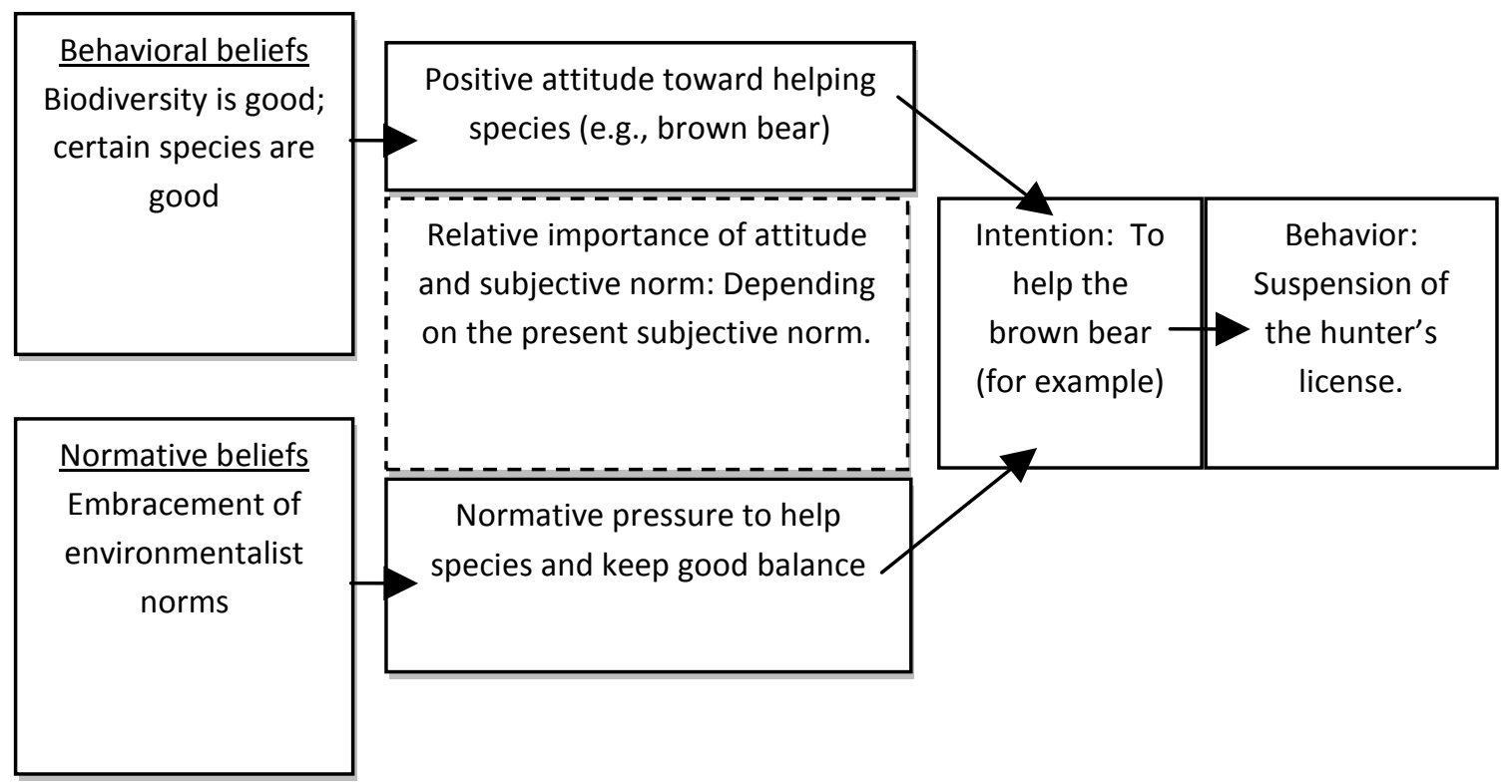

Behavioral Beliefs: Government officials and managers tended to respond first in favor of biodiversity. When asked again for a "personal” value, many changed to a valuation towards one particular species.

Normative Beliefs: All of the government officials and managers I interviewed refer to themselves as environmentalists. They claim an intense association with environmentalist beliefs and a deep value for the preservation of all natural resources. Educational institutions and popular media in the United States place a great value on the environment and natural resources. 


\section{Table 5: Seward Resident's (of greater than 5 years) Valuation of Species}

\begin{tabular}{l|l|} 
Marine Species & Responses \\
\hline All Species & 3 \\
Puffins & 2 \\
Orcas & 7 \\
Porpoises & 3 \\
\cline { 2 - 2 }
\end{tabular}

The following was one woman's response to whether she values one marine species over another.

I don't know, I don't think I personally have a favorite. I am a birder, I love to see the birds around, I really like to see the sea lions, the birds and the seals. The mammals are a little more interesting to me than the fish, I go out fishing sometimes, but it is not on top of my recreational activities. I caught a king salmon once, and that was fun, but I wouldn't do that every day.

The group of Seward residents held the most diverse opinions concerning the marine environment and had the most varied demographic backgrounds. As indicated earlier some grew up in Alaska, while others grew up in other states and moved to Seward after the age of eighteen.

The differing backgrounds not surprisingly led to the largest variety in perceptions and values within any of the groups. Seward residents who happened to have family members or friends that were commercial fishers, sport fishing captains, wildlife viewing tour boat operators or government officials tended to hold similar opinions to the marine resource user group with which they associated. However, these views were never consistently similar with their associated group, most likely because the beliefs of 
resource users are made so strong because of their daily interactions with the marine environment. In addition, the residents did not hold any values or opinions concerning the marine environment and/or conservation of marine resources that were consistent with each other. As expected, Seward residents include a large array of backgrounds and I did not find a single ideological trend.

Behavioral Beliefs: The experiences of locals were very diverse as they are from different places and hold different jobs.

Normative Beliefs: Each local has a different background and holds a job separate from the other groups of study.

The following chapter applies the Theory of Reasoned Action to analyze the behaviors and ideologies of the marine resource user groups. 


\section{CHAPTER VI}

\section{ANALYSIS OF VALUATION RESULTS}

\section{Subjective Norm (Public Pressure) vs. Personal Opinion (Self Interest)}

Sport fishing captains, wildlife viewing captains, managers and government officials all deal with the general public on a daily basis and tend to be diplomatic when addressing issues concerning the marine environment. A close association with the public and Western environmentalist influence likely provokes contradictory responses. One sport fishing boat captain said in an interview: "I do not value one species over another; I think they are all very important”. But when asked about the importance of the dogfish he said: “As far as I know the dogfish do not serve any important function and I definitely think they [Fish and Game officials] need to do a better job regulating them.” When dealing with the public, I found that sport fishing tour boat operators tend to present less controversial opinions (a valuation of biodiversity), but in actuality they hold personal opinions that are often very controversial (hatred of dogfish or any other species they consider to be a nuisance). Similarly, I found wildlife viewing captains, managers and government officials to provide less controversial responses (i.e. an appreciation of biodiversity) when initially asked about their valuation of the marine environment, but later they would admit to holding romanticized opinions towards a single species (i.e. a love for orcas because of a movie seen during childhood).

While sport fishing boat captains, wildlife viewing boat captains and government employees are always performing for an audience, it was the sport fishing captains that were actually acting in ways they believe their clients want them to act, so as to avoid a 
citation, a complaint, or lose their job or business altogether. Sport fishing tour boat operators were born and raised in Alaska and started fishing at a young age. They hold a pragmatic view towards the marine environment, but this view differs from their clients and managers who hold a Western environmentalist view. Sport fishing tour boat operators were the group that most often had to act on normative beliefs that went against their behavioral beliefs. Commercial fishers grew up in Alaska and began deckhanding at a very young age, and they act on the normative beliefs of their fellow commercial fishers. Their normative beliefs are the least influenced by Western environmentalist views. Seventy percent of them finished high school, but they talked of having shortened school years to accommodate for the fishing season. They grew up in the commercial fishing community which had been around for decades and in the process they had already established behavioral beliefs. Their behavioral beliefs are shared by all commercial fishers and this makes them less susceptible to normative pressures. Furthermore, any normative beliefs that may exist have little impact on their attitude and behaviors because commercial fishers are alone at sea with other like-minded fishers the majority of the time.

\section{What influences someone's beliefs?}

A common feature among all government officials, managers and wildlife viewing tour boat operators is that none of them are originally from Alaska, but they all now live in Alaska's extraordinary environment. Their education, religion, culture and past experiences (distal factors) are all unique, but their current occupations, social groups and location are what make them similar to others in their group. Their current 
social group makes up their dominant subjective norm, as they all share the same Western environmentalist ideas and they feel no normative pressure from other resource user groups. Their behavioral beliefs are similar if not the same as their normative environmentalist beliefs. Commonalities were found in their previous experiences and education. Scholars have used theories involving Western perceptions of nature and species of capital to explain how these similar behavioral beliefs developed.

\section{Western Perceptions of Nature}

All government officials and managers held a university-level degree (whether associates or bachelors) in some form of ecological science or resource management. All wildlife viewing tour boat operators held either a college degree or had taken college

level courses. They all grew up in a state other than Alaska and they identify with Western environmentalist beliefs. Their education and previous experiences are the distal factors which have created similar behavioral beliefs concerning the marine environment and the importance of maintaining it as a "natural" place.

\section{Species of Capital}

I found particular values to be instilled in government employees during training and throughout the course of their jobs. For instance, when one Alaska Department of Fish and Game employee was asked his opinion on commercial fishers shooting sea lions he responded as follows. 
I am not very partial to sea lions, and I can see how they are a nuisance to commercial fishermen in large numbers, but in working for Fish and Game it is best not to reveal a particular dislike for a species as this can rile up the environmental groups searching for ways to target Fish and Game for allowing certain subsistence fishing and hunting practices. I do love Orcas though, and if I were to advocate for Orca protection, I really don't think the agency [ADF\&G] would have a problem with it.

In my own experiences working for the Alaska Department of Fish and Game, I found the importance of both political and social neutrality to be stressed when discussing controversial matters. While holding a seasonal fisheries biologist position in Southeast Alaska I became heavily involved in the continuation of a federally funded salmon hatchery project. During the course of my work as a fisheries biologist I dealt with town politics while advocating for a better hatchery establishment. I was told from the start that being an employee of Fish and Game I was required to remain neutral as a scientist, although when I was not directly involved in scientific activity, I could present my personal opinion. In newspaper articles I had to consistently be referred to as an employee of Fish and Game whose opinion was in no way representative of the Alaska Department of Fish and Game.

The employee quoted above was encouraged not to reveal any opinions towards particular species, unless the opinion was in line with the Alaska Department of Fish and Game's agenda. He felt that if he became an advocate for stronger protection of Orca whales that there would be no argument because of the political and social clout these whales carry in the Western environmentalist paradigm. Advocating for different regulations on sea lion protection however would produce negative results. Sea lions are 
marine mammals and are therefore held in almost as high a regard as Orcas in Western environmentalist views.

\section{Power Differentials’ Impact on Beliefs and Behaviors}

One woman who fell in the residents’ group expressed interesting ideas about what part fishers should play in decisions involving resource management. She is a six year resident of Seward and is employed by the Forest Service as a wildlife biologist (of terrestrial species). Her opinions are interesting because of the consistency between her personal and professional beliefs. Some government officials involved in managing the halibut fishery mentioned that their personal and professional opinions occasionally differed when it came to issues concerning commercial fishers and sport fishing boat captains. I believe that some government officials over time sympathized with resource users on a personal level, as was evident in the example above of the ADF\&G employee who understood fishers’ plight with sea lions. However, dealing with people can also lead government officials and managers to become even less empathetic rather than more, such as the instance of an ADF\&G employee suspending a bear hunter’s license out of spite. The terrestrial wildlife biologist quoted below does not deal with the human implications of managing a targeted species, and therefore has not developed a compassion or hatred for resource users. She does however hold a firm belief that people placed in positions in the government are the only ones who should govern over the resources. 
Fish and Game is responsible for populations, they are able to stand back and look at the big picture, what we have and where we have it. Their scientists are always going to have a better indication of what is going on than somebody who is just looking because that happens to be their little fishing hole. Scientists are always going to have a better understanding than any local fishermen. It is up to them to create regulations for fishing, whatever regulations they come up with. It's the law and those folks should be following it and they should not be taking it into their own hands. 'Fish and Game does not know what they are talking about so I am just going to kill them'. People who do things for a living tend to get very strong opinions about what the situation is and what the right thing to do is. I am sure those dogfish sharks have their own function in the ecosystem just like everything else, and we need to learn how to share. It seems to me that whoever's job it is to regulate the halibut, needs to take a good look at the situation and needs to decide who gets what percentage of the stock. I find it kind of odd that there is no regulation on how many charter boats there are. I think sport fishing has a greater (economically beneficial) impact on Seward than commercial fishing does.

According to R. S. Pomeroy and Rebecca Rivera-Guieb (2006), scientific and local knowledge can complement each other, and combining them can greatly enhance management planning. Saying that scientists are going to have a better understanding than fishers is denying fishers the knowledge that comes with experience. Fishers hold more direct experience with their targeted species than a scientist could ever have unless he or she spent every day on the water locating, handling, cutting open and observing their migratory, feeding and breeding patterns. Bourdieu (1998) says that a position of authority, an education from a formal institutional, and government employment are all significant factors in the formation of power in a society. The biologist's assumptions 
also point to a distinct appreciation for those in positions of power; power assigned from academic institutions and government agencies.

The wildlife biologist quoted above demonstrates a lack of appreciation for people whose education comes from personal and professional experience and not from a formal institution. She says that people who "do things for a living” (i.e. commercial fish, log, etc.) tend to develop very strong opinions about how to manage the resources they target, but that these opinions are not empirically validated and therefore not relevant. She suggests that scientists who conduct research for a living say and do things correctly, but those who fish for a living and have developed their own beliefs and values through experience are incorrect. Her viewpoint stems from Western environmentalism which relies on the results of "hard science" to construct management agendas, often ignoring input from local communities. Not only have local people not played a part in the planning and implementation of many resource management projects, but their knowledge of local ecology and the structure of their social, economic and political systems have also been ignored (Pomeroy and Rivera-Guieb 2006:94). The wildlife biologist quoted above displayed characteristics of the "conventional approach" to research where the viewpoints and concerns of local resource users are not important for resource management.

In contrast to scientists, who often strive toward a 'rational' system of management based on population dynamics and other scientific measurements, local resource users are often quite aware of the role that power differentials play in how management regimes are actually implemented. One sport fishing captain spoke of how his political connections, social skills and money enabled him to influence policy and 
management of the sport fishery in section 3A (Alaska Department of Fish and Game’s label for the marine area surrounding, and including, Seward). He would often allude to things going on behind the scenes when it came to halibut management. The allocation of halibut numbers comes from the State of Alaska's legislative appointees in Washington, DC. These senators and congressman are influenced by lobbyists from both the sport and commercial fishers. This particular interviewee is responsible for the bag limit in 2007 staying at two fish per person, per day, rather than the proposed one fish per day limit. He spent approximately 20,000 dollars on a lobbyist who was able to sway the vote in the sport fishers' favor.

So, when we found out in January that there was going to be a one halibut bag limit, I was in Reno at the time. At the Sport Fishing Convention I ran into [a] congressman. He is a client of mine, you will meet him this summer. So I talked to him, we went to dinner and hung out, so I asked him what can we do on a Federal level, what can I do to get you and other representatives to help us. He said here is what you need to do; you are more than welcome to come to Washington. You will really keep your fire burning in Washington if you get a lobbyist...the commercial guys and a local charter association each have a lobbyist....you need a lobbyist. So it just so happens that the congressman and I are friends with a lobbyist. So I hired this lobbyist. I hired him, personally, I hired him.

In this case, power comes from a basic knowledge of politics, money, knowing people in positions of power and knowing how to handle oneself well in a social situation. It is easy to see why commercial fishers are often uneasy about management decision processes. 


\section{Who is Blamed for Damage to the Marine Environment?}

As tends to be the case in any natural resource allocation matter, Seward's ongoing management issues involve much blame placed on various social groups for the decline in marine stocks. It is important to look at who is blamed, by whom, and why in order to get an idea of why behavioral and normative beliefs exist. Arizpe, Paz and Velázquez’s (1998) work in the Lacandón rain forest is presented in Chapter II as an example of how different stakeholders can develop different beliefs of who is responsible for resource degradation. Arizpe and colleagues believe that in issues of resource management, it is important to understand the context in which blame originated. For the purposes of this study, the different beliefs about whom is to blame and why this blame originated is important context for looking at each group's opposing beliefs. The following are quotes taken from interviews which illustrate how groups allocate blame to other groups.

\section{Commercial Fishers Attitudes towards Sport Fishing Boat Captains}

We have been fishing these waters for almost a century and have all these regulations and quotas to deal with. They [sport fishing boat operators] came in here a decade ago and are continuing to grow in numbers with limited, unchanged regulations. It’s ridiculous.

Throughout my fieldwork, I found that commercial fishers tended to be the most distressed with the lack of management of sport fishing boats. They feel justified for having these feelings because they pay for their catch size (IFQ), and sport fishers do not. However, when sport fishers exceed their catch size, the commercial fishers' catch size 
(IFQ) is reduced. This tension between commercial fishers and sport fishers leads to commercial fishers' belief that sport fishers should be better managed as well as some of the negative feelings they hold towards managers. These negative feelings keep commercial fishers out of the realm of management processes and further perpetuate their lack of involvement in issues of fisheries management.

\section{Sport Fishing Boat Captains’ Attitudes towards Commercial Fishers}

I am nothing more than a water taxi, I take sport fishermen out to catch their fish. They are not my fish to keep, so why are they trying to regulate me with an IFQ [Individual Transfer Quota]. Furthermore, I am outraged that the sport fishermen will be regulated and even shut down, because the commercial guys have reduced the halibut population to a critical level through their years of "dirty” fishing.

Most sport fishing captains I interviewed felt that commercial fishers use "dirty” fishing practices, such as excessive bycatch mortality, the killing of sea lions, over fishing a limited resource and illegal dumping of waste. These ideas seem to come as a defense to accusations made by commercial fishers that sport captains are stealing their fish. A lot of these are coming from the media's responses to heightened concerns and awareness with commercial fishing on a global scale. Many of the sport fishing tour boat operators work seasonally in Alaska and elsewhere, such as Hawaii or Florida during the winter months. This exposure to other areas of the world allows for the sport fishers to develop this idea of irresponsible commercial fishing in other areas and bring it back to Alaska. Thereby, they are adopting ideologies of a global forum that may or may not apply to the circumstances in Seward, Alaska. 


\section{Government Officials}

...it should be an allocation between the recreational fishery and the commercial fishery and leave the charter out of it....so that is kind of my personal take on the whole thing....I mean is the charter operator any more of the charter fishery than the guy who sells the bait?....it is just someone else providing a service in the pursuit of halibut by an angler....

Talking with government and management officials I found that there is no consistency in placing blame on one fishery or the other. When asked professionally, they remain neutral but that is not always the case when asked personally. Consistently, managers (employees of the International Pacific Halibut Commission (IPHC)) tended to side with the commercial fishers, while state of Alaska government employees tended to side with the sport fishers. After conducting many interviews I noted the practice of frequent monetary donations, political support and personal fishing trips given to Alaska Fish and Game employees and political representatives by sport fishing boat captains. Also, there is a tendency for commercial fishers to hold seats at the IPHC when they retire. Having the money for a good lobbyist also gained the sport fishers a good rapport with many political representatives. Knowing this, commercial fishers are quick to place blame on sport fishing captains and government employees.

\section{Commercial Fishers’ Attitudes towards Scientists}

I tell ya girl....I see the way they manage the stocks out here it don't make any sense. They got the charter guys fishing without any limits, they got us on a short rope and the numbers keep dropping below their predictions. And I ask you, if these scientists get it right, wouldn't they be out of a job? 
Cause as I see it, if they sustain the fish stocks they are screwed, so they don't.

I have found this perspective to be very common among commercial fishers in Alaska and elsewhere. And when an outsider looks at the situation it would appear that the perspective holds legitimacy. The government does not limit the number of sport fishing boats; they do however regulate the commercial fishers down to their very last pound of quota (fish allowed to catch). Also, to a commercial fisher, it is easy to wonder what scientists employed by ADF\&G would do if all the fish stocks were managed successfully. Looking from inside ADF\&G however there is a web of paperwork, bureaucracy, politics, and grant funds. Two years had passed and Fish and Game employees had not yet been able to reduce the number of charter fishing boats in the area surrounding Seward, Alaska. The process is slow and tedious. While data are collected by researchers concerning what numbers they need to match, lobbyists are hired by sport fishers and commercial fishers to battle it out for months on Capitol Hill. During that time, ADF\&G employees continue to conduct the multitude of other daily tasks that tend to take precedence, such as responding to e-mails, phone calls, and paperwork. After looking at the situation from the inside and the outside, it is easy to see how commercial fishers would feel the way they do about scientists and the processes of government.

\section{Residents}

The residents tended to place blame according to the beliefs of whichever group they were most closely affiliated, either by way of occupation, family, or friends. With the exception of the woman who works for the Park Service, no residents mentioned 
favoring government officials or managers. In their responses, residents never shared exactly the same ideas of who is to blame for environmental problems.

\section{Alaskans vs. Non-Alaskans: Environmental Responsibility}

One Seward resident presented a belief I found to be common amongst people living in Alaska who were born and raised elsewhere. This is the belief that people born and raised in Alaska (not including Native Alaskans) do not respect or value the natural resources around them as much as those visiting from other areas of the world. In addition, she held a commonly found belief that sport fishing boat captains are less conservation oriented than wildlife viewing tour boat captains. This primarily stems from the fact that sport fishing boat captains were raised in Alaska, their livelihood involves bringing people to the ocean to kill fish and they hold a more pragmatic view towards the marine environment. Wildlife viewing tour boat operators, however, were born in another state, university educated and hold Western environmentalist beliefs.

I think a lot of Alaskans go fishing, more than the tourists. If they are residents, they want to go out and get their limit, they want to go dip netting and fill their freezers. You know it is their resource, they are subsistence fishing. And when they are out fishing, you know they are not necessarily thinking "oh, you know I need to stay back a certain distance and not disturb the salmon”. They are paying a certain amount of money and they want to see the animals and catch the fish. The big [wildlife viewing] tour boats, they are supposed to stay a certain distance from the wildlife, and I think they do pretty well with that. Whether the fishing boats actually do it or not, I don't know, I get the feeling that possibly they are a bit pushier about getting up close to things. I have just heard things 
here and there, so I think that maybe that's going on. Personally, when I am recommending tours to my customers, I will only recommend tour companies that I know are conservation minded and do not disturb the animals and their habitats.

This was not the only person I interviewed who believed that people raised in Alaska were less environmentally responsible than those born elsewhere. The statement below was made by a wildlife viewing boat captain who moved to Alaska in his early twenties.

\begin{abstract}
Alaskan fishermen are much less conservation responsible than the lower forty-eight fishermen/tourists. The lower forty-eight do not see the grand landscape every day, so they are much more careful and treat it more delicately. Alaskans don't care, they think it will always be there; they come up and want to fill their freezers with fish for the winter. Alaskans think there is no problem, but there is always a problem.
\end{abstract}

None of the interviewees who were born and raised in the state of Alaska believed that Alaskans were any less environmentally responsible than those not born in Alaska (this included commercial fishers, some residents and sport fishing boat captains). However, they were also not inclined to say that those inside the state were more environmentally responsible. The perceptions held by people who were raised elsewhere and moved to Alaska are often different because they were raised with a Western environmentalist paradigm of what is good for ecology and conservation. Having taught in an Alaskan school for over a year, I was concerned with the low priority given to science. It is difficult to coax teachers into coming to Alaska to teach during the winter months; therefore many teachers are hired who may not be fully qualified for their 
positions. In the school where I worked, the science teacher taught all grades and subjects from ecology to chemistry to physics, all at introductory levels. The same teacher was also coach of the basketball team during the season and spent every third week away from school for basketball meets in other Alaskan towns. Non-Alaskans, who are often required to take several science courses with emphasis on Western environmentalism, feel that the pragmatic views of Alaskans tend to be environmentally irresponsible.

Alaskan children are brought up hiking, fishing, boating and camping. Fishing derbies are encouraged to raise money for team sports and people in need; learning how to shoot a rifle and use a can of mace for bear protection is common and can be started as early as age seven. Unlike the rest of the U.S., fresh fish and meat are not available during winter months in most small Alaskan towns. Food is brought in by barge once a week and is very high in preservatives. Accumulating fish and meat during the summer months and freezing it for consumption during the winter is a modern form of subsistence living in Alaska. For non-Alaskans who grew up thinking that hunters and fishers abuse resources and pollute the environment, they will often believe that Alaskans are not conservation conscious because they partake in these activities.

Another perspective I found amongst people raised outside the state of Alaska and who are currently in a position which requires that they deal with the public on a daily basis (such as scientists, managers, sport fishing and wildlife viewing tour boat captains and some residents) is the inclination to state Western environmentalists ideals. Others, such as commercial fishers, some residents and sport fishing boat captains (when clients 
are not present), on the contrary, seemed to express pragmatic attitudes towards the area and its resources.

\section{Conclusion}

Managing marine resources is always a complicated task. In a world where resource management involves environmental, industrial, and cultural sustainability there are many factors that need to be taken into consideration. It is important to understand the reasons why people value the marine environment and particular species within the marine environment. It is just as important to understand why resource user groups hold beliefs about other resource user groups and how these beliefs are constituted. The beliefs and values common to different groups can be used to predict their behaviors in circumstances concerning the marine environment. In this chapter, I presented the values and beliefs of each social group with regards to the marine environment that were salient in interviews and the most relevant to this study. I also briefly explained how these beliefs and values have come about through the group's shared experiences. In the next chapter I will examine how these beliefs and values translate into behaviors. I will also summarize the findings of the study and present the most notable implications for future studies. 


\section{CHAPTER VII}

\section{RELATIONSHIPS BETWEEN IDEOLOGY AND PRACTICE AND THEIR IMPLICATIONS FOR RESOURCE MANAGEMENT}

\section{Summary of Findings}

I describe below how people's behaviors in each of the groups studied are shaped by their personal and normative beliefs. I also show how the impact of peoples' beliefs on their behaviors varies in different situations.

\section{Sport Fishing Tour Boat Captains}

Several commonalties were found within the group of sport fishing boat captains. They tend to claim value for all halibut, both young and old, but they shoot and harpoon older halibut despite this. I found that captains believe this act makes the fishing experience more enjoyable for their clients (and, thus, may increase business). Although they see it as displaying poor sportsmanship, it is the belief that it enhances the experience of customers by providing the customer with a trophy fish that seems to drive this behavior the most. Captains also express a hatred of dogfish, a hatred they are willing to override when they feel others would be critical of them. Each of these circumstances illustrates how the sport fishing boat captains' behaviors often oppose some of their behavioral beliefs as another behavioral belief or a normative belief comes to dominate their choices. In many cases, the subjective norm invokes Western environmentalist perspectives. For the case where the emphasis is on killing mature halibut for trophies, the community and ADF\&G could intervene by educating people 
about the importance of keeping mature halibut alive and diminishing the importance of catching a trophy fish. Also, informing the customers of how much it will cost to ship the meat of a large halibut back home.

\section{Commercial Fishers}

Commercial fishers were the most unique group, showing considerable consistency between their behavioral beliefs and behavioral intentions. This is because when they are working at sea, they have only other commercial fishers around them. They can shoot at sea lions, dump garbage overboard, keep quantities of fish above their limit, and perform other illegal behaviors. But these are not common practices, nor are they performed without some kind of justification. If fishers do shoot at sea lions and catch a few pounds above their limit, they justify these actions by saying they are sparing the sea lions' lives and by catching fish that would have died anyway. The fishers believe that their practices are sustainable and do not damage the environment. When Jessie threw garbage bags overboard, he justified his actions by identifying them as having no impact on the marine environment in comparison to what cruise ships dump each year. Instruction on practices that are sustainable versus those that are not could be beneficial in influencing fishers to change certain practices.

\section{Government and Management Officials}

Officials from the Alaska Department of Fish and Game, the National Oceanic and Atmospheric Administration, and the International Pacific Halibut Commission all tended to respond similarly during interviews. They all expressed a value for biodiversity 
and an understanding of its meaning and significance. However, when it came to their personal valuation of a particular marine creature, they were rather existential in their reasoning. They valued a creature for its spiritual (an inexplicable connection the individual felt with the creature), aesthetic (the intrinsic beauty of the creature), or internal (the feeling they got from seeing the creature) appeal. This is in contrast to commercial fishers who tended to value creatures because of the memories they provoked or because without them, they would not have a livelihood.

Government officials working for the ADF\&G identified themselves personally during interviews as environmentalists. Probing deeper, I found that many of them hold personal feelings towards certain species and those that target those species. They also believed that in cases of natural resource allocation, the stakeholders were never satisfied.

\section{Residents of Seward Alaska for More than Five Years}

Residents were unique in that people interviewed in this group tended not to share common normative and behavioral beliefs. Their diverse beliefs and values, however, accentuated the consistency found within the other groups. The residents tended to work for the tourism industry and more often than not were in some way related to individuals in one of the groups studied (whether they were friends, family, spouse or a colleague). The group with which they held relations was the group with which their views tended to align. 


\section{Contributions}

This study offers three significant contributions to the discipline of anthropology and to our understanding and management of marine resources. From the perspective of theory, the study employs the Theory of Reasoned Action, widely used in social psychology, to complement more traditional sociocultural studies. The TRA contributes to the cultural modeling approach and adds an additional dimension to our understanding of the immediate relation between our beliefs and practices.

The study found that all marine resource user groups in Seward were united in their intentions and orientations to conserve the environment. However, they had different ideas of what is beneficial or detrimental to the environment. The study also found that marine resource managers, government officials, wildlife viewing tour boat captains and scientists all hold a Western environmentalist perspective towards marine life, while commercial and sport fishers hold a more pragmatic view towards the environment and the resources they harvest that is at times in contradiction with environmentalist assumptions. I address these three contributions below.

\section{Utility of the Theory of Reasoned Action}

This dissertation did not pursue a detailed analysis of more distal variables that influence environmentally relevant behaviors (such as power relations and social class) but instead focused on the more immediate determinants of behaviors, namely the constructs of the Theory of Reasoned Action. Analysis of the TRA constructs has several advantages over more traditional analyses of such distal variables. First, beliefs, attitudes, and perceived norms are constructs that are amenable to change in education programs. 
By contrast, distal variables, such as social class and power relations between groups, are difficult to change. By focusing on constructs that are amenable to change, the present research can better inform the design of practical education/communication programs that can lead to meaningful behavior change with respect to the environment. Second, TRA provides a general conceptual framework for thinking about the proximal influences of any behavior, be it killing dogfish, shooting at sea lions, or shooting fish. In each case, one identifies the relevant perceived advantages and disadvantages of performing the behavior (the behavioral beliefs) and the normative pressures to perform the behavior (the normative beliefs). One then considers the relative importance of these two factors in shaping a person's decisions to perform a behavior and analyzes if this decision translates into actual behavior. The theory has proven to be effective in analyzing behavioral choices in hundreds of studies. Applying the framework to the present case makes substantive sense and yielded numerous insights into the bases of group differences in environmental orientations of fishers and resource managers that more traditional analyses of distal variables would fail to reveal.

\section{Different Ideas of what is “Good” for the Marine Environment}

A notable finding of the study was that individuals from each resource user group held a strong valuation towards the marine environment as a whole. While the valuations for each group were similarly strong, their actions differed. Whether he or she was a sport fishing tour boat captain who kills protected dogfish, a commercial fisher who shot at protected sea lions, a private sport fisher who kept baby halibut for food, or a government 
scientist who suspended the license of a law abiding bear hunter, each individual justified their opposing actions as nondestructive towards the valued marine environment.

This justification stemmed from an individual's behavioral and/or normative beliefs. Their behavioral beliefs derive from the individual's larger socio-cultural context of distal factors. The more relevant distal factors include the person's formal education, upbringing, travels, and training for previous and present occupations. When asked about these domains, individuals revealed an important framework of experiences with the marine environment that led them to their current behavioral beliefs and subjective norms.

Pertinent distal factors also include an individual's cultural traditions, as for example a display of respect towards the marine environment or the killing of a particular species. These traditions come from the culture in which an individual was raised, the communities he/she has lived in, or the communities and social groups with which he/she is currently associated. Each of these variables contributes to the current, proximal beliefs and values of all people involved in this study. The different marine resource user groups in Seward all want to conserve the environment; they simply have different ideas of what is good and what is bad for the environment.

\section{Different Forms of Knowledge}

As noted earlier, several scholars (Nadasdy 2003; Cronon 1996; Price 1996) discuss the existence of a dichotomy between a Western environmentalist perspective and the perspective of people who live and work in close proximity to nature. In this study, it was found that in general, people who held a Western environmentalist perspective were 
those people born outside the state of Alaska, had a university level education, and were employed as government officials, managers, or wildlife viewing tour boat operators. Those who held a more pragmatic view of the environment generally were people who were raised in Alaska, with an education based on experiences with the environment and who were employed as commercial fishers and sport fishing boat captains. People's education, professional environment and socialization had the greatest impact on the formation of their systems of beliefs and resulting behaviors concerning the marine environment.

\section{Implications}

Social psychologists who have used TRA in studies involving the environment have tended to use their findings to advocate for environmental education.

Environmental anthropologists using the cultural model approach have often used their findings to stress the importance of LEK and cultural traditions and to advocate for the inclusion of these factors in the development of management protocol. Providing fishers with proper information concerning the ecological importance of protecting sea lions could help the situation, but the most important issue is to improve communication between all groups. This could be achieved by providing all with a greater awareness of each group's behavioral and normative beliefs surrounding marine resources and the difficulties and challenges that each group experiences in the management, exploitation, and use of marine resources. If scientists were to acknowledge that sea lions can be a nuisance, just as bears can be a nuisance in camp sites, it would be a productive step towards an outcome that satisfies both groups involved. Just as scientists have developed 
bear spray to keep bears away from camp sites, perhaps the development of a high frequency, underwater noise admitter could keep the sea lions away from commercial long lines. In turn, this would protect the sea lions from the potential harm of shotguns, save the fishers' equipment and catch, and result in better communication and respect between fishers and managers.

With regards to the dogfish issue, fishers could bring managers out on their boats and show them how prevalent the dogfish are, which could lead to a re-evaluation of the dogfish stock and, ultimately, removal of some of the dogfish regulations. However, if the resource managers reassess the stock and find that the numbers are still dangerously low, they would need to educate fishers in ways that would be convincing in spite of the fishers' perceptions that dogfish are overly abundant. Furthermore, resource managers have not made a convincing case to fishers on the importance of the shark species to Seward's marine environment, or concerning sharks' threatened status. Addressing these scenarios would result in better rapport between the groups and eventually build trust and better enforcement of existing or new regulations.

It is clear from this study that fishers (representatives of the group) should be allowed to participate in some form in resource management discussions. Currently, they play a small role in such decisions and this leads them to pay lip service to Western environmentalist ideas, hiding their actual attitudes towards existing regulations Finally, resource managers would benefit from a better understanding of the behavioral/normative beliefs of commercial fishers and sport fishing tour boat captains. For example, managers are not aware that fishers are committed to protecting the environment and they often believe that they are the only ones working towards 
conservation. By documenting the diverse perspectives towards the environment by groups differentially involved with the marine environment in Seward, Alaska, this study hopes to contribute to improved communication and greater understanding among the groups and ultimately to measures that ensure environmental conservation in the context of sustainable practices. 


\section{LIST OF REFERENCES}

Acheson, James M.

1981 Anthropology of fishing.

Annual Review of Anthropology 10:275-316.

1988 The Lobster Gangs of Maine. Hanover.

New Hampshire: University Press of New England

Aipanjiguly, Sampreethi, Susan K. Jacobson and Richard Flamm

2003 Conserving Manatees: Knowledge, Attitudes, and Intentions of Boaters in Tampa Bay, Florida. Conservation Biology. 17:4(1098-1105).

Ajzen, Icek and Martin Fishbein

1980 Understanding Attitudes and Predicting Social Behavior.

Prentice Hall Inc.: NJ

Alaska Department of Fish \& Game (ADF\&G)

1994 Pacific Halibut. ADF\&G Wildlife Notebook Series. Electronic document, http://www.state.ak.us/adfg/notebook/fish, accessed December 16, 2008.

Amend, Donald F.

1989 Alaska’s Regional Aquaculture Associations: Co-Management of Salmon in Southern Southeast Alaska. In Cooperative Management of Local Fisheries: New Directions for Improved Management and Community Development. Evelyn Pinkerton, ed. Vancouver: University of British Columbia Press.

Anderson, Raoul and Geoffrey Stiles

1973 Resource Management and Spatial Competition in Newfoundland Fishing: An Exploratory Essay. In Seafarer and Community: Towards a Social Understanding of Seafaring, Peter H. Fricke, ed. Pp. 44-66. London: Croom Helm.

Apostle, Richard, Gene Barrett, Petter Holm, Svein Jentoft, Leigh Mazany, Bonnie McCay, and Knut Mikalsen

1998 Community, State, and Market in North Atlantic Fisheries: Challenges to Modernity in the Fisheries. Toronto: University of Toronto Press.

Arizpe, Lourdes, Fernanda Paz, and Margarita Velazquez.

1998 Culture and Global Change: Social Perceptions of Deforestation in the Lacandona Rain Forest in Mexico. Society and Natural Resources. 11(5): 541-542. 
Arnold, David

1996 The Problem of Nature: Environment, Culture and European Expansion. Cambridge: Blackwell Publishers.

Babbie, Earl

2002 Fundamentals of Social Research. KY: Wadsworth Publishing.

Barlow, Elisia D. and Andrew N. Bakke

2006 Managing Alaska’s Halibut: Observations from the Fishery.

Electronic document, http://www.edf.org/documents/489_halibut.PDF, accessed December 16, 2008.

Biersack, Aletta

1999 From the 'New Ecology' to New Ecologies.

American Anthropologist 10(1):5-18.

Blaikie, $\mathrm{P}$.

1985 The Political Economy of Soil Erosion in Developing Countries.

New York: Wiley.

Blount, Benjamin G.

2002 Keywords, Cultural Models, and Representation of Knowledge: A Case Study from the Georgia Coast (USA).Occasional Publication Number 3.

Athens, GA: Coastal Anthropology Resources Laboratory, Department of Anthropology, University of Georgia.

2000 Coastal refugees: marginalization of African-Americans in marine fisheries of Georgia, Urban Anthropology and Studies of Cultural Systems and World Economic Development. 29(3)285 -313.

Boldero, J.

1995 The Prediction of Household Recycling of Newspapers: The Role of Attitudes, Intentions, and Situational Factors. Journal of Applied Social Psychology. 25(5): 440-462.

Bourdieu, Pierre

1998 Practical Reason: On the Theory of Action.

California: Stanford University Press.

Bright, A. D., Manfredo, M. J., Fishbein, M. \& A. Bath

1993 Application of the Theory of Reasoned Action to the National Park Service's controlled burn policy, Journal of Leisure Research, 25(3), 263-280. 
Brosius, J. Peter and Diane Russell.

2003 Conservation from Above: An Anthropological Perspective on Transboundary Protected Areas and Ecoregional Planning. Journal of Sustainable Forestry 17 (1 \&2):39-65.

Brush, Stephen B. and Doreen Stabinsky, eds.

1996 Valuing Local Knowledge: Indigenous People and Intellectual Property Rights. Covelo, CA: Island Press.

Carlton, Eric.

1984 Ideologies as Belief Systems. The International Journal of Sociology and Social Policy. 4(2):17-29.

Carr, S. and J. Tait

1991 Differences in the Attitudes of Farmers and Conservationists and Their Implications. Journal of Environmental Management. 32(3) 281-294.

Carrier, James G.

2004 Environmental Conservation and Institutional Environments in Jamaica. In Confronting Environments: Local Understandings in a Globalizing World. ed. James G. Carrier. AltaMira Press: New York: Pp. 119-142.

Clay, P. and J. R. McGoodwin

1995 Utilizing Social Sciences in Fisheries Management. Aquatic Living Resources 8:203-207.

Commercial Fisheries Entry Commission

1998 Changes under Alaska’s Halibut IFQ Program, 1995 to 1997. Electronic document, http://www.cfec.state.ak.us/research, accessed October 6, 2008.

Cook, Linda and Frank Norris

1998 A Stern and Rock-Bound Coast: Historical Resource Study, Kenai Fjords National Park Historic Resource Study. Electronic document,

Cordano, Mark and Irene Hanson Frieze

2000 Pollution Reduction Preferences of U.S. Environmental Managers: Applying Ajzen's Theory of Planned Behavior. The Academy of Management Journal. 43(4): 627-641. http://www.nps.gov/archive/kefj/hrs/hrs.htm, accessed Nov. 26, 2008.

Corraliza, Jose A. and Jaime Berenguer

2000 Environmental Values, Beliefs, and Actions: A Situational Approach. Environment and Behavior. 32: 832-848. 
Cripe, L. M.

1998 Predictors of Community Participation in Sanitation Facility Improvement: Attitudes among Female Peri-urban Residents of Quezon City. Dissertation Abstracts International: Section B: The Sciences \& Engineering. 58(10-B): 5697.

Croll, Elisabeth and David Parkin

1992 Cultural Understandings of the Environment. In Bush Base: Forest Farm. Elisabeth Croll and David Parkin, eds. Pp. 11-36. London: Routledge.

Cronon, William

1996 The Trouble with Wilderness; or, Getting Back to the Wrong Nature. In Uncommon Ground: Rethinking the Human Place in Nature. William Cronon, ed. Pp.69-90. W.W. Norton.

D'Andrade, Roy

1992 Schemas and Motivation. In Human Motives and Cultural Models.

D'Andrade, Roy G. and Claudia Strauss, eds. Pp. 23-44. New York:

Cambridge University Press.

Einarrson, Niels

1990 Of Seals and Souls: Changes in the Position of Seals in the Worldview of Icelandic Small-scale Fishermen. Maritime Anthropological Studies 3(2):35-48.

Ellis, Carolyn

1986 Fisher Folk: Two Communities on Chesapeake Bay. Lexington: University Press of Kentucky.

Emerson, Robert M.

1983 Contemporary Field Research: A Collection of Readings. Prospect Heights: IL: Waveland Press.

Fairchild, James and Melissa Leach

1996 Misreading the African Landscape: Society and Ecology in a ForestSavanna Mosaic. Cambridge: Cambridge University Press.

Finlayson, Alan Christopher

1994 Fishing for the Truth: A Sociological Analysis of Northern Cod Stock Assessments from 1977-1990. St. John's: Institute of Social and Economic Research, Memorial University of Newfoundland. 
Finalyson, Alan Christopher and Bonnie McCay

1998 Crossing the Threshold of Ecosystem Resilience: The Commercial Extinction of Northern Cod. In Linking Social and Ecological Systems: Institutional Learning for Resilience Carl Folke and Fikret Berkes, eds. Pp. 311-337. Cambridge UK: Cambridge University Press.

Fishbein, M. and M. J. Manfredo

1992 A Theory of Behavior Change. Influencing Human Behavior. M. J. Manfredo. Champaign, Illinois, Sagamore Publishing Inc.: 29-50.

Fishbein, M., and I. Ajzen.

1975 Belief, Attitude, Intention, and Behavior: An Introduction to Theory and Research. Addison-Wesley. Reading, Massachusetts.

Frykman, Jonas and Orvar Löfgren

1987 Culture Builders: A Historical Anthropology of Middle Class.

New Brunswick: Rutgers University Press.

Fulton, D. C., M. J. Manfredo, and J. Lipscomb

1996 Wildlife Value Orientations: A Conceptual and Measurement Approach. Human Dimensions of Wildlife 1: 24-47.

Gamba, R. J.

2000 A Cross-Cultural Study of Attitudes and Behaviors Regarding Curbside Reycling. Dissertation Abstracts International: Section B: The Sciences \& Engineering. 61(4-B): 2270.

Gotch, Chad and Troy Hall

2004 Understanding Nature-Related Behaviors among Children through a Theory of Reasoned Action Approach. Environmental Education Research. 10(2):157-177.

Gross, Louis J.

1989 Plant Physiological Ecology: A Theoretician's Perspective. In Ecological Theory. Jonathan Roughgarden, Robert M. May and Simon A. Levin, ed. Pp. 11-24. Princeton, New Jersey: Princeton University Press.

Gupta, Anil K.

1995 Survival Under Stress: Socioecological Perspectives on Farmers'

Innovations and Risk Adjustments. In The Cultural Dimension of Development: Indigenous Knowledge Systems. Warren, D. Michael, L, Jan Slikkerveer, and David Brokensha, eds. Pp. 407-418. London: Intermediate Technology Publications. 
Hamid, P. N. \& S. T. Cheng

1995 Predicting Antipollution Behavior: The Role of Molar Behavioral Intentions, Past Behavior, and Locus of Control. Environment and Behavior. 27(5): 679-698.

Heong, K.L. \& M. M. Escalada

1999 Quantifying Rice Farmers' Pest Management Decisions: Beliefs and Subjective Norms in Stem Borer Control. Crop Protection, 18: 315-322.

Ingold, Tim

1992 Culture and the Perception of the Environment. In Bush base. Forest Farm. E. Croll and D. Parkin, eds. Pp. 39-56 London: Routledge.

Inkeles, A.

1950 Social Stratification and Mobility in the Soviet Union, 1940-1950.

American Sociological Review 15:465-479.

International Pacific Halibut Commission (IPHC)

1998 Technical Report No. 40 (Revision of Nos. 6, 16, and 22) The Pacific Halibut: Biology, Fishery, and Management, Electronic document, http://www.iphc.washington.edu/HALCOM/pubs/techrep/tech0040.pdf, accessed July 10, 2008.

Jentoft, Svein and Bonnie McCay

1995 User Participation in Fisheries Management, Lessons Drawn from International Experiences. Marine Policy 19(3).

Kantola, S. J., Syme, G. J. \& N. A. Campbell

1982 The Role of Individual Differences and External Variables in a Test of the Sufficiency of Fishbein's Model to Explain Behavioral Intention to Conserve Water. Journal of Applied Social Psychology. 12: 70-83.

Kottak, Conrad P.

1999 The new ecological anthropology.

American Anthropologist 101(1):23-35.

Leach, Melissa and James Fairchild

2003 Science, Society and Power: Environmental Knowledge and Policy in

West Africa and the Caribbean. Cambridge, UK: Cambridge University

Press.

Levi-Strauss, Claude

1967 The Savage Mind. Chicago: University of Chicago Press.

1972 Elementary Structures of Kinship. Boston: Beacon Press.

1985 Structuralism and Ecology. The View from Afar. J. Neugroschel and P. Hoss. trans. Pp. 101-137. New York: Basic Books 
Luzar, E. J. \& A. Diagne

1999 Participation in the Next Generation of Agriculture Conservation Programs. The Role of Environmental Attitudes. Journal of Socioeconomics. 28(3): 335-349.

Lynch, Owen J. and Janis L. Alcorn

1994 Tenurial Rights and Community Based Conservation. In Natural Connections: Perspectives in Community-Based-Conservation. Western, David, R. Michael Wright, and Shirley C. Strum, eds. Pp. 373-392. Washington D.C: Island Press.

MacArthur, Robert H. and Edward O. Wilson

1963 An Equilibrium Theory of Insular Zoogeography. Evolution. 17(4): 373-387.

Maiolo, John R., Jeffrey Johnson, and David Griffith

1992 Applications of Social Science Theory to Fisheries Management: Three Examples. Society and Natural Resources 5(4):391-407.

Martin, K.O.

1979 Play by the Rules or Don't Play at All: Space Division and Resource Allocation in a Rural Newfoundland Fishing Community. In North Atlantic Maritime Cultures. R. Anderson, ed. Pp. 277-299. The Hague: Mouton

McCay, Bonnie J.

2001 "Environmental Anthropology at Sea”. In New Directions in Anthropology and Environment. Carole L. Crumley, ed. Pp. 254-272. CA: AltaMira Press.

1987 The Culture of the Commoners: Historical Observations on Old and New World Fisheries. In The Question of the Commons: The Culture and Ecology of Communal Resources. Bonnie McCay, and James Acheson, eds. Pp. 195-216. Tucson: University of Arizona Press.

1978 Systems Ecology, People Ecology, and the Anthropology of Fishing Communities. Human Ecology. 6(4): 397-422.

McGoodwin, James R.

1990 Crisis in the World's Fisheries; People, Problems, and Policies. Stanford, CA: Stanford University Press.

McIntosh, Robert P.

1987 Pluralism in Ecology. Annual Review of Ecology and Systematics. 18: 321-341. 
Miller, Marc L. and John Van Maanen

1979 Boats Don't Fish, People Do: Some Ethnographic Notes on the Federal Management of Fisheries in Gloucester. Human Organization 38(4):377-385.

Nadasdy, Paul

2003 Hunters and Bureaucrats: Power, Knowledge, and Aboriginal-State Relations in the Southwest Yukon. Vancouver: UBCPress.

Neumann, Roderick P.

2005 Making Political Ecology. New York: Oxford University Press

Olson, E. C., M. Bowman, and R. Roth

1984 Interpretation and Nonformal Environmental Education in Natural

Resources Management. Journal of Environmental Education 15:6-10.

Ortner, Sherry B.

1974 Is Female to Male as Nature Is to Culture? In Woman, Culture and Society. Michelle Z. Rosaldo and Louise Lamphere, eds. Pp. 67-87. Stanford, CA: Stanford University Press.

Paine, Robert

1957 Coast Lapp Society, Vol. 1. Tromso, Norway: Tromso Museum.

Palmer, Craig T., and Peter R. Sinclair

1996 Perceptions of a fishery in crisis: Dragger skippers on the Gulf of Saint Lawrence cod moratorium. Society and Natural Resources 9:267-279.

Paolisso, Michael

2007 Cultural Models and Cultural Consensus of Chesepeake Bay Blue Crab and Oyster Fisheries. National Association for the Practice of Anthropology Bulletin. 28(1): 123-135.

Paolisso, Michael and R. Shawn Maloney

2000 Farmer Morality and Maryland’s Nutrient Management Regulations. Culture and Agriculture 22(3): 32-39.

Park, H. S., Levine, T. R. \& W. F. Sharkey

1998 The Theory of Reasoned Action and Self-Construals: Understanding Recycling in Hawaii. Communication Studies. 49(3): 196-208.

Pate, J., M. J. Manfredo, A. D. Bright, and G. Tischbein.

1996 Coloradans' Attitudes toward Reintroducing the Gray Wolf into Colorado. Wildlife Society Bulletin 24: 421-428. 
Pautzke, Clarence G. and Chris W. Oliver

1997 Development of the Individual Fishing Quota Program for Sablefish and Halibut Longline Fisheries off Alaska. Electronic document, http://www.fakr.noaa.gov/npfmc/sci_papers/ifqpaper.htm, accessed September 10, 2008.

Pomeroy, R.S. and R. Rivera-Guieb

2006 Fishery Co-Management: A Practical Handbook. Cambridge, Massachusetts: CABI Publishing.

Price, Jennifer

1996 Looking for Nature at the Mall: A Field Guide to the Nature Company. In. Uncommon Ground: Rethinking the Human Place in Nature. William Cronon, ed. Pp. 186-203. W.W. Norton.

Price, Thomas L.

1995 Use of local knowledge in managing the Niger River Fisheries Project. In The Cultural Dimension of Development: Indigenous Knowledge Systems. Warren, D. Michael, L, Jan Slikkerveer, and David Brokensha, eds. Pp. 286-295. London: Intermediate Technology Publications

Proctor, James D.

1996 Whose Nature? The Contested Moral Terrain of Ancient Forests. In Uncommon Ground: Rethinking the Human Place in Nature. William Cronon, ed. Pp. 269-297, W.W. Norton.

QSR International

2001 NVivo Qualitative Data Analysis Software Package

Randall, C and R. Rollins

2004 Voluntary Policies as a Way to Manage for Ecological Integrity: An Examination of Visitor Attitudes Towards a Voluntary no Fishing Policy in the Broken Group Islands, Pacific Rim National Park Reserve. Electronic document, http://www.sampaa.org/PDF/ch15/15.1.pdf, assessed on Feb. 18, 2009.Pp. 1-8

Rappaport, Roy A.

1979 Ecology, Meaning, and Religion. Richmond, CA: North Atlantic Books.

1984 Epilogue. Pigs for the Ancestors: Ritual in the Ecology of a New Guinea People. New Haven, CT: Yale University Press.

Rossi, A. N., and J. B. Armstrong

1999 Theory of Reasoned Action vs. Theory of Planned Behavior: Testing the Suitability and Sufficiency of a Popular Behavior Model using Hunting Intentions. Human Dimensions of Wildlife 4: 40-56. 
Roughgarden, Jonathan.

1989 The Structure and Assembly of Communities In Perspectives In Ecological Theory. Jonathan Roughgarden, Robert M. May and Simon A. Levin, ed. Pp. 203-226. Princeton, NJ: Princeton University Press.

Rubin, Herbert J. and Irene S. Rubin

1995 Qualitative Interviewing: The Art of Hearing Data. Thousand Oaks, CA: Sage.

Sayre, Nathan F.

2002 Ranching, Endangered Species, and Urbanization in the Southwest

Species of Capital. Tucson: The University of Arizona Press.

Schelhas, John and Max J. Pfeffer

2008 Saving Forests, Protecting People? Environmental Conservation in Central America. New York: AltaMira Press.

Seligman, C., Hall, D. and J. E. Finnegan

1983 Predicting home energy conservation: An application of the Fibein-Ajzen model. In R.P. Bagozzi and A.M. Tybout (Eds.), Advances in Consumer Research (vol. 10, pp. 647-651) Ann Arbor, MI: Association for Consumer Research.

Sheppard, B. H., J. Hartwick and P. R. Warshaw

1988 The Theory of Reasoned Action: A Meta-analysis of Past Research with Recommendations for Modifications and Future Research. Journal of Consumer Research 15: 325-343.

Shore, Bradd

1996 Culture in Mind: Cognition, Culture, and the Problem of Meaning. New York: Oxford University Press.

Showers, D.E. and R. L. Shrigley

1995 Effects of knowledge and persuasion on high school students' attitudes toward nuclear power plants. Journal of Research in Science Teaching, 32(1), 29-43.

Sinclair, Peter R.

1983 Fishermen Divided: The Impact of Limited Entry Licensing in northwest Newfoundland. Human Organization 42(4):307-313

Slater, Candace

1996 Amazonia as Edenic Narrative In Uncommon Ground: Rethinking the Human Place in Nature. William Cronon, ed., New York: W.W. Norton and Company. Pp. 114-132. 
Smith, Courtland L. and Susan S. Hanna

1993 Occupation and Community as Determinants of Fishing Behaviors.

Human Organization 52(3):299-303

Smith, M. E.

1995a The Nature Of Nature - Conflict And Consensus In Fisheries

Management. Aquatic Living Resources 8(3):209-213.

1995b Chaos, Consensus, and Common Sense. The Ecologist 25(2/3): 80-85.

Smith, Suzanna

1996 Social Implications of changes in Fisheries Regulations for Commercial Fishing Families. Fisheries 20(7):24-26

Smith, S. and M. Jepson

1993 Big Fish, Little Fish: Politics and Power in the Regulation of Marine Resources. Social Problems 40(1).

Stanley, Denise L.

1998 Explaining Persistent Conflict among Resource Users: The Case of Honduran Mariculture. Society and Natural Resources 11:267-278.

State of Alaska Commercial Fisheries Entry Commission

2006 Annual Report, Electronic document, http://www.cfec.state.ak.us/annrpts/ar2006.pdf, accessed June 20, 2008.

Steward, Julian

1977 Evolution and Ecology: Essays on Social Transformation. Illinois: University of Illinois Press.

Stigter, Kees J.

1995 Transfer of Indigenous Knowledge and Protection of the Agricultural Environment in Eastern Africa. In The Cultural Dimension of Development: Indigenous Knowledge Systems. Warren, D. Michael, L, Jan Slikkerveer, and David Brokensha, eds. Pp. 419-425. London: Intermediate Technology Publications

Stott, P. and S. Sullivan

2000 Political Ecology: Science, Myth and Power. London: Arnold.

Strauss, Claudia

1993 Models and Motives. In Human Motives and Cultural Models, Roy D’Andrade and Claudia Strauss, eds. Pp. 1-20. Cambridge: Cambridge University Press.

2005 Analyzing Discourse for Cultural Complexity. In Finding Culture in Talk: A Collection of Methods, eds. Pp. 203-242. New York: MacMillan. 
Strauss, Claudia and Naomi Quinn

1997 A Cognitive Theory of Cultural Meaning.

England: Cambridge University.

Stutzman, T. M. and S. B. Green

1982 Factors affecting energy consumption: two field tests of the FishbeinAjzen model. Journal of Social Psychology. 117: 183-201.

Sylvia, Gilbert

1992 Concepts in Fisheries Management: Interdisciplinary Gestalts and Socioeconomic Policy Models. Society and Natural Resources 5(2):115-133.

Taylor, S. and P. Todd

1997 Understanding the Determinants of Consumer Composting Behavior. Journal of Applied Social Psychology. 27(7): 602-628.

Townsend, P.

2000 Environmental Anthropology: From Pigs to Politics. Prospect Heights, IL:Waveland.

Trumbo C. W. and G. J. O'Keefe

2001 Intention to Conserve Water: Environmental Values, Planned Behavior, and Information Effects. A Comparison of Three Communities Sharing a Watershed Source: Society and Natural Resources, 14 (10): 889-899.

US Census Bureau

2003 United States Census 2000, State and County QuickFacts. Electronic Document, http://quickfacts.census.gov/qfd/, accessed January 4, 2009.

Western, David, R. Michael Wright, and Shirley C. Strum, eds.

1994 Natural Connections: Perspectives in Community-Based-Conservation. Washington D.C: Island Press.

White, L.A.

1959 The Evolution of Culture. New York: McGraw-Hill.

White, T. G.

1993 Evaluating Conservation Education Programs at a South American Zoo. M.S. thesis. University of Florida, Gainesville.

Young, R. A. and A. T. Kent

1985 Using the Theory of Reasoned Action to Improve Understanding of Recreation Behavior. Journal of Leisure Research 17(2): 90-106. 
Young, R.A. and M. R. Reichenbach

1987 Factors Influencing the Timber Harvest Intentions of Nonindustrial Private Forest Owners. Forest Science. 33(2) 381-393.

Zelezny, L. C.

1999 Educational Interventions that Improve Environmental Behaviors: A Meta-analysis. Journal of Environmental Education 31:5-14.

Zerner, Charles

1994 Transforming Customary Law and Coastal Management Practices in the Maluku Islands, Indonesia 1870-1992. In Natural Connections:

Perspectives in Community-Based-Conservation. Western, David, R. Michael Wright, and Shirley C. Strum, eds. Pp. 80-112. Washington D.C: Island Press.

Zimmerer, Karl S.

1994 Human Geography and the 'New Ecology': The Prospect and Promise of Integration. Annals of the Association of American Geographers, 84(1): 108-25.

1996 Ecology as Cornerstone and Chimera in Human Geography. In Concepts in Human Geography, C. Earle, K. Mathewson, and M. Kenzer eds., pgs. 161-188. Lanham: Rowman and Littlefield Publishers Inc.

2000 The Reworking of Conservation Geographies: Nonequilibrium Landscapes and Nature-Society Hybrids. Annals of the Association of American Geographers, 90(2): 356-69. 
APPENDIX - A Glossary of Photographes to Illustrate Items Within the Text. 


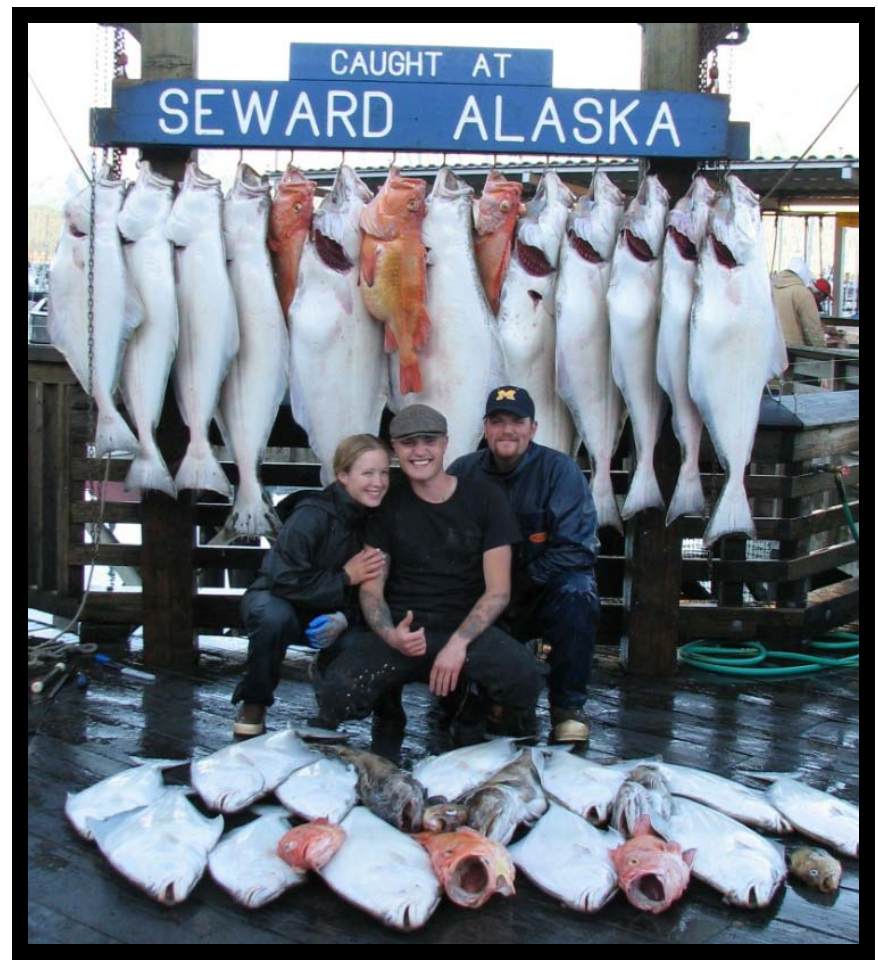

Daily sport fishing boat catch from a sport fishing tour boat based out of Seward, Alaska. Fish: halibut, yellow eye rockfish, lingcod and black rock fish.
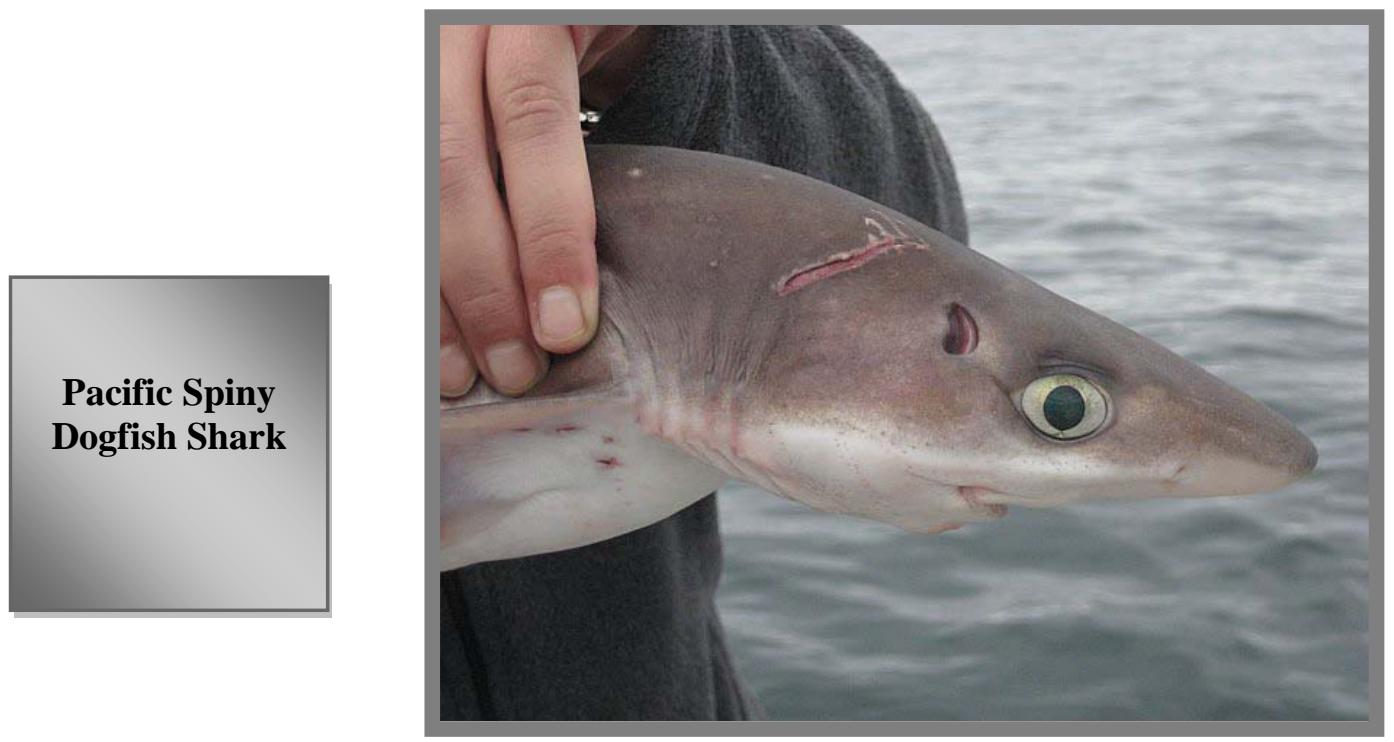


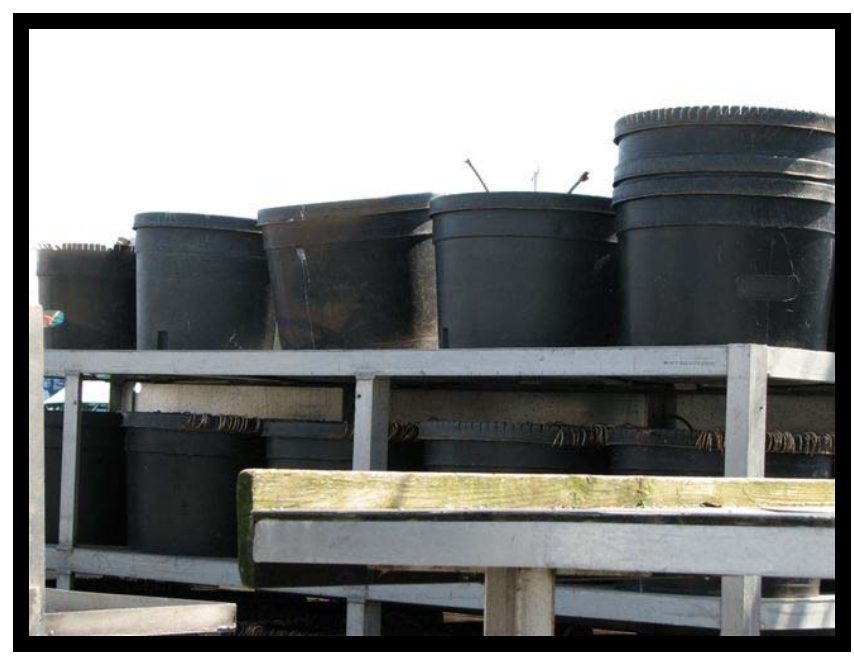

Buckets containing long lines on a commercial halibut long line vessel.

Commercial halibut long lines are kept in buckets. Each hook is carefully hung around the rim and the line is spiraled around in the bucket so as not to get the line tangled.

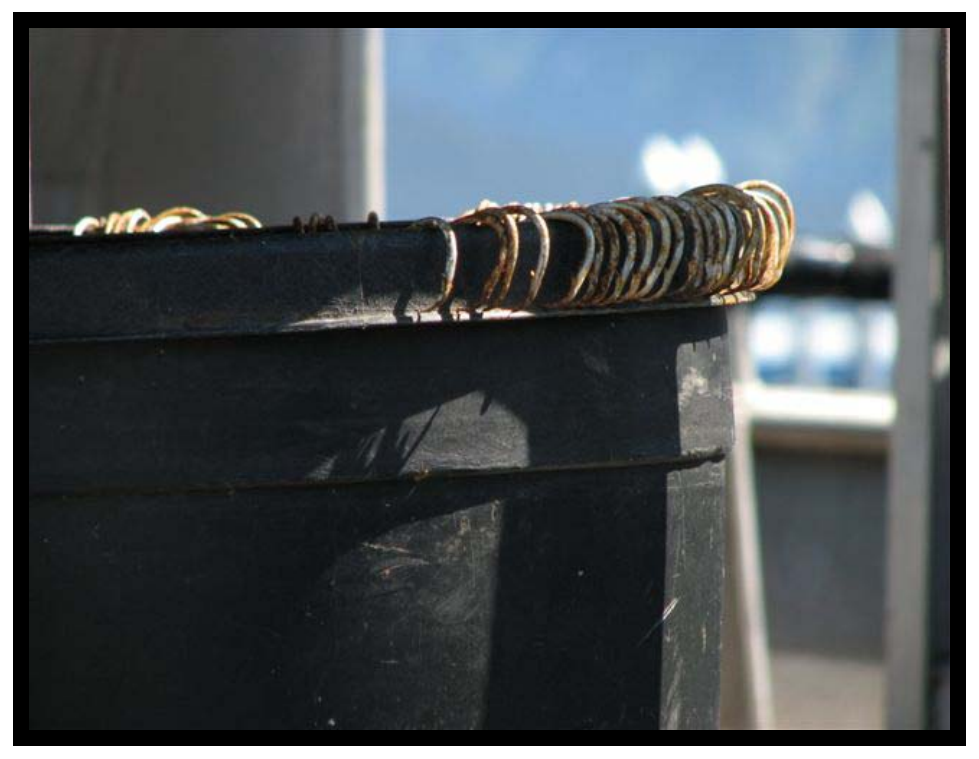



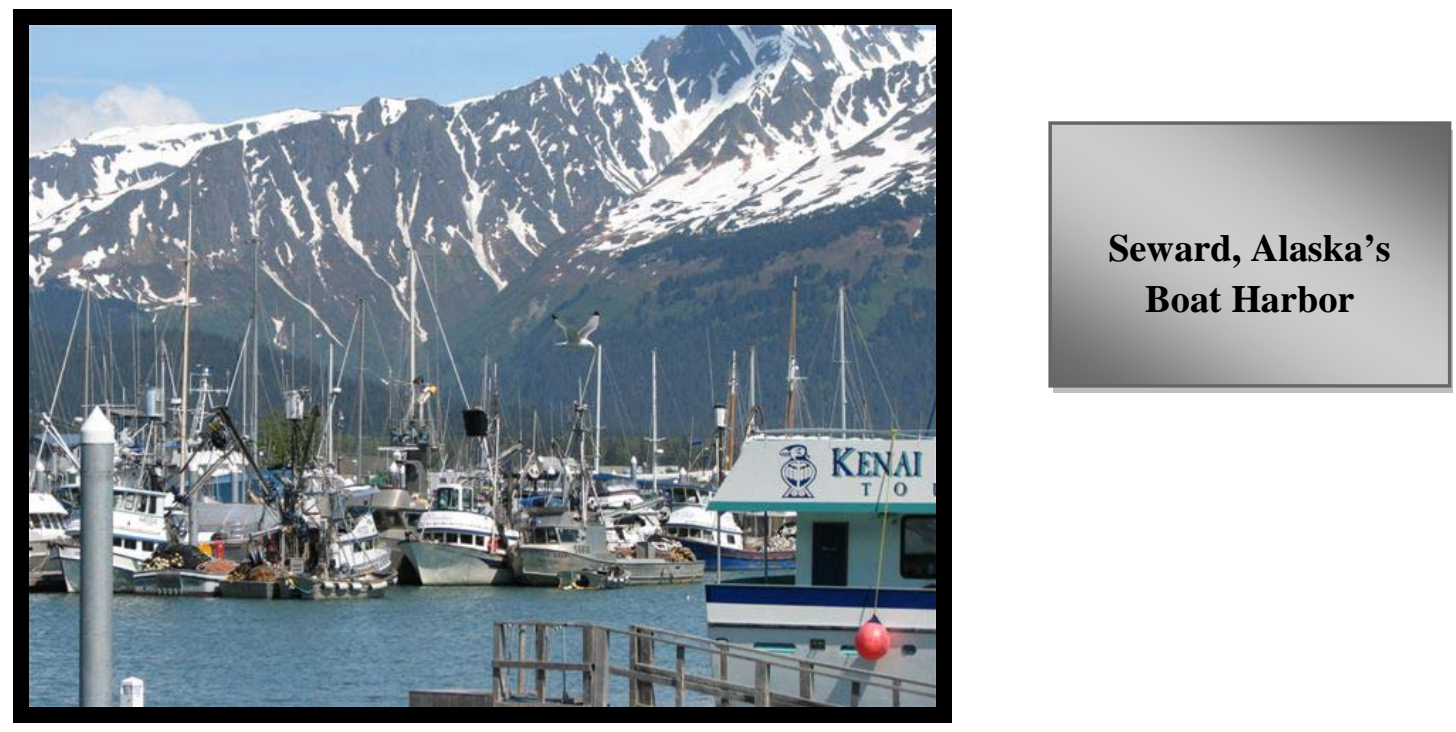

Sport fishing boat deckhands in line waiting to hang their customer's catch for pictures.

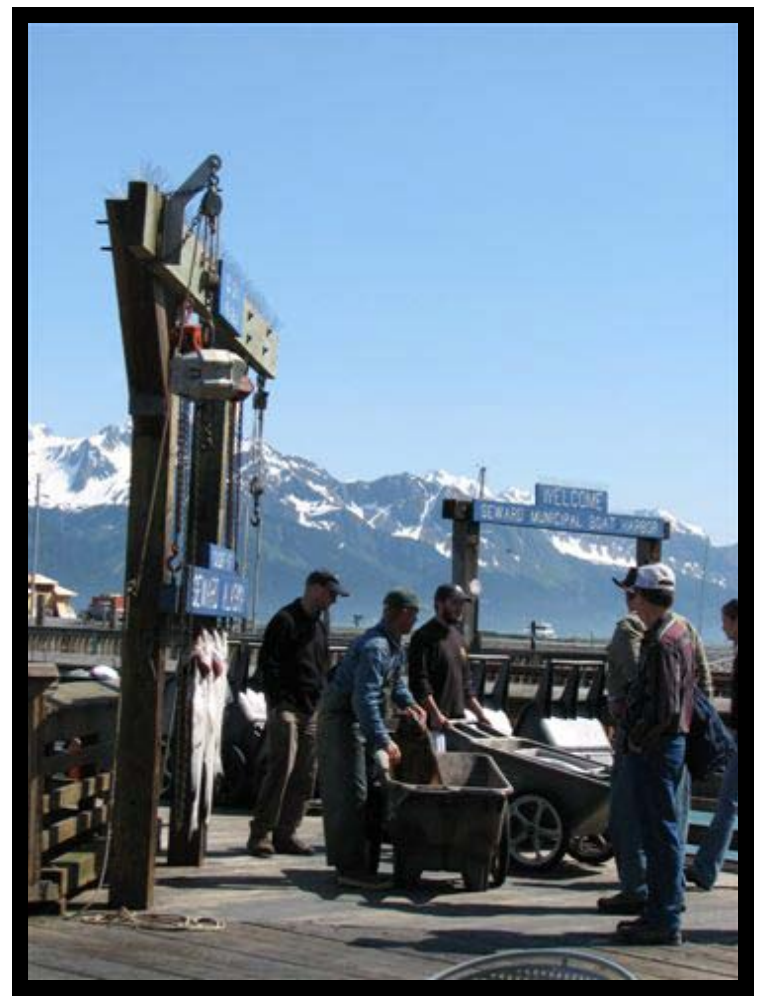




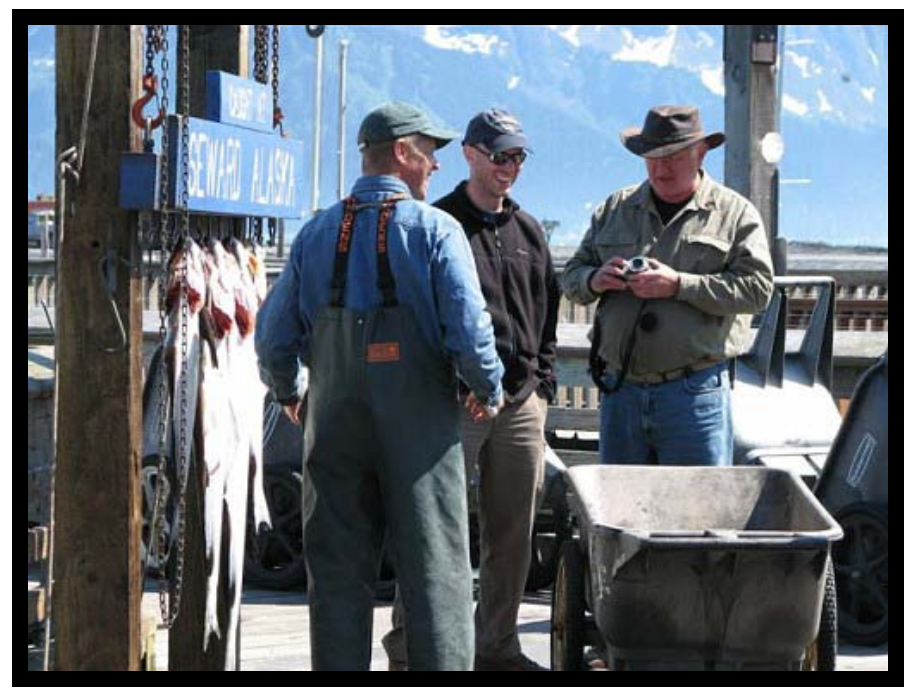

A deckhand hanging fish and tourists getting their camera's ready for pictures with the catch.

Halibut caught on a sport fishing boat hung for pictures at the end of the day.

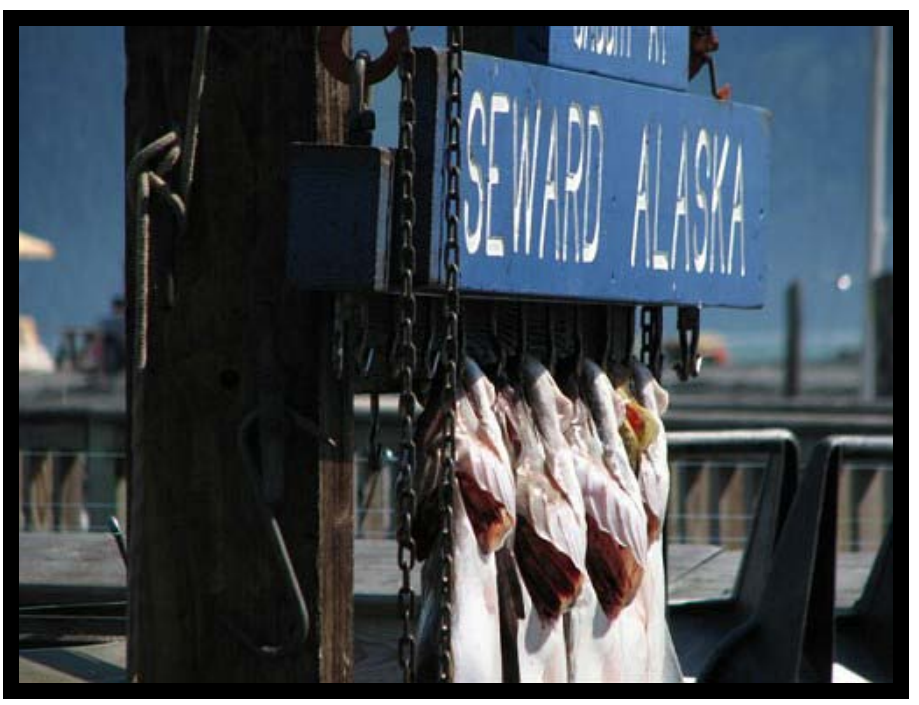




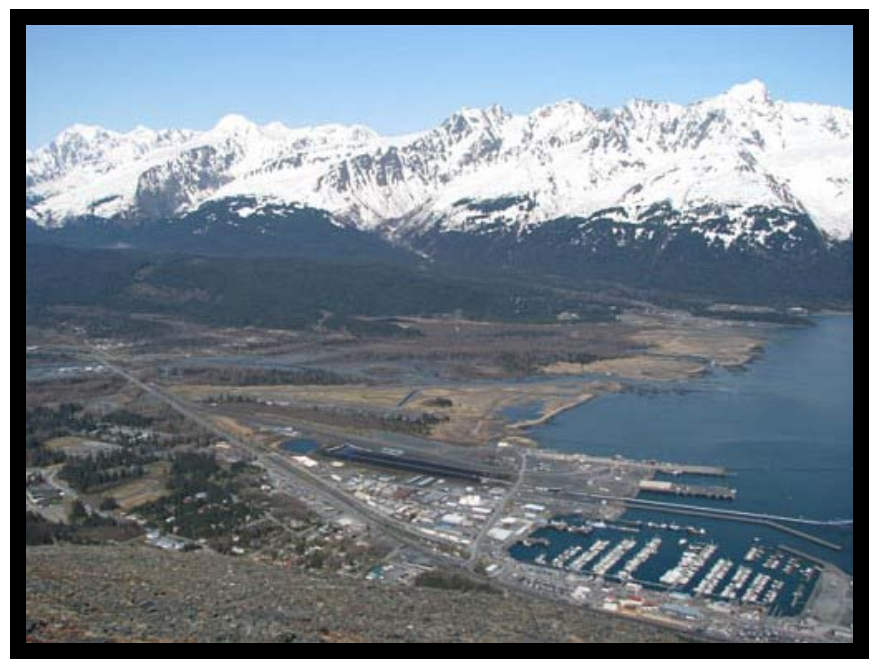

Seward, Alaska

(view from Mount

Marathon)

Resurrection Bay

(view from Mount

Marathon)

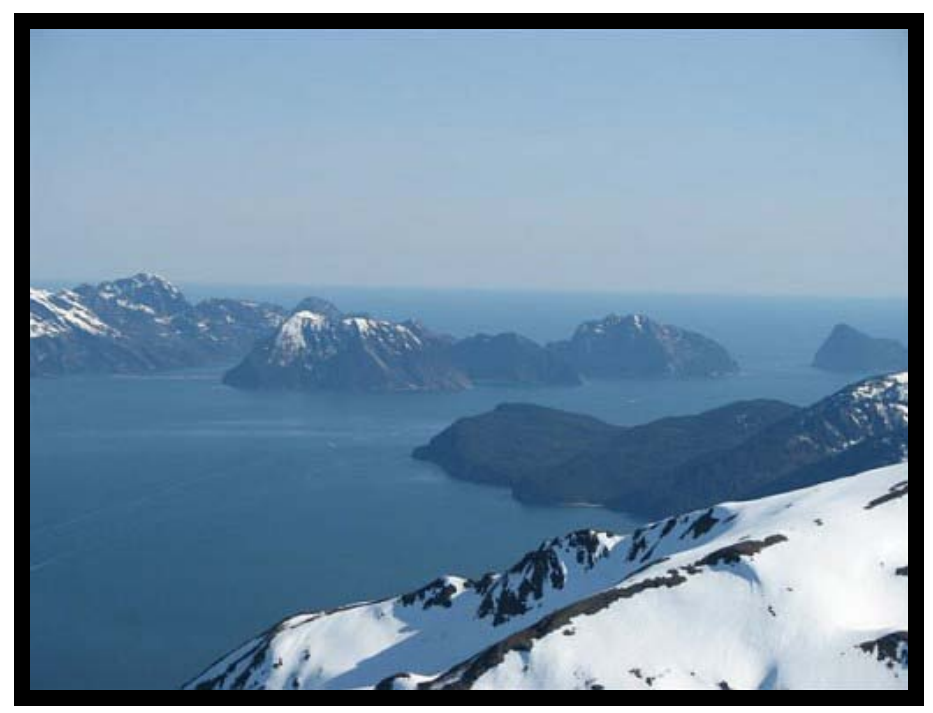




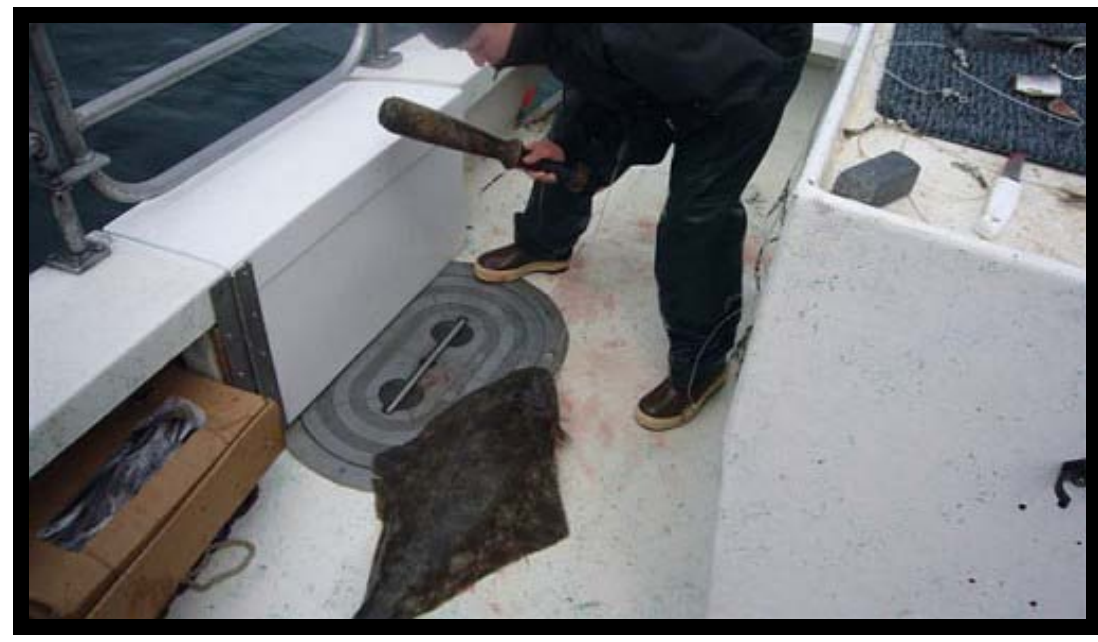

"Fish Beating"

(the practice of beating a halibut on the head until it stops moving)

Pulling in a "chicken" (small halibut) that a customer caught.

The customer does not want to keep the fish so it cannot be gaffed and must be treated with care.

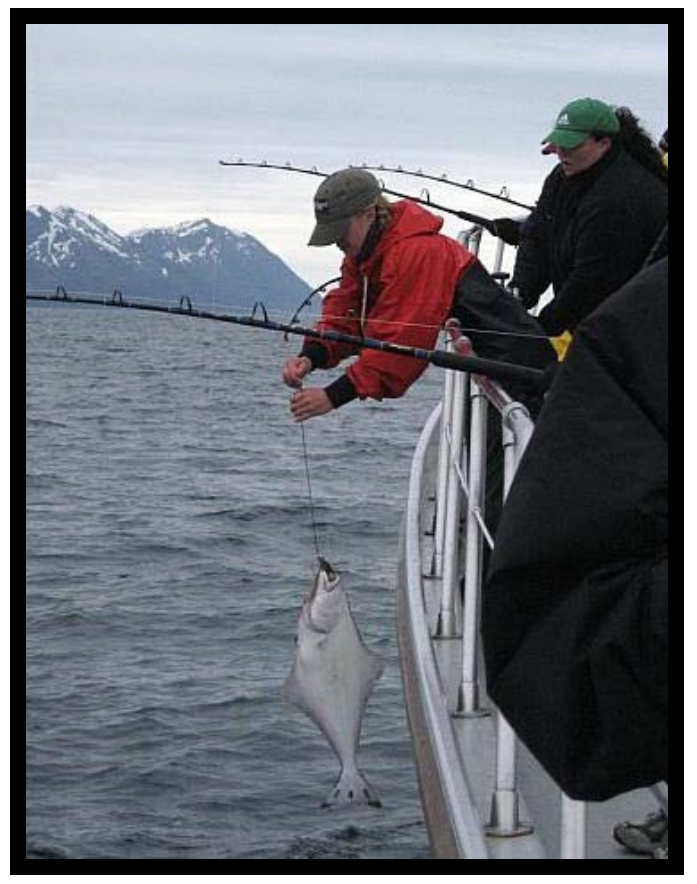




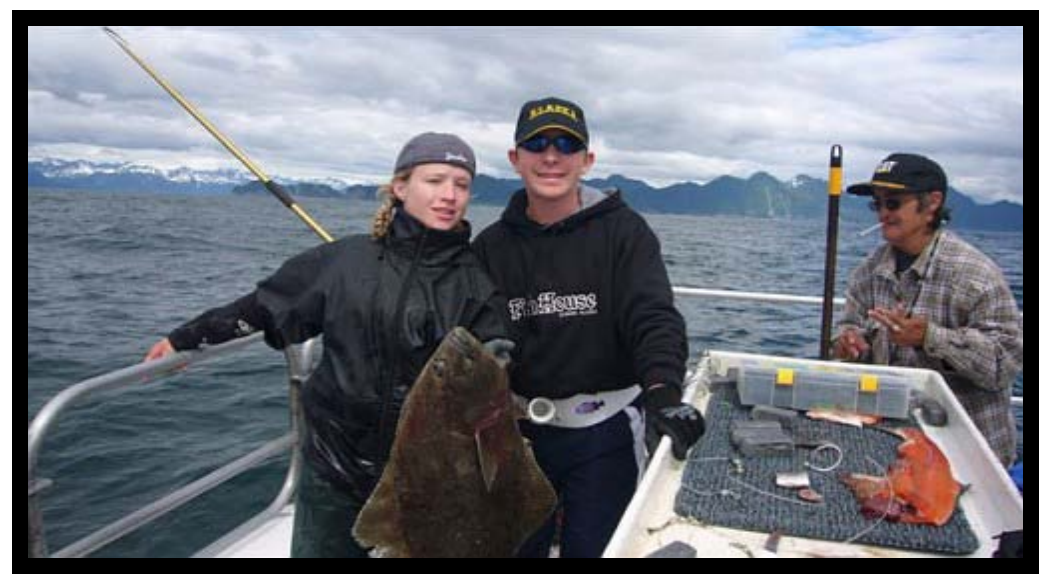

Holding a fish up for pictures so the fish can be filleted on the way in and does not have to be hung at the dock for pictures. The crew can begin cleaning the boat on the way in and finish a bit early.

The captain shooting a "hog" (very large halibut) before it is brought onboard.

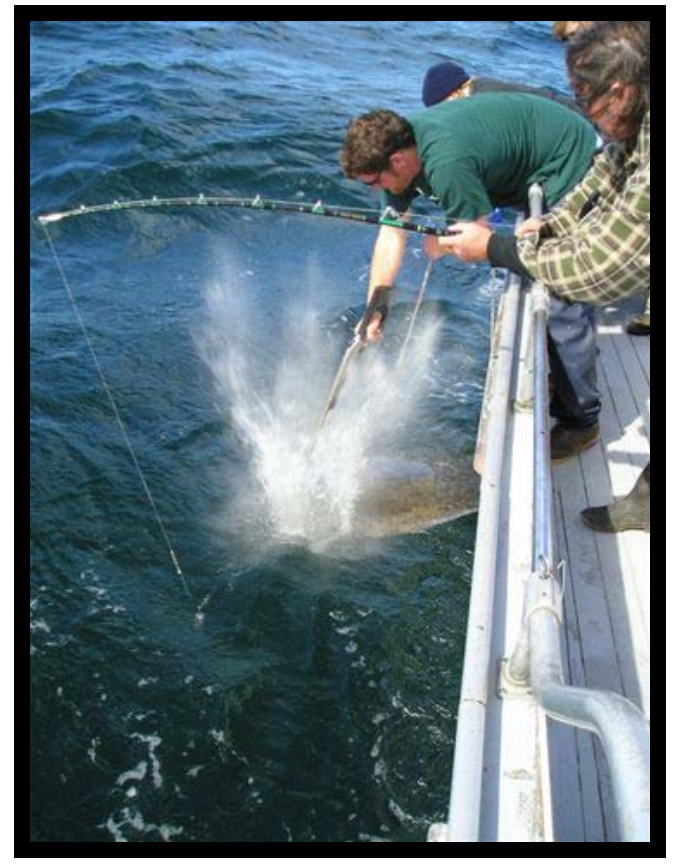



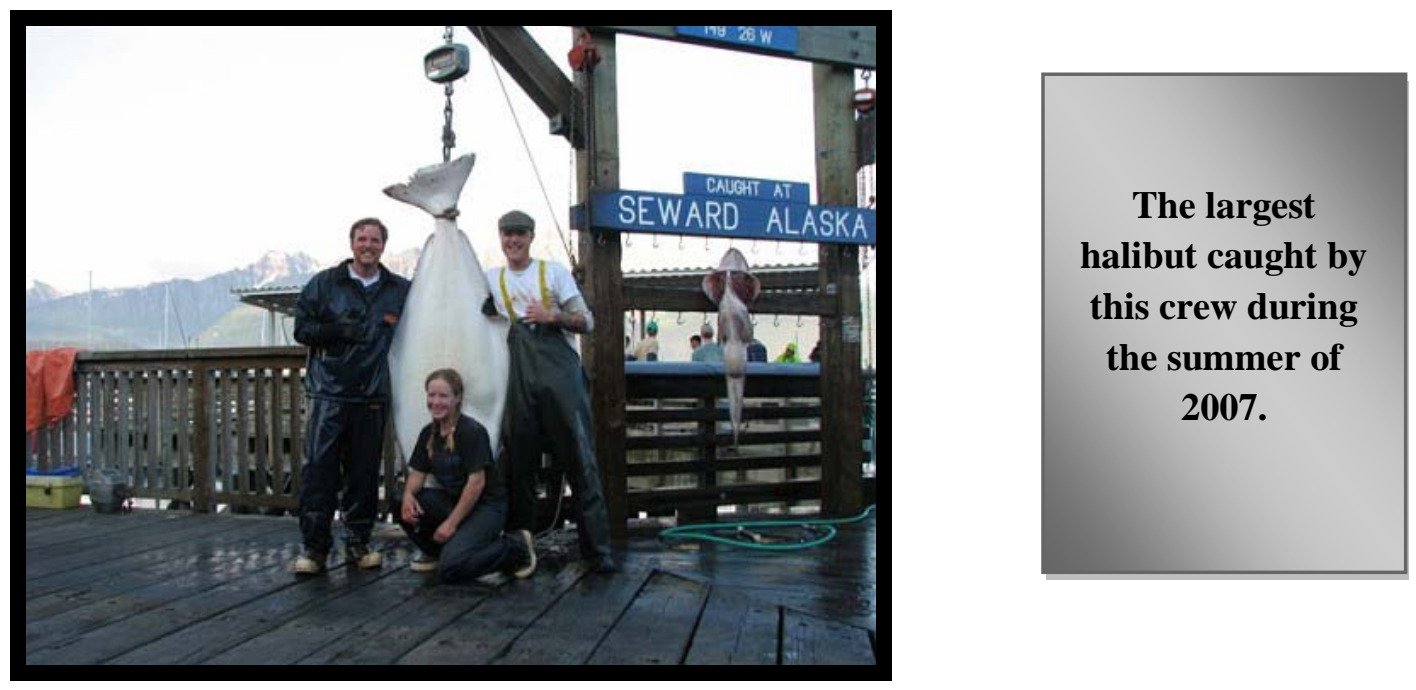

A sport fishing boat captain measures a halibut to determine its weight. The captains of his company all had a bet for who caught the biggest (heaviest) halibut during the season. While out on the water the only way to roughly determine weight is to take the length and see what the Fish and Game guidebook say it should weigh.

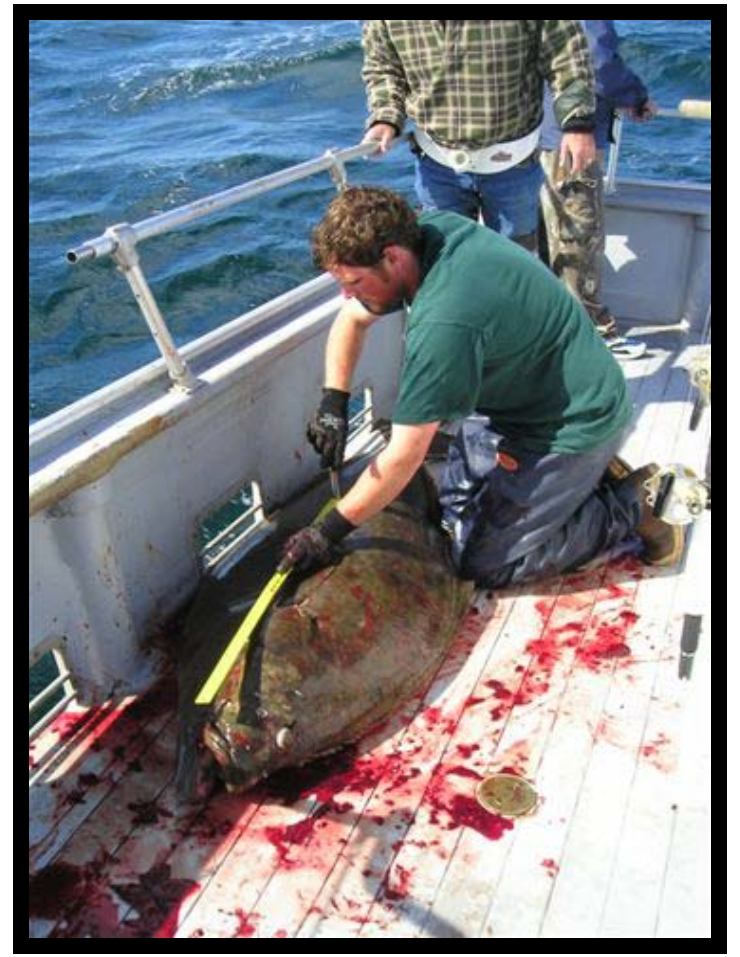




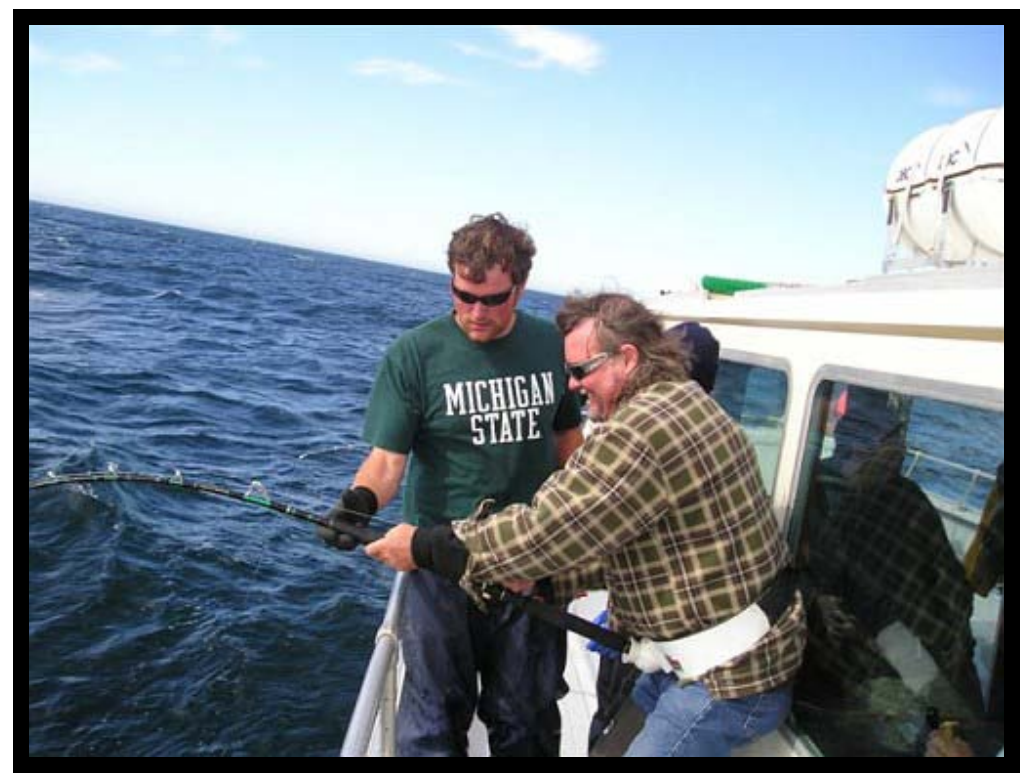

A customer on a sport fishing boat reels in a big halibut while wearing a "fishing belt".

A commercial halibut long liner.

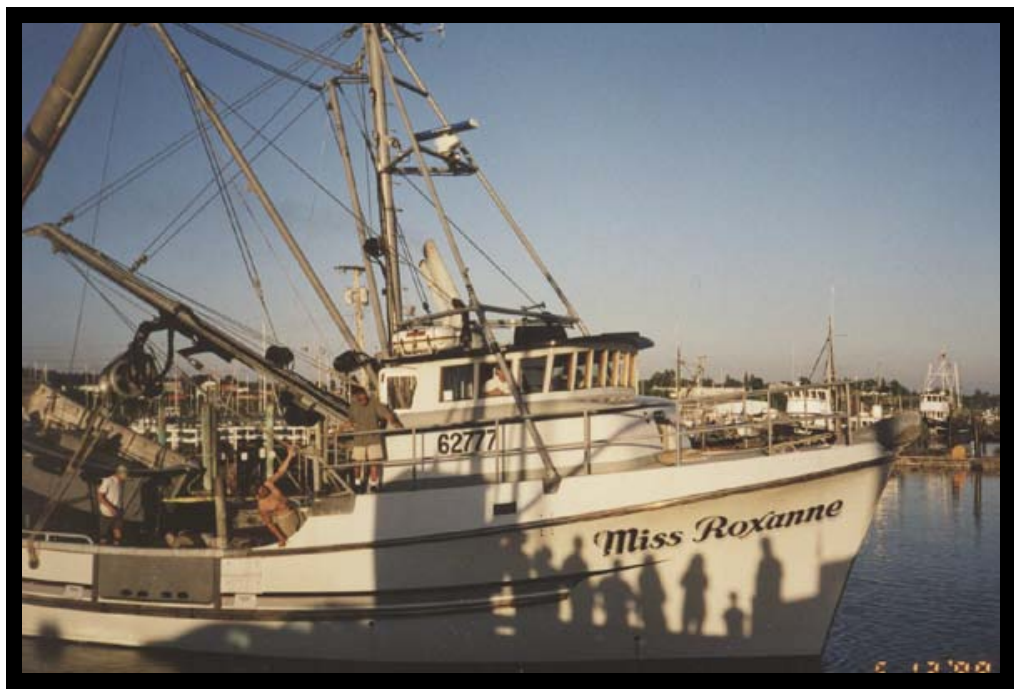




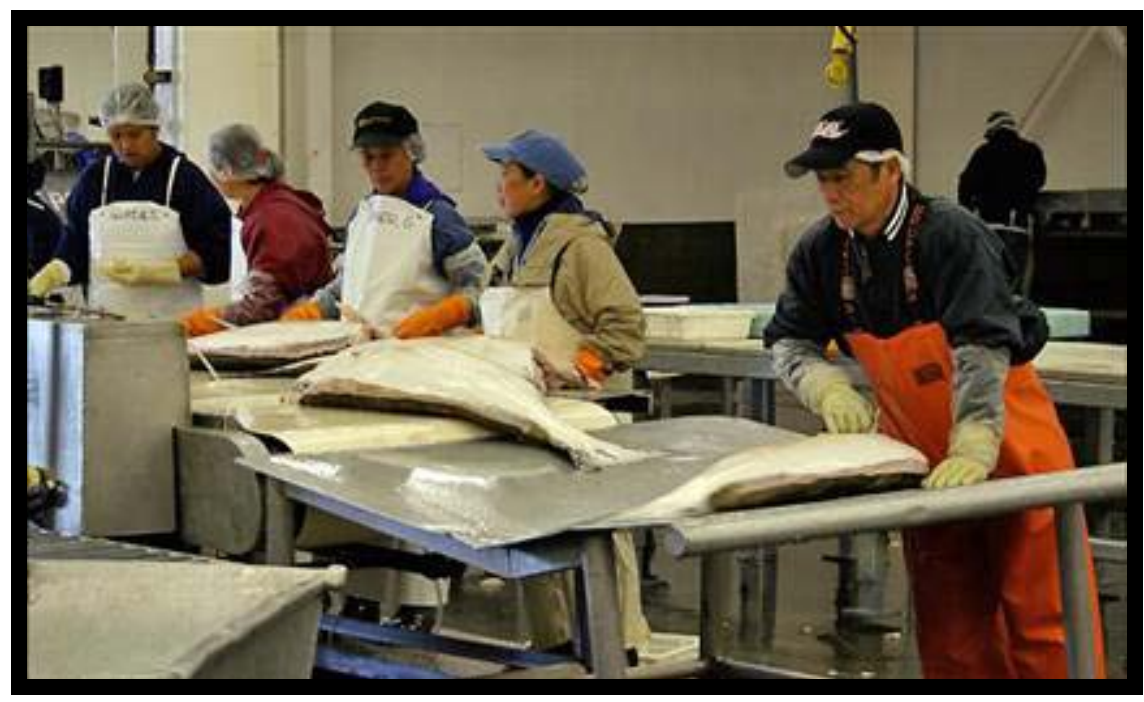

The "slime line"; a term used to describe worker's gutting the fish in a fish processing plant.

A commercial long liner's halibut catch being moved out of the hull so it is ready for the processing plant.

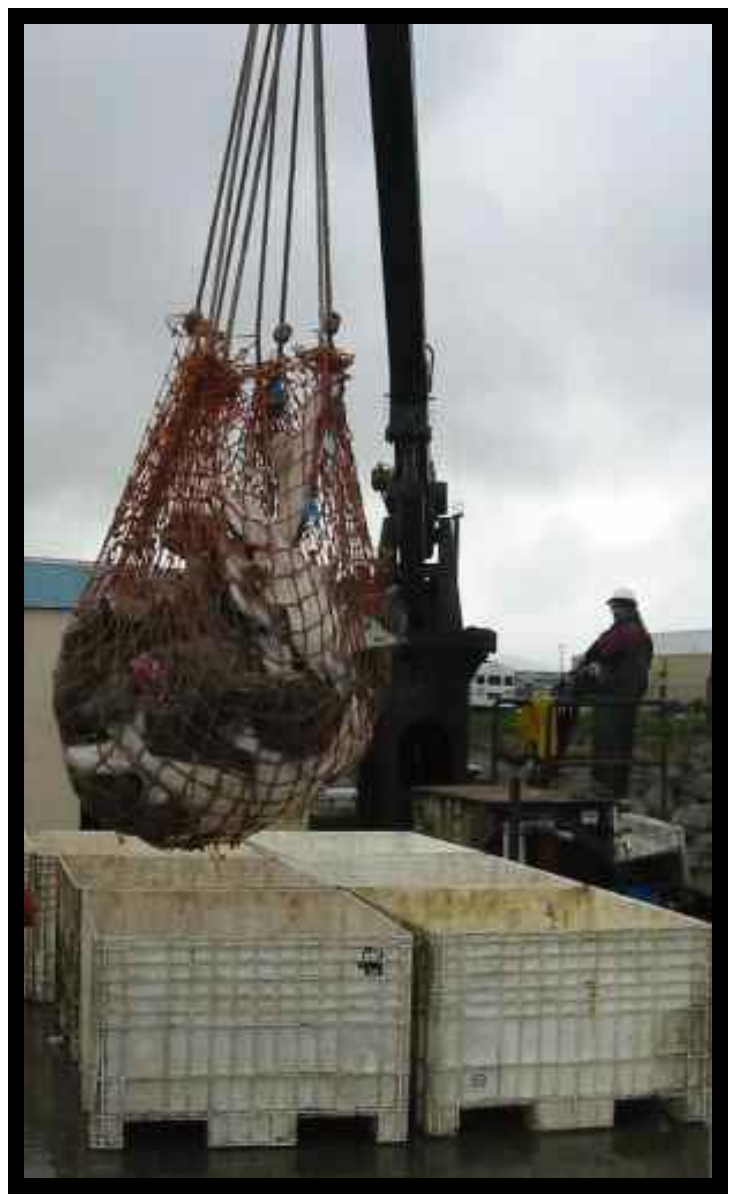


The Gulf of Alaska

The water surrounding Seward falls within Region 3A.

(Elisia and Bakke 2006)

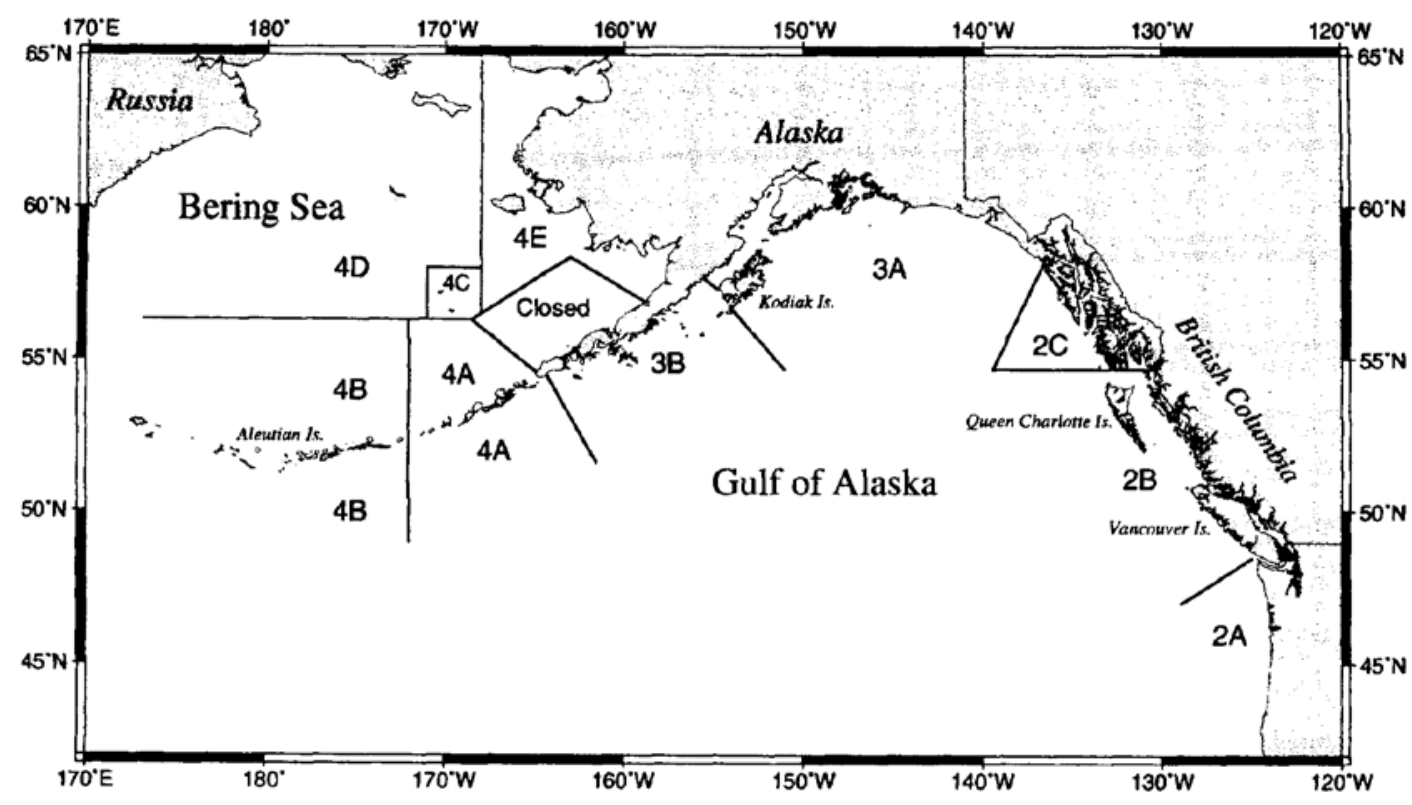


VITA

MEREDITH ANN MARCHIONI

2001

2003

2003-2008

2008-2009
B.A., Behavioral Science Drew University

Madison, New Jersey

M.A., Public Anthropology

American University

Washington, D.C.

Teaching Assistant

Florida International Univ.

Miami, Florida

Ethnographer

MarBEF

Isles of Scilly, England

Ethnographer

Houston Adv. Res. Center

Galveston, Texas

M.A.,Comparative Sociology

Florida International Univ.

Miami, Florida

Professor of Sociology

Pennsylvania State Univ.

Harrisburg, PA

\section{PRESENTATIONS}

Marchioni, M.A., (November 2006). Public Perceptions of Hatchery-Raised Chinook Salmon in Skagway, Alaska. Poster presented at the annual meeting of the American Anthropological Association, San Jose, California.

Marchioni, M.A. (March 2009). Vulnerability and Resilience in Texas Coastal Communities. Paper presented at the annual meeting of the Society for Applied Anthropology, Santa Fe, New Mexico. 